Fernando de Abreu e Lima Alves

\title{
Estendendo o Luaproc: Suporte para aplicações em ambientes móveis
}

Dissertação de Mestrado

Dissertação apresentada como requisito parcial para obtenção do grau de Mestre pelo Programa de Pós-graduação em Informática do Departamento de Informática do Centro Técnico Científico da PUC-Rio.

Orientador: Profe ${ }^{a}$ Noemi de La Rocque Rodriguez 


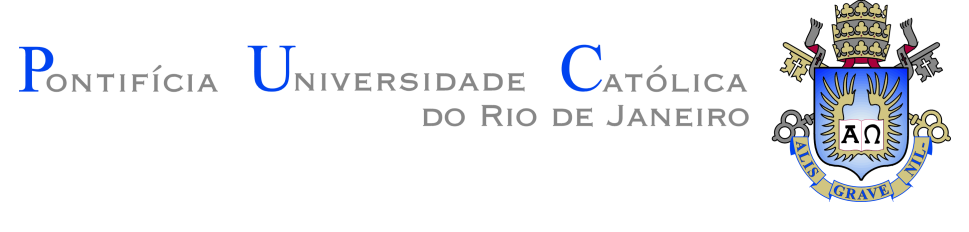

Fernando de Abreu e Lima Alves

\title{
Estendendo o Luaproc: Suporte para aplicações em ambientes móveis
}

Dissertação apresentada como requisito parcial para obtenção do grau de Mestre pelo Programa de Pós-graduação em Informática do Departamento de Informática do Centro Técnico Científico da PUC-Rio. Aprovada pela Comissão Examinadora abaixo assinada.

\author{
Prof ${ }^{a}$. Noemi de La Rocque Rodriguez \\ Orientador \\ Departamento de Informática - PUC-Rio
}

Profa. Ana Lucia de Moura

Departamento de Informática - PUC-Rio

Prof. Markus Endler

Departamento de Informática - PUC-Rio

Prof. Marcio da Silveira Carvalho

Coordenador Setorial do Centro Técnico Científico - PUC-Rio 
Todos os direitos reservados. É proibida a reprodução total ou parcial do trabalho sem autorização da universidade, do autor e do orientador.

Fernando de Abreu e Lima Alves

Graduou-se em Engenharia de Computação na Pontifícia Universidade Católica do Rio de Janeiro (PUC-Rio). Participou do desenvolvimento do sistema OCTOPUS junto ao Laboratório de Inteligência Computacional Aplicada da PUC-Rio, hoje em funcionamento na PETROBRAS. Trabalha como pesquisador e desenvolvedor na área de métodos de apoio a decisão.

Ficha Catalográfica

Alves, Fernando de Abreu e Lima

Estendendo o Luaproc: Suporte para aplicações em ambientes móveis / Fernando de Abreu e Lima Alves; orientador: Noemi de La Rocque Rodriguez. - Rio de janeiro: PUC-Rio, Departamento de Informática , 2018.

v., 90 f: il. color. ; $30 \mathrm{~cm}$

Dissertação (mestrado) - Pontifícia Universidade Católica do Rio de Janeiro, Departamento de Informática .

Inclui bibliografia

1. Informática - Teses. 2. Luaproc;. 3. Concorrência;. 4. Android;. 5. Broker;. 6. Filas de Mensagens;. I. Rodriguez, Noemi de La Rocque. II. Pontifícia Universidade Católica do Rio de Janeiro. Departamento de Informática. III. Título. 


\section{Agradecimentos}

Gostaria de agradecer principalmente a minha orientadora Prof. Noemi Rodriguez pela atenção, carinho e apoio ao decorrer do Mestrado.

Também gostaria de agradecer meus amigos, colegas e familiares pelo apoio, compreensão e incentivo durante este trabalho.

Por fim, gostaria de agradecer o $\mathrm{CNPq}$ e a Pontifícia Universidade Católica do Rio de Janeiro pelos auxílios concedidos, sem os quais este trabalho não poderia ter sido realizado. 


\section{Resumo}

Alves, Fernando de Abreu e Lima; Rodriguez, Noemi de La Rocque. Estendendo o Luaproc: Suporte para aplicações em ambientes móveis. Rio de Janeiro, 2018. 90p. Dissertação de Mestrado - Departamento de Informática , Pontifícia Universidade Católica do Rio de Janeiro.

Cada vez mais os aparelhos móveis estão se aperfeiçoando, com aumentos em suas capacidades de processamento e memória. Essa tendência acaba tornando o processamento móvel uma alternativa interessante. Este trabalho visa explorar esse mundo mobile e o seu potencial através do paralelismo, tanto localmente, na forma de exploração multicore, quanto distribuida, na forma de exploração multidispositivo. Exploramos isto através de uma biblioteca de paralelismo da linguagem de programação Lua, chamada Luaproc. Propomos um novo modelo de comunicação para esta biblioteca, para incluir esse cenário multidispositivo e combinar as facilidades de um serviço de enfileiramento de mensagens com o suporte para paralelismo já existente. Apresentamos algumas aplicações da biblioteca desenvolvida, avaliando sua utilização e desempenho em diferentes cenários.

\section{Palavras-chave}

Luaproc; Concorrência; Android; Broker; Filas de Mensagens; 


\section{Abstract}

Alves, Fernando de Abreu e Lima; Rodriguez, Noemi de La Rocque (Advisor). Extending Luaproc: Support for applications in mobile environments. Rio de Janeiro, 2018. 90p. Dissertação de mestrado - Departamento de Informática , Pontifícia Universidade Católica do Rio de Janeiro.

Mobile devices are undergoing constant increases in their processing and memory capabilities. This tendency is making mobile processing an interesting alternative. This work aims to support the programmer in exploring this potential by using parallelism, both local, in the form of multicore exploitation, as well as distributed, in the form of multidevice exploration. We explored this through a parallel library for the Lua programming language, called Luaproc. We propose an extension to this library and its communication model, to include this multidevice scenario and combine the facilities of a message queuing service with the existing facilities for multicore programming. We then present some applications to show different use cases with distribution and their performance.

\section{Keywords}

Luaproc; Concurrency; Android; Broker; Message Queueing; 


\section{Sumário}

$\begin{array}{lll}1 & \text { Introdução } & 10\end{array}$

$\begin{array}{lll}1.1 & \text { Objetivo do trabalho } & 10\end{array}$

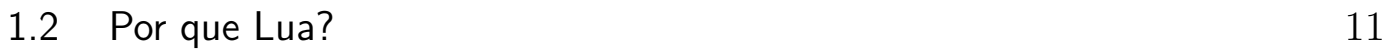

1.3 Comunicação e Luaproc 11

$\begin{array}{lll}1.4 & \text { Organização do trabalho } & 12\end{array}$

2 Conceitos básicos $\quad 13$

$\begin{array}{lll}2.1 & \text { Luaproc } & 13\end{array}$

2.2 Comunicação por Filas de Mensagens 14

2.2.1 Implementações dos protocolos para Android $\quad 15$

$\begin{array}{ll}\text { 2.2.2 Teste entre bibliotecas } & 16\end{array}$

3 Trabalhos relacionados $\quad 18$

3.1 Corona Labs 18

$\begin{array}{ll}3.2 & 18 \\ 3.3 & 19\end{array}$

$\begin{array}{ll}3.3 \text { MARE SDK } & 19\end{array}$

$\begin{array}{lll}3.4 & \text { COMPSs-Mobile Framework } & 20\end{array}$

4 Transporte da biblioteca Luaproc para o ambiente Android 22

4.1 Lua no Android 22

4.1.1 Android Assets 22

4.1.2 Memória Interna e o Lua package.loaders 23

4.2 Wrapper Lua 23

4.2.1 Utilizando o Wrapper 23

4.3 Luaproc no Android 24

5 Modelo proposto $\quad 25$

5.1 Interface MQ Luaproc 25

5.2 Implementação 26

$\begin{array}{ll}\text { 5.2.1 Eclipse Paho MQTT C client } & 27\end{array}$

$\begin{array}{ll}\text { 5.2.2 Arquitetura } & 27\end{array}$

5.2.3 Comunicação e concorrência 32

5.2.4 Alternativa de implementação cogitada 34

6 Avaliação $\quad 35$

6.1 Sobrecarga de Lua $\quad 35$

6.1.1 MQTT C vs MQTT Lua 35

$\begin{array}{lll}6.2 & \text { Aplicativos } & 37\end{array}$

6.3 Teste do Caixeiro Viajante 42

7 Conclusão e trabalhos futuros $\quad 44$

$\begin{array}{ll}\text { Referências bibliográficas } & 45\end{array}$

$\begin{array}{lll}\text { A Interface Luaproc } & 47\end{array}$ 
B Processo para a utilização da extensão Luaproc para Android $\quad 48$

B.1 Gerando o pacote AAR 48

B.2 Importando o pacote AAR Luaproc em seu aplicativo 48

B.3 Alternativa para utilizar Luaproc Android em seu aplicativo 49

B.4 Utilizando o pacote AAR Luaproc em seu aplicativo 49

C Código dos aplicativos $\quad 50$

C.1 Aplicativo de chat $\quad 50$

C.2 Aplicativo do jogo "Hare and hounds" 54

C.3 Aplicativo de compartilhamento de fotos 76

C.4 Aplicativo de busca e reconhecimento facial 82 


\section{Lista de figuras}

$\begin{array}{lll}\text { Figura 2.1 Tempo de execução do ping-pong de mensagens. } & 17\end{array}$

Figura 5.1 Tratamento de um yield feito por um processo Lua. 28

Figura 5.2 Canais Luaproc com suas respectivas listas de LP's bloqueados por envio e por recebimento.

Figura 5.3 Procedimento de bloqueio por operação MQ. 30

Figura 5.4 Threads da aplicação: os workers e as threads auxiliares. 31

Figura 5.5 Arquitetura do Cliente MQTT. 32

Figura 5.6 Comunicação com o servidor, tratada pelas threads da Paho.

Figura 6.1 Tempo de execução do ping-pong de mensagens entre Lua e C.

Figura 6.2 Tempo do envio e recebimento unidirecional de mensagens. 36

Figura 6.3 Aplicativo Chat com dois usuários. 37

Figura 6.4 Antes e depois da sugestão de jogada. 38

Figura 6.5 Tempo do cálculo da sugestão do jogo Hare and Hounds. 39

Figura 6.6 Tempo do compartilhamento de fotos. 40

Figura 6.7 Clusterização por reconhecimento facial. 41

Figura 6.8 Tempo de busca no conjunto de fotos. 42

Figura 6.9 Tempo da resolução do problema do Caixeiro Viajante. 43 


\section{Introdução}

Uma tendência crescente em computação é a das plataformas mobile. Com avanços frequentes, essas tem se tornado cada vez mais interessantes como uma forma alternativa de processamento. Além da disseminação e do poder de processamento, uma das coisas que também torna o mobile atraente é a versatilidade e potencial na criação de programas/aplicativos, assim podendo realizar das mais diversas tarefas, desde lazer até processamento de dados sensoriais/científicos.

Com a crescente oferta de computadores multicore, vem crescendo também o interesse por bibliotecas que explorem o paralelismo. A biblioteca Luaproc(1) permite a exploração de paralelismo em Lua, oferecendo um modelo $m x n$, onde o programador pode trabalhar com diferentes números de threads de aplicação e threads de sistema. Isto torna fácil a paralelização conceitual de programas sem necessariamente ter que pagar o custo de criar e gerenciar várias threads de sistema operacional. No entanto, essa biblioteca não oferece suporte a aplicações distribuídas, que é algo desejável atualmente com o avanço do uso de modelos/aplicações distribuídas e portanto a comunicação entre os aparelhos envolvidos. As áreas de jogos, sensoriamento e chat são alguns exemplos de aplicações beneficiadas por essa forma de comunicação.

A proposta deste trabalho é explorar o uso da biblioteca Luaproc no ambiente móvel, estendendo a biblioteca para permitir a comunicação entre diferentes dispositivos. Como parte do trabalho, estudamos diferentes alternativas para essas extensões tanto em termos de interface como implementação.

\section{1}

\section{Objetivo do trabalho}

Nosso objetivo é oferecer uma plataforma que combine facilidades para explorar o paralelismo com o suporte para programação de aplicações distribuídas. O modelo atual de comunicação do Luaproc é o de troca de mensagens, em que o sistema não permite compartilhamento de memória e oferece canais de comunicação. Vamos estender este modelo de canais para múltiplos dispositivos.

Investigamos uma arquitetura e interface apropriadas tendo em mente o 
modelo atual de comunicação oferecido pelo Luaproc, para criar uma interface semelhante para comunicação entre dispositivos.

\section{2}

\section{Por que Lua?}

Lua tem a reputação de ser robusta e ter um bom desempenho apesar de ser uma linguagem interpretada. Em comparação com outras linguagens scripts, como Python, Lua utiliza menos memória e tem um interpretador mais rápido(2). Alguns casos de destaque são softwares famosos como Adobe's Photoshop Lightroom, o middleware Ginga ${ }^{1}$, e jogos como World of Warcraft ${ }^{2}$, Angry Birds, Dark Souls, entre outros.

Lua também permite rodar os seus scripts dinamicamente. Isto é útil para a manutenção de seu código, já que mudanças em Lua não necessitam da recompilação de seu código. Além de facilitar a escalabilidade de uma aplicação, pois é suportado uma carga dinâmica de scripts para execução podendo ser ajustado conforme a necessidade. Também é possível montar uma string, representando um código válido Lua, em tempo de execução e executálo.

Lua é pequena (menos de 1MB) e requer apenas um compilador C padrão, tornando-a portátil e embutível. Isso é um incentivo para utilizar Lua no Android pois é simples de compilá-la através do $\mathrm{CMake}^{3}$ e não ocupa muito espaço. Um exemplo de software que tira proveito disso é a Engine de jogos 2D Corona $^{4}$, baseado em Lua e focado no desenvolvimento de aplicações mobile.

Lua facilita a implementação do mecanismo de segurança Sandboxing. Esta técnica permite limitar o ambiente para apenas utilizar as funções que você permitir, gerando assim um ambiente protegido. Isto é útil para garantir a segurança de seu aplicativo, protegendo-o de códigos maliciosos.

\section{3}

\section{Comunicação e Luaproc}

Neste trabalho apresentaremos um modelo de comunicação para múltiplos dispositivos em nossa extensão Luaproc. Diversas classes de aplicações podem se beneficiar desse novo modelo de comunicação conjugada com o paralelismo Luaproc. Alguns exemplos seriam:

- Aplicações científicas com processamento distribuídas.

${ }^{1}$ http://www.ginga.org.br/

${ }^{2}$ http://wowwiki.wikia.com/wiki/Lua

${ }^{3}$ https://cmake.org/

${ }^{4}$ https://coronalabs.com/ 
- Jogos com comunicação entre jogadores (ou que simplesmente precisem realizar um broadcast de informações para sua base de jogadores).

- Aplicações que envolvem compartilhamento de dados.

- Aplicações de coleta, organização e análise de dados via sensoriamento distribuído.

Nosso novo modelo leva em consideração as peculiaridades da comunicação mobile. No ambiente de dispositivos móveis, onde há muitas desconexões, falhas e latência, o modelo síncrono original do Luaproc não é apropriado. Devido à essas incertezas optamos por seguir um modelo assíncrono de comunicação.

Para realizar a comunicação também integramos ao nosso modelo um serviço de gerênciamento de mensagens via broker, que permite o desacoplamento entre os diferentes dispositivos móveis.

\section{4}

\section{Organização do trabalho}

O capítulo 2 apresenta um resumo sobre a biblioteca Luaproc, além de uma análise de alguns protocolos de troca de mensagens para realizar nossa comunicação multidispositivo. O capítulo 3 descreve sucintamente alguns trabalhos nas plataformas móveis, em que focamos no paralelismo e/ou comunicação apresentados pelos mesmos. O capítulo 4 descreve o processo de transporte da biblioteca Luaproc para o Android, além de nossa solução para executar scripts Lua (com dependências de módulos externos, como o próprio Luaproc). O capítulo 5 apresenta nosso modelo de comunicação multidispositivo proposto para a extensão da biblioteca Luaproc, detalhando suas características e arquitetura. O capítulo 6 apresenta nossos resultados de avaliação da biblioteca Luaproc estendida em testes comparativos com outras bibliotecas de comunicação Android, além da implementação de alguns aplicativos. Finalmente, o capítulo 7 apresenta nossas conclusões e sugestões para trabalhos futuros. 


\section{2}

\section{Conceitos básicos}

Neste capítulo, apresentamos inicialmente a biblioteca Luaproc. A seguir discutimos diferentes protocolos de comunicação por filas de mensagens, relevantes para a escolha do protocolo de comunicação para nossa extensão da biblioteca Luaproc.

\section{1}

\section{Luaproc}

Luaproc é uma biblioteca de extensão para programação concorrente, desenvolvida em C por Alexandre Skyrme(2). Ela oferece ao usuário uma forma de programação paralela em Lua por meio de seus processos Lua, ou LP's (Lua Processes). Esses processos Lua funcionam como threads de aplicação que podem ser rodados por uma certa quantidade de threads de sistema operacional (ou kernel threads), definidas pelo usuário. Assim, o ganho paralelo ocorre ao definir a quantidade ideal de threads de sistema, ou workers, para a máquina utilizada. Por exemplo, em um Octa-core o ideal tipicamente seriam 8 ou 16 workers (já que um número maior resultaria em uma competição por tempo de CPU).

Os processos Lua, não compartilham memória. Isto é intencional pois este modelo de paralelismo evita diversas condições de corrida (data races) e a necessidade de sincronização entre os LP's, assim facilitando o entendimento do programa e minimizando as possibilidades de bugs. A biblioteca oferece troca de mensagens síncrona entre os LP's através de canais de comunicação, em que um LP pode enviar uma cópia de seus dados ao outro. Dessa forma, os tipos de valores transmitidos pelas mensagens são restringidos a números, booleanos, strings e nil.

Apesar da linguagem Lua não oferecer suporte integrado à programação concorrente, ela inclui o conceito de co-rotina, que dá apoio à concorrência não preemptiva(1). As primitivas resume e yield são usadas para ativar uma co-rotina e para abrir mão do controle, retornando à co-rotina ativadora.

Cada LP é uma co-rotina, composta por código Lua, e está encapsulada em um Lua State, que por sua vez é uma instância do interpretador Lua, ou seja, é uma estrutura que guarda o estado do interpretador Lua. Dessa 
forma, cada Lua State tem seu próprio conjunto de variáveis globais, e consequentemente cada LP também.

Cada worker é uma thread da biblioteca POSIX, também conhecida como pthread. A biblioteca Luaproc mantém uma fila FIFO de processos Lua, em que cada um é selecionado e executado por um worker repetidamente. Porém os LP's não são preemptivos, o que significa que eles só param a execução através de um comando explícito, yield, ou se a execução for concluída. Na troca de mensagens entre LP's, pode ocorrer um yield implícito caso esteja faltando um LP para completar essa troca, liberando o worker para executar outros LP's.

O paralelismo em Luaproc está diretamente relacionado com a quantidade de workers. Em particular, se houver apenas um worker, o programa executará em apenas um processador. Se um LP fizer uma chamada bloqueante (como por exemplo uma operação de E/S), o worker também ficará bloqueado.

\section{2}

\section{Comunicação por Filas de Mensagens}

No mundo da computação móvel, os dispositivos estão sujeitos a falhas e quedas de conexão. A comunicação nesse ambiente torna necessária a realização de tarefas complementares, como o tratamento a falhas e o gerenciamento da entrega de mensagens. Um serviço de enfileiramento de mensagens nos permite delegar boa parte dessas tarefas, facilitando o desacoplamento entre dispositivos. Sendo assim, pesquisamos alguns protocolos de troca de mensagens para utilizar esse tipo de serviço.

Consideramos os protocolos AMQP ${ }^{5}$, ZMQ (ou ZeroMQ) ${ }^{6}$ e MQTT $^{7}$. Todos utilizam enfileiramento de mensagens para armazenar mensagens não consumidas, mas variam com relação à confiabilidade da transmissão e forma de conexão. Em geral, o gerenciamento das mensagens é feito por um nó central, conhecido como Broker. Assim, a conexão entre os diversos nós é indireta e intermediada pelo broker. Pesquisamos sobre tolerância a falhas oferecidas pelas implementações dos brokers nesses protocolos (por exemplo, RabbitMQ ${ }^{8}$ e ActiveMQ ${ }^{9}$ ), como desconexões de clientes e falhas/quedas de servidor. No caso do ZeroMQ, porém, a conexão é direta e deve-se conhecer o endereço de destino. Como a utilização de um broker é essencial para o desacoplamento espacial que desejamos e para a delegação de responsabilidades (como garantias

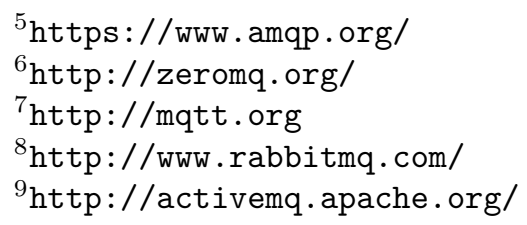


de entrega), optamos por desconsiderar o protocolo ZeroMQ como candidato na extensão Luaproc.

Também estudamos o envio de mensagens e as devidas garantias oferecidas por cada protocolo. Os protocolos AMQP e MQTT oferecem diferentes configurações de confiabilidade de envio, dentre as quais 3 se destacam:

- Envio sem confirmação: Mais eficiente, porém sem nenhuma garantia de envio.

- Envio com confirmação: Garante que a mensagem é entregue pelo menos uma vez, podendo haver duplicatas

- Envio exato: Menos eficiente, mas garante que todas mensagem chegue sem duplicatas.

O MQTT se diferencia dos protocolos anteriores por ter sido criado tendo em mente redes não confiáveis (alta chance de queda) ou de alta latência(3). Já o AMQP se diferencia por oferecer alta configurabilidade e flexibilidade para troca de mensagens(3). Com base nisso, uma aplicação com alta chance de queda de conexão pode se beneficiar da escolha do protocolo MQTT. Já para o caso de uma aplicação com conexão confiável e necessidade de uma transmissão de mensagem diferenciada, talvez a melhor escolha seja utilizar o AMQP. Porém um estudo comparativo entre AMQP e MQTT(4), que simulou ambientes instáveis, concluiu que ambos são eficientes nesse cenário de instabilidade. Contudo, no mesmo estudo o AMQP se mostrou melhor com relação à segurança enquanto MQTT em relação à eficiência (consumo energético). Outra diferença foi a inversão da ordem das mensagens acumuladas pelo AMQP, devido ao gerenciamento LIFO, enquanto MQTT sempre garante a entrega em ordem, o que pode ser relevante em alguns casos. Assim, a escolha do protocolo dependerá de diferentes critérios e da aplicabilidade visada.

\subsection{1}

\section{Implementações dos protocolos para Android}

Nesta subseção apresentamos algumas bibliotecas que implementam os protocolos vistos na Seção 2.2. Foram realizados testes comparativos entre elas e serão apresentados na Subseção 2.2.2.

- Paho MQTT

Os responsáveis pelo projeto Eclipse $\mathrm{Paho}^{10}$ oferecem uma versão do cliente MQTT para Android, que utilizamos em nossos testes (Subseção 2.2.2). Também há diferentes implementações de clientes MQTT

${ }^{10}$ https://www.eclipse.org/paho/ 
para sua biblioteca. Em particular, nos interessamos pela implementação em C como candidata para a extensão da biblioteca Luaproc.

- RabbitMQ para Android

Os responsáveis pelo RabbitMQ oferecem um cliente Java de sua biblioteca, podendo ser integrado com o Android através do Gradle (um sistema de automação de compilação open source).

Apesar de haver uma implementação em C do cliente RabbitMQ ${ }^{11}$, acabamos desconsiderando-a em favor da implementação da Paho pois esta última oferecia uma API melhor e também por nosso interesse pelo protocolo MQTT.

- ZeroMQ para Android

Os responsáveis pela biblioteca ZeroMQ também oferecem um cliente Java, chamado JeroMQ ${ }^{12}$, podendo ser integrado com o android através do Gradle. Há uma implementação em $\mathrm{C}$ da biblioteca, porém como mencionado na Seção 2.2 desconsideramos pela ausência de um broker nativo.

\subsection{2}

\section{Teste entre bibliotecas}

Foi realizado um teste comparativo entre as diversas bibliotecas de troca de mensagem oferecidas para o Android, no caso: Paho MQTT Java, Paho MQTT C, RabbitMQ para Android e JeroMQ (ZeroMQ Java, compatível com Android).

O teste se resume em realizar um ping-pong de mensagens entre dois celulares cuja entrega é intermediada por um servidor (broker). Dessa forma os celulares aguardam receber uma mensagem para então responder. O tempos medidos, mostrados na Figura 2.1, são relativos ao celular que inicia com um envio.

O teste foi realizado em um Samsung SM-J700M, versão Android 6.0.1 API 23, 1.5BG de RAM e processador ARM Cortex-A53 (Octa-Core 64bit) em conjunto com um emulador Nexus 5 do Android Studio executados em uma máquina com 16GB RAM e processador Intel i7-4770 (Octa-Core 64bit).

\footnotetext{
${ }^{11}$ https://github. com/alanxz/rabbitmq-c

${ }^{12}$ https://github.com/zeromq/jeromq
} 


\begin{tabular}{|l|c|c|c|c|}
\cline { 2 - 5 } \multicolumn{1}{c|}{} & \multicolumn{4}{c|}{1000 Msgs } \\
\cline { 2 - 5 } \multicolumn{1}{c|}{} & RabbitMQ & ZeroMQ & Paho Java & Paho C \\
\hline $\begin{array}{l}\text { Média } \\
\text { (segundos) }\end{array}$ & 5,65 & 18,40 & 40,34 & 6,96 \\
\cline { 2 - 5 } & \multicolumn{4}{c|}{10000 Msgs } \\
\cline { 2 - 5 } & RabbitMQ & ZeroMQ & Paho Java & Paho C \\
\hline \begin{tabular}{|l|l|l} 
Média \\
(segundos)
\end{tabular} & 70,91 & 173,18 & 430,17 & 70,46 \\
\hline
\end{tabular}

Figura 2.1: Tempo de execução do ping-pong de mensagens.

O desempenho ruim do ZeroMQ pode ser atribuido ao broker, já que foi necessário implementá-lo e esta implementação foi simplória (sendo apenas um servidor single thread que recebe/envia mensagens entre duas portas).

Já o caso do cliente Paho Java aparenta ser um problema da portabilidade da biblioteca para o Android, pois esta implementação utiliza estruturas diferentes na versão Android com relação à versão original para Java, ou do serviço MQTT da Paho para o Android. Na página online do cliente Android da $\mathrm{Paho}^{13}$ é mencionado que estão tentando gerar a biblioteca no formato AAR (Android Archive Library) para Android, unindo todas as dependências em um único arquivo. Isto pode sugerir que a versão atual, em formato JAR e dividido em duas dependências, pode ser a causa do desempenho ruim.

As demais bibliotecas se mostraram com desempenho bem semelhante. 


\section{3}

\section{Trabalhos relacionados}

Neste capítulo apresentamos alguns trabalhos que se propuseram a tirar proveito da plataforma mobile, explorando diferentes formas de paralelismo.

\section{1}

\section{Corona Labs}

Corona Labs oferece um framework multiplataforma de desenvolvimento mobile, chamado Corona SDK, integrado à linguagem Lua acima de uma camada $\mathrm{C}++$ /OpenGL para aplicações gráficas (como jogos, em geral). Luaproc também está disponível como um plugin ${ }^{14}$ podendo ser integrado de forma semelhante a um módulo em Lua (através do comando require). A popularidade do Corona demonstra o sucesso da integração Lua e mobile e que há demanda pelo uso de Lua nos celulares.

Para a comunicação entre dispositivos, pode-se utilizar a biblioteca LuaSocket $^{15}$, que fornece suporte para as camadas de transporte TCP e UDP. Este SDK também disponibiliza troca de mensagens através de push notifications, que são mensagens exibidas na interface do celular no estilo popup (como por exemplo, mensagens de chat recebidas recentemente). Podese realizar isto de forma nativa (com a função showPopup ()$\left.^{16}\right)$ ou através de plugins (como OneSignal ${ }^{17}$ ).

Em geral, os push notifications atendem às necessidades dos jogos (que são a maioria dos casos) porém não permitem ao programador processar a mensagem. Caso o programador queira realizar outra forma de comunicação (como por exemplo, um chat entre 2 clientes) ele deverá implementá-lo. Isto pode ser feito com o auxilio de plugins também, como o framework multiplayer da Photon $^{18}$.

Assim, através do Corona há a possibilidade que tirar proveito do paralelismo multicore dos celulares, além de implementar a troca de mensagens entre aparelhos. Porém isto é feito de maneira não integrada, sendo necessário

\footnotetext{
${ }^{14}$ https://marketplace. coronalabs. com/corona-plugins/luaproc

${ }^{15}$ https://github.com/diegonehab/luasocket

${ }^{16}$ http://docs.coronalabs.com/api/library/native/showPopup.html

${ }^{17}$ https://marketplace.coronalabs.com/corona-plugins/onesignal

${ }^{18}$ https ://marketplace.coronalabs.com/corona-plugins/photon-cloud
} 
incluir plugins ou implementar a própria comunicação. Isto pode ser uma inconveniência ao usuário, pois ele deve usar de seu tempo para buscar o plugin ideal para suas necessidades. Caso não haja tal plugin, o usuário terá então que implementar ele mesmo a comunicação ou paralelismo.

\section{2}

\section{ZOOMM Engine}

A ZOOMM(5) é uma engine de browser para aparelhos móveis multicore. Ela foi criada com a motivação de que maior parte do uso dos celulares é gasto nos browsers. A ZOOMM propõe uma nova arquitetura de browser paralela a fim de diminuir o tempo e consumo energético do carregamento dos browsers.

A Engine atinge isso ao explorar a concorrência multicore para esconder a latência da rede, através de prefetching de recursos, e melhorar o desempenho. Em seus testes, feitos em um aparelho HTC Jetstream com processador Snapdragon Dual-Core, o tempo de carregamento dos browsers (das páginas CNN, BBC, Yahoo, Guardian, NYT, Facebook, Engadget e QQ) chegou a ser reduzido em torno da metade (aceleração de aproximadamente $2 \mathrm{x}$ ).

Isto demonstra como a exploração da paralelização nos aparelhos móveis pode resultar em um bom retorno de desempenho, que é algo que queremos possibilitar da forma mais completa (tanto local quanto distribuída) com nossa extensão.

\section{3}

\section{MARE SDK}

MARE (Multicore Asyncronous Runtime Environment)(6) é um SDK de programação paralela, voltado para desenvolvedores Android. Foi criado com a motivação de que a programação paralela é difícil, com a necessidade de gerenciamento de diversas threads e da refatoração de algoritmos para serem paralelizáveis. Outra motivação foi o padrão atual de celulares multicore, justificando o uso desses cores adicionais na forma de paralelismo. MARE se propõe como a biblioteca para resolver essas dificuldades, facilitando a programação multicore, especialmente para a programação mobile.

No caso do Luaproc, oferece-se um modelo de programação paralela em Lua por meio de seus processos Lua. Já MARE oferece um modelo orientado a tarefas,em que o usuário apenas dispara as tarefas que precisem ser feitas em paralelo sem se preocupar com sincronismo. Supostamente ela é capaz de melhorar o desempenho de forma quase linear além de economizar diversas linhas de código devido à sua API simples ${ }^{19}$.

\footnotetext{
${ }^{19}$ https : //www . qualcomm. com/news/onq/2014/02/25/qualcomm-mare-making-multicore-programming-easie
} 
Os desenvolvedores realizaram um teste ${ }^{20}$ com a engine de física Bullet $^{21}$ em conjunto com a engine gráfica OGRE ${ }^{22}$ (Object-oriented Graphics Rendering Engine) com o objetivo de paralelizar os hot-spots das porções seriais de Bullet, utilizando MARE. Os resultados demonstraram uma saída de aproximadamente 2x mais FPS (Frames Per Second).

Os resultados demonstram a relevância da programação paralela mobile e as vantagens de sua utilização/exploração.

\section{4}

\section{COMPSs-Mobile Framework}

A COMPSs-Mobile(7) é um framework para aplicações MCC (Mobile Cloud Computing, computação móvel em nuvem) paralelas. Parte da motivação de sua criação está na grande disseminação de dispositivos móveis, como smartphones e tablets, gerando um interesse em explorar esse potencial computacional na forma de computação móvel distribuída.

Os autores propõem unir a computação móvel em nuvem com detecção e paralelização automática de trechos de código, oferecendo ao desenvolvedor um modelo sequencial de programação. Isto ocorre em tempo de compilação, em que a aplicação é modificada para inserir um conjunto de invocações que, em tempo de execução, gerencia seu particionamento e sua implementação na infraestrutura subjacente. Assim, o programador pode escrever suas aplicações de forma sequencial sem a preocupação com detalhes de infraestrutura e paralelismo. No entanto, os autores reconhecem as dificuldades da computação móvel, como instabilidade causada pela latência e queda de conexão, que podem comprometer o desempenho. Eles tratam disso ao dar prioridade às tarefas (ou tasks) dos dispositivos móveis cujos dados de entrada já foram coletados (já que as outras tarefas não podem iniciar sem seus dados de entrada).

Para avaliar o framework, os autores executaram a aplicação HeatSweeper. O aplicativo HeatSweeper é um workflow de várias soluções, cujo objetivo é encontrar o posicionamento ideal de 1 a $\mathrm{N}$ fontes de calor na superfície de um corpo sólido para reduzir o tempo de aquecimento. Para tal, o aplicativo executa um algoritmo de busca intensivo procurando a melhor combinação de localizações para as fontes de calor.

\footnotetext{
${ }^{20}$ Infelizmente não é mencionado explicitamente o aparelho em que os testes foram executados. Porém, na apresentação é comparado um celular single-core de 2010 com um celular de processador Snapdragon Quad-Core de 2013 (ano da apresentação). Assim, talvez o teste foi realizado nesse último celular.

${ }^{21}$ http://bulletphysics.org/wordpress/

${ }^{22}$ https://www .ogre3d.org/
} 
Os resultados dos seus testes mostraram a diminuição do tempo de execução e consumo energético, demonstrando a relevância da computação móvel distribuída, que é algo que queremos possibilitar com nossa extensão Luaproc. 


\section{4}

\section{Transporte da biblioteca Luaproc para o ambiente Android}

Neste capítulo, descrevemos o processo de migração da biblioteca Luaproc para a plataforma de desenvolvimento Android Studio ${ }^{23}$.

\section{1}

\section{Lua no Android}

No primeiro momento, buscamos simplesmente utilizar Lua no Android para rodar scripts autosuficientes, ou seja, executar scripts Lua que não necessitem de módulos externos ou outros scripts para a sua execução.

As tentativas iniciais de utilizar Lua em Android envolveram a utilização de ferramentas que possibilitam a manipulação das estruturas de Lua em Java, como Luaj ${ }^{24}$ e JnLua ${ }^{25}$. Porém acabamos abandonando essa opção e optando pela simplicidade de utilizar Lua diretamente através do CMake do Android Studio, uma ferramenta que possibilita a compilação de código C e $\mathrm{C}++$ em bibliotecas nativas. Assim, fomos capazes de utilizar Lua como uma biblioteca nativa e fazer uso de sua API C, graças ao NDK (Native Development Kit) do Android Studio, que possibilita o uso de código C e $\mathrm{C}++$ em aplicativos Android. Desta forma, é possível rodar os scripts de Lua primeiramente carregando o código (através da função luaL_loadbuffer da API) e em seguida executando esse código (através da função lua_pcall da API).

\subsection{1}

\section{Android Assets}

O diretório Assets permite armazenar diversos arquivos (que serão compilados para a aplicação). Através do AssetManager podemos navegar nesse diretório da mesma forma que em um sistema de arquivos normal, usando URIs (Uniform Resource Identifier), e ler arquivos como streams de bytes. Assim, utilizamos esta pasta como um repositório para os scripts Lua e binários/módulos Lua que serão utilizados.

\footnotetext{
${ }^{23}$ https : //developer . android.com/studio/

${ }^{24}$ https://sourceforge.net/projects/luaj/

${ }^{25}$ https ://github.com/danke-sra/jnlua-android
} 


\subsection{2}

\section{Memória Interna e o Lua package.loaders}

Devido ao acesso dos nossos arquivos Lua e binários serem feitos pelo AssetManager, não existe um caminho fixo (o qual podemos referenciar) para dentro da pasta Assets. Isto se torna um problema quando um script tiver alguma dependência, por exemplo um script que utiliza outro script Lua (através do require). Assim, é necessário copiar os mesmos para a memória interna do Android, a partir da qual teremos acesso a esses caminhos.

Para simplificar e facilitar a busca dos arquivos e binários Lua, convencionamos que todos estes devem estar dentro de uma pasta chamada "files". Dessa forma, conseguimos separar os arquivos relevantes para Lua de possíveis outros desnecessários (como, por exemplo, imagens), além de definir uma pasta raiz dos arquivos Lua. Uma vez definido esse diretório raiz, podemos então complementar o package loader de Lua de forma que este seja capaz de encontrar e carregar as bibliotecas (através do require de Lua). Isto é necessário, pois por padrão Lua procura em diretórios fixos (como por exemplo em Linux no diretório "/usr/local/").

\section{2 \\ Wrapper Lua}

A fim de encapsular a execução dos scripts Lua e a cópia dos arquivos Lua para memória interna, criamos um Wrapper em Java responsável por chamar o código nativo que realizará estas funções. Esta cópia é feita pelo Wrapper somente na primeira instanciação da classe.

\subsection{1}

\section{Utilizando o Wrapper}

Desenvolvemos nosso Wrapper de forma que fosse bem simples executar um script Lua. Assim, basta copiar o script que se deseja rodar para dentro do diretório "assets/files/", instanciar o Wrapper e passar o caminho do script dentro desse diretório. Também implementamos a opção de passar argumentos de entrada para o script Lua a ser executado, através do Wrapper. Como exemplo, o código a seguir irá executar o script no diretório "assets/files/test/script1.lua" e configurar o argumento de entrada arg[1] com o valor "arg1" (e $\arg [0]$ como "script1.lua"):

wrapper ("test/script1.lua' , ' 'arg1' ) 


\section{3}

\section{Luaproc no Android}

Concluída a etapa de utilizar Lua no Android, partimos para a importação do módulo Luaproc e execução de um script que utilize-a no seu código (através do require de Lua). Para a execução de scripts que utilizem a biblioteca Luaproc, a solução foi integrar o Luaproc com o wrapper através do luaL_requiref da API C. Porém para o caso de outras dependências (como outros scripts Lua), foi necessário modificar seu código fonte pois os processos Lua criados não compartilham memória. Isto significa que a referência para os arquivos Lua na memória interna Android tem que ser refeita para cada LP criado. Para solucionar esse problema, armazenamos este caminho para então adicioná-lo ao package loader de cada LP novo criado. 


\section{5}

\section{Modelo proposto}

Neste capítulo, apresentamos nosso modelo de troca de mensagens entre processos distribuídos para a biblioteca Luaproc. Discutiremos sobre a interface, a arquitetura e a implementação do mesmo.

O propósito deste modelo é disponibilizar Luaproc na plataforma Android de forma que seja possível combinar as facilidades de um serviço de enfileiramento de mensagens com o suporte para processamento concorrente e paralelo já existente na biblioteca. Essa combinação permite a exploração de paralelismo em aplicações distribuídas, que exigem comunicação entre dispositivos, e também a simples paralelização entre múltiplos dispositivos.

Para a interface utilizamos um padrão semelhante aos tópicos/canais da biblioteca Luaproc. Qualquer mensagem transmitida terá como destino uma fila nomeada (ou tópico). Para a implementação, após estudar os diferentes protocolos de enfileiramento (discutido com detalhes na Seção 2.2), optamos pelo protocolo MQTT.

\section{1}

\section{Interface MQ Luaproc}

Para a nova interface de troca de mensagens, que chamamos de "MQ", tentamos nos manter fiéis para com a interface oferecida pelo Luaproc. Dessa forma, nos inspiramos na sua API de troca de mensagens entre processos (IPC) e de criação/destruição de canais. Assim, oferecemos uma API semelhante, com operações de envio/recebimento de mensagens, além de realizar/desfazer o registro em tópicos (semelhante aos canais Luaproc). No entanto, vale ressaltar que a semântica da nova comunicação não segue o mesmo sincronismo da comunicação original (entre LP's através dos canais). O envio de informações é apenas sincronizado com o servidor, assim não é possível garantir a sincronia de dois LP's executando em máquinas distintas, um enviando e outro recebendo, da mesma forma como é feito originalmente.

O gerenciamento dos tópicos é feito pelo broker, o que significa que o usuário não precisa se preocupar com a criação ou destruição dos mesmos. O usuário pode assumir que o servidor vai tratar corretamente os pedidos de registro e publicações de mensagens, por exemplo. Somente strings são 
trafegadas pela rede, dessa forma os tipos aceitos no envio de mensagens em Lua são apenas números e strings. Todas as operações MQ que enviam informações, ou pedidos, são sincronizadas com o broker, o que quer dizer que os LP's correspondentes estarão bloqueados até que as operações sejam confirmadas pelo mesmo. No caso do recebimento de mensagens, há a opção da operação ser síncrona ou assíncrona. A primeira bloqueia o LP até o recebimento de uma mensagem e a outra não.

- mqconnect( configuration )

Conecta ao servidor com as configurações fornecidas. O processo é bloqueado até o término (sucesso ou falha).

- mqdisconnect()

Desconecta do servidor. O processo é bloqueado até o término (sucesso ou falha).

- mqregister( topic)

Registra o cliente ao tópico fornecido. O processo é bloqueado até o término (sucesso ou falha).

- mqunregister( topic )

Cancela o registro do cliente MQTT ao tópico fornecido, além de eliminar as mensagens armazenadas deste tópico. O processo é bloqueado até o término (sucesso ou falha).

- mqsend( message, topic)

Envia a mensagem fornecida ao tópico escolhido. O processo é bloqueado até o término (sucesso ou falha).

- mqreceive( topic, [ asynchronous ] )

Se há uma mensagem armazenada do tópico escolhido, retorna-a. Caso contrário, se o booleano "asynchronous" for verdadeiro retorna-se nil e uma mensagem de erro, senão o processo Lua é bloqueado até o recebimento de uma mensagem.

\section{2}

\section{Implementação}

Tendo em vista a baixa confiabilidade de conexão do mundo mobile escolhemos o protocolo MQTT, já que ele foi criado para ambientes de alta latência e sujeitos a quedas de conexão. Outro fator influenciador foi a implementação em C da Paho MQTT ter se mostrado mais estável do que a implementação em C do RabbitMQ ${ }^{26}$.

\footnotetext{
${ }^{26}$ https : //github.com/alanxz/rabbitmq-c
} 


\subsection{1}

\section{Eclipse Paho MQTT C client}

Realizamos a extensão da biblioteca Luaproc através da implementação C do protocolo MQTT feita pela Eclipse Paho. Como a implementação da biblioteca Luaproc é em C, isto facilitou a integração com a biblioteca cliente MQTT.

\subsection{2}

\section{Arquitetura}

A arquitetura original de Luaproc consiste em uma ou mais threads de sistema operacional (workers) responsáveis pelo processamento e gerenciamento dos processos Lua, implementados por co-rotinas. Os workers adquirem os LP's a partir de uma fila de processos prontos. Cada LP é então executado por um worker até que o processo termine ou realize um yield, o que pode ocorrer em 3 casos (ilustrado na Figura 5.1):

- A execução de um yield explícito no script Lua

- A execução de um yield implícito através da função send (quando não há um processo esperando para receber)

- A execução de um yield implícito através da função receive (quando não há um processo esperando para enviar) 


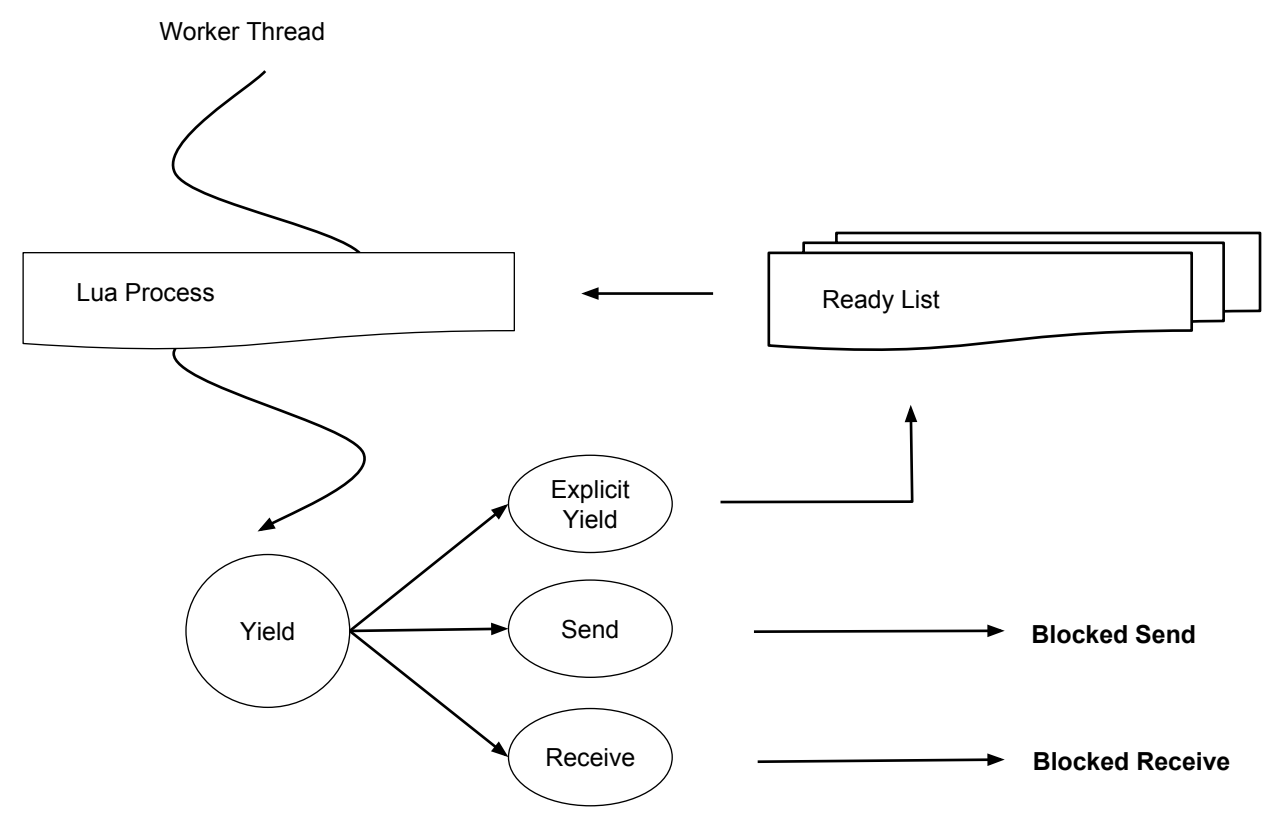

Figura 5.1: Tratamento de um yield feito por um processo Lua.

No caso de um processo Lua realizar um send/receive, se houver um processo Lua esperando para completar um receive/send, a operação é completada imediatamente. Caso não exista, a chamada send/receive coloca o processo Lua em uma fila de bloqueados e realiza um yield, liberando a thread atual para executar outro LP. Apenas quando aparecer um outro processo para casar com ele a operação será finalizada, retornando-o para a fila de processos prontos. A estrutura dos canais pode ser vista na Figura 5.2. 


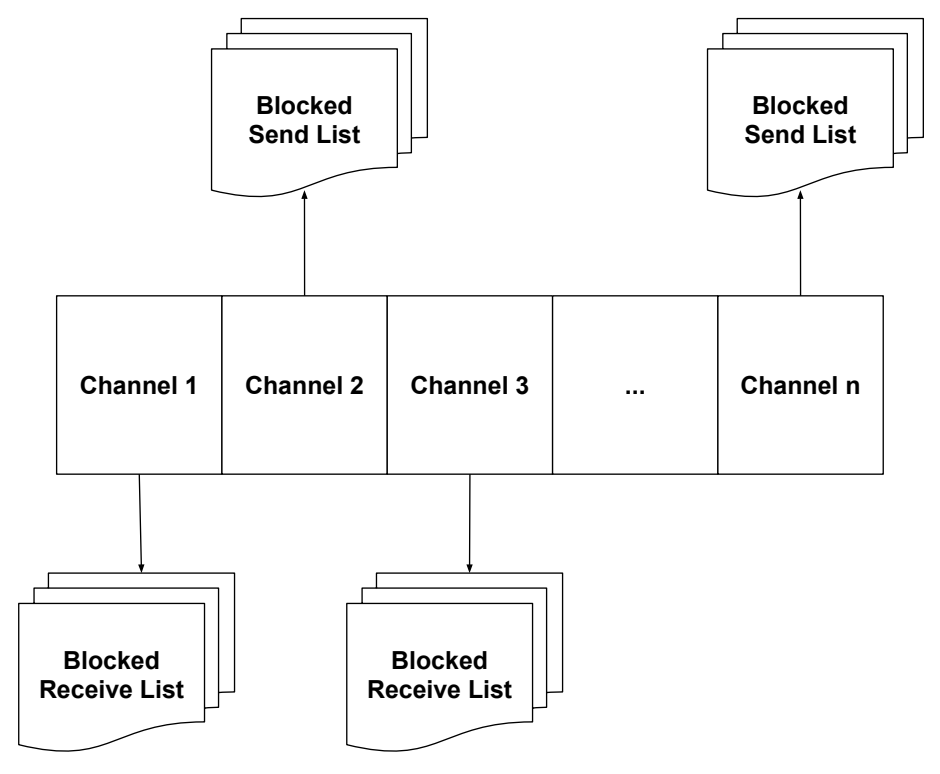

Figura 5.2: Canais Luaproc com suas respectivas listas de LP's bloqueados por envio e por recebimento.

A arquitetura original de Luaproc também prevê os seguintes estados em que os processos Lua podem se encontrar:

- LUAPROC_STATUS_IDLE

Estado ocioso (inicial)

- LUAPROC_STATUS_READY

Estado pronto para executar.

- LUAPROC_STATUS_BLOCKED_SEND

Estado bloqueado ao tentar enviar uma mensagem.

- LUAPROC_STATUS_BLOCKED_RECV

Estado bloqueado ao tentar receber uma mensagem.

- LUAPROC_STATUS_FINISHED

Estado de execução concluída.

Com a arquitetura existente, apesar das operações send/receive serem síncronas, o worker não fica bloqueado (graça ao yield). Assim, nesse trabalho nos preocupamos em estender a arquitetura de forma a não bloquear a thread 
de SO (worker) em chamadas síncronas às funções da interface MQ. Fizemos uso das chamadas assíncronas da biblioteca para manter um comportamento semelhante ao send/receive da biblioteca original, em que realizamos o yield quando necessário de maneira a obter um sincronismo (em Lua) sem comprometer/bloquear o worker.

Com a introdução das novas operações MQ, foram acrescentados dois novos estados LUAPROC_STATUS_BLOCKED_MQ_SEND e LUAPROC_STATUS_BLOCKED_MQ_RECEIVE (semelhantes aos estados bloqueados acima). Assim, os processos Lua podem ficar bloqueados aguardando uma operação MQ terminar. Quando estão neste estado eles são colocados em uma fila de processos bloqueados por MQ, conforme a Figura 5.3.

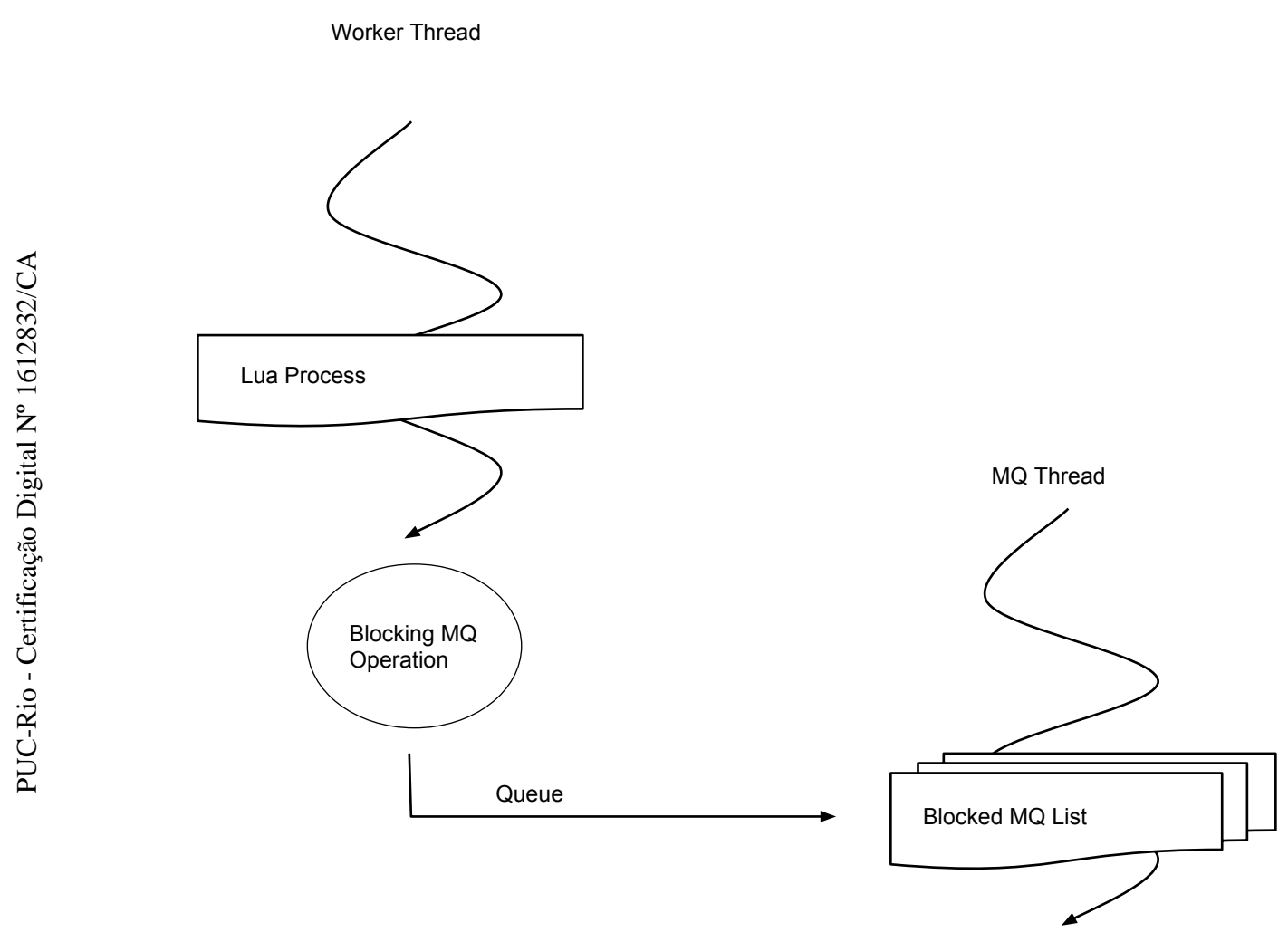

Figura 5.3: Procedimento de bloqueio por operação MQ.

Em nossa extensão, dedicamos uma thread de SO (Sistema Operacional) para o gerenciamento dos processos Lua bloqueados por operações MQ, chamada de MQ_Worker. Uma única thread independente - a MQ_Worker - gerencia os processos Lua da lista de bloqueados (por MQ).

A biblioteca Paho define a figura de um cliente MQTT. Este cliente é uma estrutura da biblioteca Paho que é utilizada nas operações de comunicação com 
o servidor/broker. Pode-se pensar nele como a representação de uma conexão com o servidor. Assim, o cliente MQTT é o responsável pela comunicação com o servidor/broker, já que ele é utilizado em todas as operações de comunicação. Para tratar dessa comunicação, a biblioteca cria duas threads de SO quando ocorre uma conexão: uma thread para envio e outra para o recebimento de informações ${ }^{27}$. Isto totaliza então 3 threads auxiliares na aplicação, como ilustrado na Figura 5.4: nosso MQ_Worker, que gerencia os LP's bloqueados (por MQ); a thread Paho de envio, que envia informações ao servidor (como mensagens, pedidos de inscrições à tópicos, etc); e a thread Paho de recebimento, que recebe as mensagens do servidor.

Worker Threads

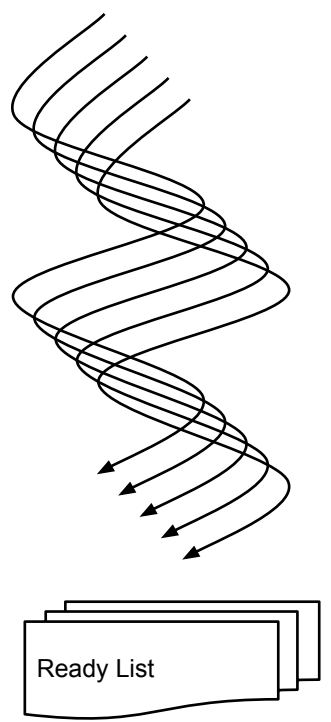

MQ Worker Thread

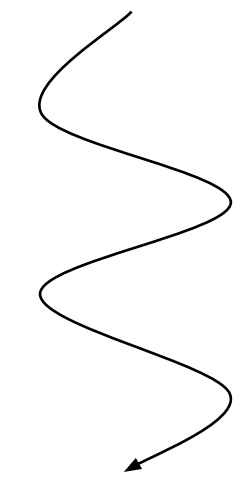

Blocked MQ List
Paho Send Thread
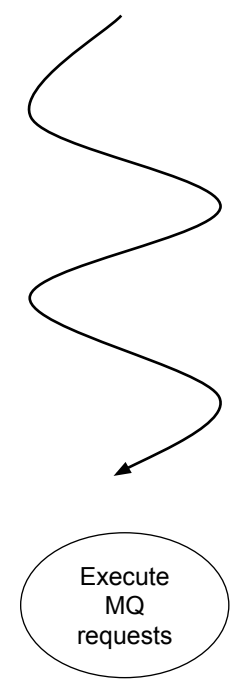

Paho Receive Thread

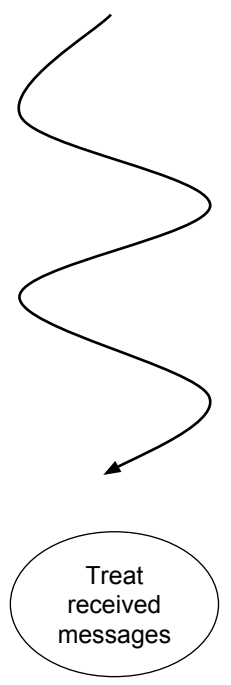

Figura 5.4: Threads da aplicação: os workers e as threads auxiliares.

$\mathrm{Na}$ arquitetura do nosso modelo, um detalhe importante é que há apenas um cliente MQTT por aplicativo, atendendo a todos os pedidos dos processos Lua. Essa escolha de utilizar somente um cliente foi feita considerando que cada aplicativo poderia distribuir suas mensagens recebidas dentre seus processos Lua. Outra razão para essa escolha foi que se colocássemos uma conexão por LP

${ }^{27}$ Apesar de não termos encontrado essa informação na documentação oficial, através de nossas observações e analise do código fonte constatamos que são criadas essas duas threads pela biblioteca Paho. 
poderíamos sobrecarregar o sistema de comunicação do dispositivo. Também, ao multiplexar a comunicação dos diversos LP's, visamos uma economia de energia. Caso implementássemos a arquitetura utilizando vários clientes, o trafego das múltiplas conexões iria acarretar em um maior consumo energético pelo celular e consequentemente um menor tempo útil do aparelho. Assim, ao evitar o uso de múltiplas conexões evitamos então gastos adicionais de energia. A Figura 5.5 mostra essa relação entre o cliente e os processos Lua.

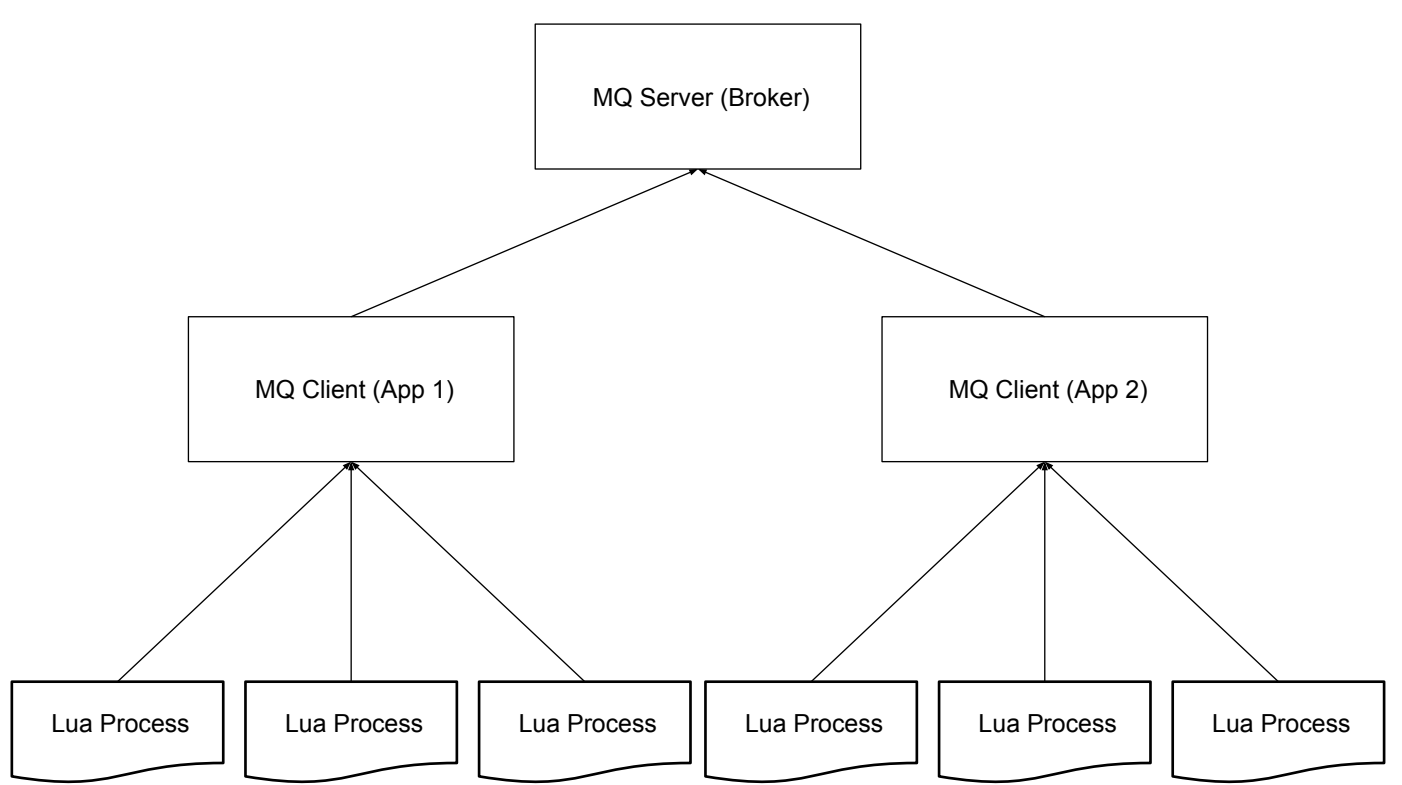

Figura 5.5: Arquitetura do Cliente MQTT.

\subsection{3}

\section{Comunicação e concorrência}

Toda a comunicação com o servidor MQTT ocorre utilizando um único cliente MQTT central (como visto na Subseção 5.2.2). Assim, os processos Lua não se comunicam diretamente com o servidor e apenas realizam requisições. As operações que então forem feitas pelos LP's serão realizadas assincronamente pelas threads criadas pela biblioteca Paho. Em outras palavras, as chamadas à interface MQ são implementadas como requisições a uma única thread da Paho (de envio). Isto ocorre em todas as operações da interface MQ com exceção do recebimento de mensagens. Isto porque o recebimento real das 
mensagens é feito pela outra thread Paho, de recebimento, que ao receber uma mensagem do broker executa uma callback de recebimento que armazena a mensagem localmente. Assim, a chamada mqreceive apenas verifica localmente a existência de alguma mensagem armazenada e não interage com o cliente MQTT. Este funcionamento pode ser visualizado na Figura 5.6.

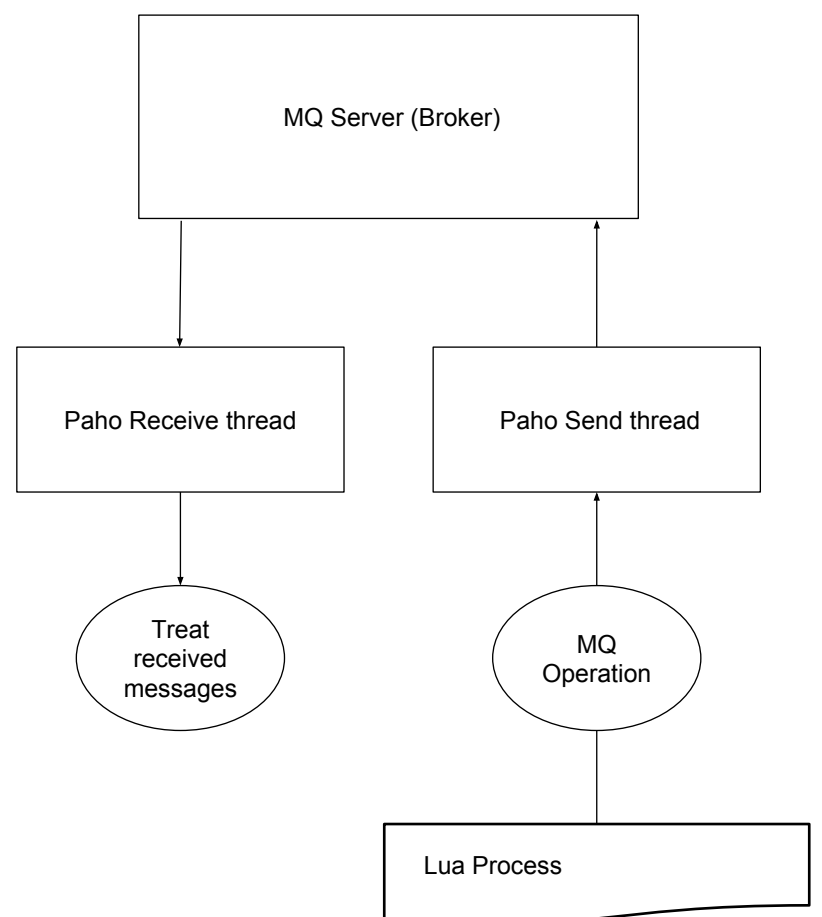

Figura 5.6: Comunicação com o servidor, tratada pelas threads da Paho.

Caso uma operação MQ (executada assincronamente pela thread Paho) finalize antes do término da função que a disparou, o processo Lua segue sua execução normalmente. Caso contrário, o processo Lua é bloqueado de forma a liberar o worker executando-o(através de um yield). Desta forma conseguimos atingir um sincronismo no código Lua, que faz a requisição MQ, sem comprometer o worker (ao bloqueá-lo até a conclusão da requisição). Neste último caso, o LP é então posto em uma fila de processos bloqueados por operações MQ e permanece na mesma até a conclusão da operação.

O nosso MQ_Worker (responsável pelo gerenciamento dos processos Lua bloqueados) é criado ao se conectar com o servidor e destruído ao se desconectar. Após uma operação MQ finalizar (com sucesso ou falha), o devido LP é então retornado para a fila de processos prontos (pelo MQ_Worker), onde será executado novamente pelos workers. A sincronização dos pedidos MQ 
paralelos é realizada pelas threads da biblioteca Paho, como por exemplo 2 LP's enviando mensagens para o servidor ao mesmo tempo. Porém a sincronização do gerenciamento dos estados dos processos Lua bloqueados é feita por nosso MQ_Worker, utilizando mutexes para garantir a corretude da lista dos processos Lua (semelhante à implementação original dos workers). No caso particular de desconexão, utilizamos também uma variável de condição para sinalizar ao $M Q$ _ Worker que o mesmo deve finalizar. Assim, o MQ_Worker espera a finalização dos processos Lua bloqueados por envio (já que estes podem estar finalizando, e se não for o caso há um timeout definido que garante o término). Já para os LP's esperando o recebimento de mensagens, estes são liberados imediatamente na desconexão, retornando um código de erro.

Mensagens recebidas de canais nos quais ocorreram inscrições são armazenadas localmente e são consumidas pelo primeiro LP que executar um pedido de recebimento. Em outras palavras, um LP que executar um mqreceive vai consumir e liberar a mensagem (se houver) da fila local do tópico escolhido. Dessa forma, o broadcast feito pelo broker não se aplica aos diversos LP's que podem ter se inscritos no mesmo tópico. Modelamos dessa forma tendo em mente que seria a melhor forma de distribuir possíveis tarefas a serem recebidas, ou de processar dados paralelamente, já que cada LP poderia processar uma mensagem independentemente. Caso seja necessário que vários LP's recebam o mesmo dado, é possível compartilhar a mensagem através dos canais Luaproc. Dessa forma, esse modelo não prejudica esse último caso de uso.

\subsection{4}

\section{Alternativa de implementação cogitada}

Em um primeiro estudo, cogitamos aproveitar a estrutura orientada a callbacks do biblioteca da Eclipse Paho. A ideia era usar as callbacks de operação bem sucedida para alterar o estado do processo Lua relevante de bloqueado de volta para pronto. Em outras palavras, quando uma operação MQ finalizar e então chegar o momento executar sua callback de sucesso, seria neste instante que pretendiamos alterar o estado do LP para pronto. O problema dessa abordagem, porém, foi sincronizar o yield do LP com essa callback assíncrona de sucesso. Por exemplo, seria possível a operação assíncrona finalizar logo antes de ser realizado o yield do LP para bloqueá-lo, assim deixando o processo em limbo (pois seu estado nunca seria alterado). Cogitamos realizar uma sincronização por meio de flags intermediárias porém esta ideia foi abandonada por sua falta de clareza para uma futura manutenabilidade de código. 


\section{6 \\ Avaliação}

Para fins de avaliação, testamos a implementação do nosso modelo (Paho MQTT Lua) contra a biblioteca Paho MQTT C a fim de medir a sobrecarga de Lua, além também do desempenho. Também implementamos alguns aplicativos utilizando nossa biblioteca Luaproc com a extensão MQTT. Quase todas as aplicações que desenvolvemos trocam informações pontuais e realizaram o processamento localmente (tirando proveito do paralelismo local da biblioteca original). Porém realizamos um exemplo que utilizou processamento distribuído com a nossa implementação do problema do Caixeiro Viajante, descrita na Seção 6.3.

Os testes foram realizados em um Samsung SM-J700M, versão Android 6.0.1 API 23, 1.5BG de RAM e processador ARM Cortex-A53 (Octa-Core 64bit). Nos testes com mais de um aparelho, além do Celular J700M foram utilizados também emuladores Nexus 5 do Android Studio executados em uma máquina com 16GB RAM e processador Intel i7-4770 (Octa-Core 64bit)

\section{1}

\section{Sobrecarga de Lua}

A versão Paho MQTT Lua desenvolvida por nós utiliza a implementação C da Paho e nessa seção pretendemos avaliar o desempenho e sobrecarga de nossa biblioteca em comparação com a biblioteca Paho MQTT C (sem Lua).

\subsection{1}

\section{MQTT C vs MQTT Lua}

Realizamos o mesmo teste de ping-pong da Subseção 2.2.2 entre as versões Lua e C, cuja medidas podem ser vistas na Figura 6.1. As bibliotecas se mostraram com desempenho bem semelhantes, porém a versão Lua se mostrou um pouco mais rápida. Apesar da diferença ser pequena, acreditamos que ela ocorreu provavelmente devido ao uso dos emuladores, que pode ter criado alguma distorção nos tempos de execução. 

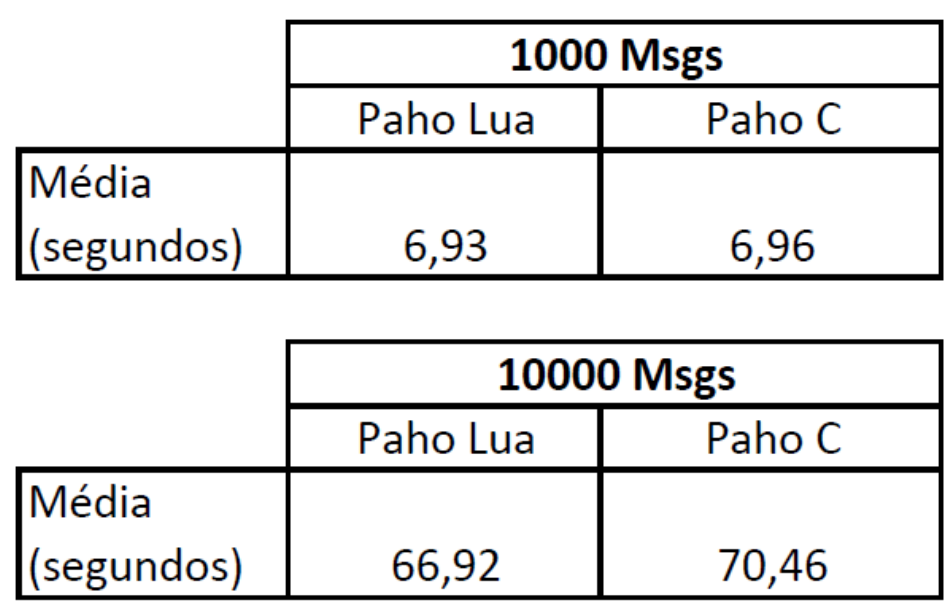

Figura 6.1: Tempo de execução do ping-pong de mensagens entre Lua e C.

Também realizamos alguns testes comparando apenas as versões Paho Lua e Paho C. Neste teste em particular, pareamos o celular J700M com outro celular ao invés de um emulador, no caso um LGE LG-D686, versão Android 4.4.2 API 19, 1GB de RAM e processador ARM Cortex-A9 (Dual-Core 32bit).

Nelas realizamos medições de uma comunicação unidirecional, com um dispositivo apenas enviando e outro apenas recebendo. O objetivo desse teste é analisar o tempo do comunicação dos aparelhos sem a influência da espera de uma resposta (como no teste ping-pong). Os resultados estão ilustrados na Figura 6.2.

\begin{tabular}{|l|c|c|c|c|}
\cline { 2 - 5 } \multicolumn{1}{c|}{} & \multicolumn{4}{c|}{10000 Msgs } \\
\cline { 2 - 5 } \multicolumn{1}{c|}{} & \multicolumn{2}{c|}{ Send } & \multicolumn{2}{c|}{ Receive } \\
\cline { 2 - 5 } \multicolumn{1}{c|}{} & Paho Lua & Paho C & Paho Lua & Paho C \\
\hline $\begin{array}{l}\text { Média } \\
\text { (segundos) }\end{array}$ & 17,06 & 12,92 & 21,09 & 18,18 \\
\hline
\end{tabular}

Figura 6.2: Tempo do envio e recebimento unidirecional de mensagens.

Os resultados mostram um desempenho melhor pela versão $\mathrm{C}$ sobre a versão Lua. Acreditamos que a diferença de tempo entre as medidas das versões ocorreu pela sobrecarga do gerenciamento dos processos Lua Bloqueados. Ou seja, pelo tempo de inserção na lista de bloqueados, na verificação de completude da operação MQ e finalmente o tempo de retorno à lista de execução. Isto não foi um problema no teste anterior (ping-pong) devido ao tempo de espera gerado pelo recebimento síncrono da resposta do outro aparelho, que acreditamos que escondeu essa sobrecarga. 


\section{2}

\section{Aplicativos}

Foram feitos 4 aplicativos no total, cada um deles explorando de forma diferente a biblioteca desenvolvida:

1. Aplicativo de chat

2. Aplicativo do jogo "Hare and hounds" com sugestão de jogada

3. Aplicativo de compartilhamento de fotos

4. Aplicativo de busca e reconhecimento facial

O primeiro aplicativo é uma implementação de chatroom, realizando troca de mensagens textuais. Um usuário então recebe e envia mensagens. para um determinado tópico, e as mensagens trocadas são exibidos na tela de formas diferentes dependendo se a mensagem for do próprio usuário ou não. Uma execução do aplicativo pode ser vista na Figura 6.3.

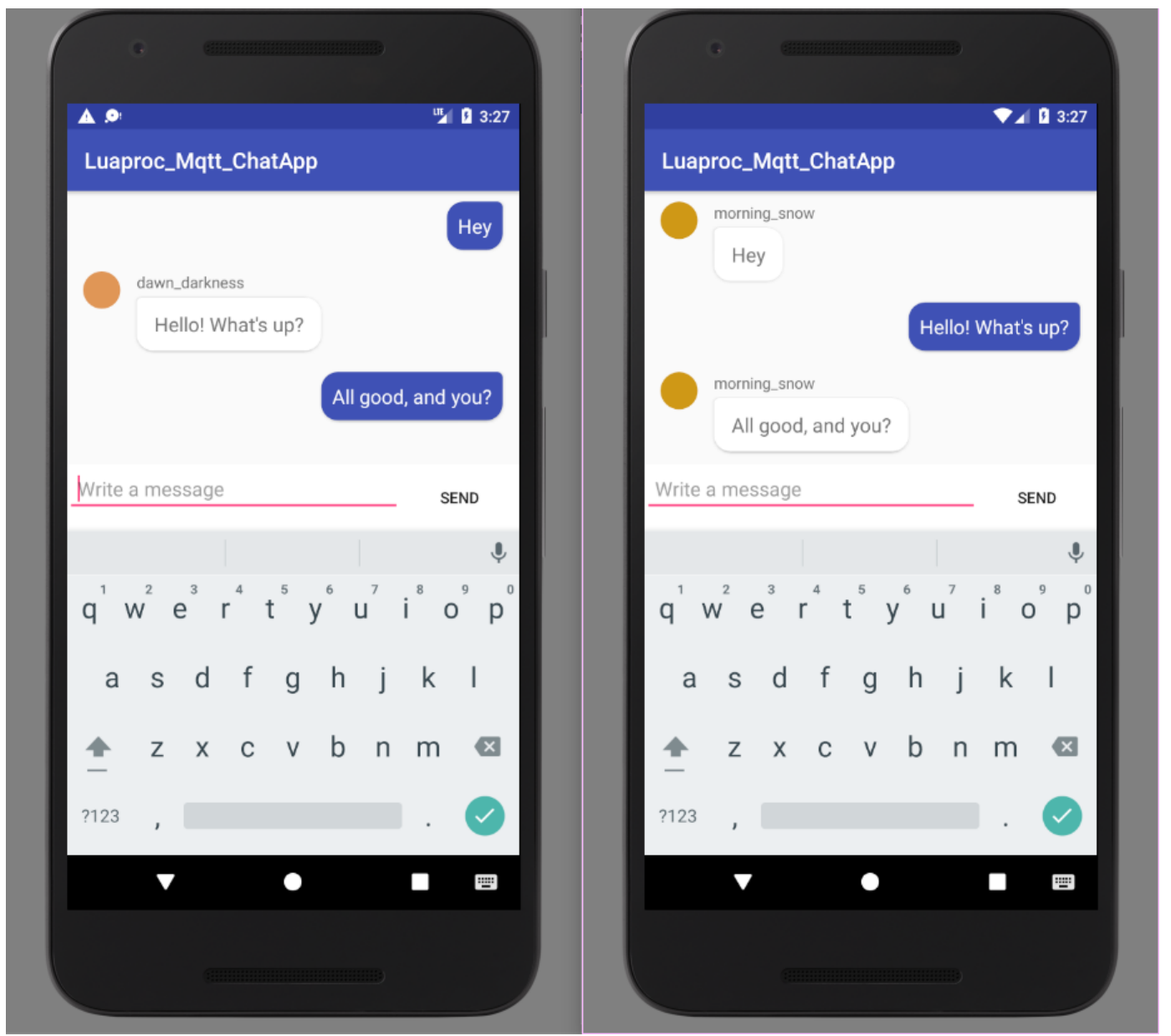

Figura 6.3: Aplicativo Chat com dois usuários. 
O objetivo deste aplicativo foi exemplificar um caso de uso em que a biblioteca pode ser usada somente para realizar a comunicação, ou troca de mensagens. Em outras palavras, não necessariamente precisa-se ter um problema paralelizável para utilizar a biblioteca. Luaproc pode ser utilizado para a simples conveniência de realizar trocas de mensagens em Lua. Um detalhe relevante foi que neste aplicativo se mostrou importante o uso do recebimento assíncrono de mensagens para não travar a interface gráfica do celular. A Seção C.1 do apêndice mostra o código do aplicativo.

O segundo aplicativo é uma implementação do jogo "Hare and hounds"28, um jogo de tabuleiro para dois jogadores podendo escolher ou o lado da lebre (hare) ou o lado dos cães (hounds). O objetivo do jogo para os cães consiste em prender a lebre, enquanto para a lebre consiste em ultrapassar os cães (já que eles não podem se mover para trás). A comunicação das jogadas entre os jogadores é feita pelo tópico do jogo, e para cada jogada é calculada uma sugestão de jogada para o jogador. Essa sugestão é computada localmente através do algoritmo de Poda Alpha-beta (ou Alpha-beta pruning)(8), como pode ser visto na Figura 6.4.

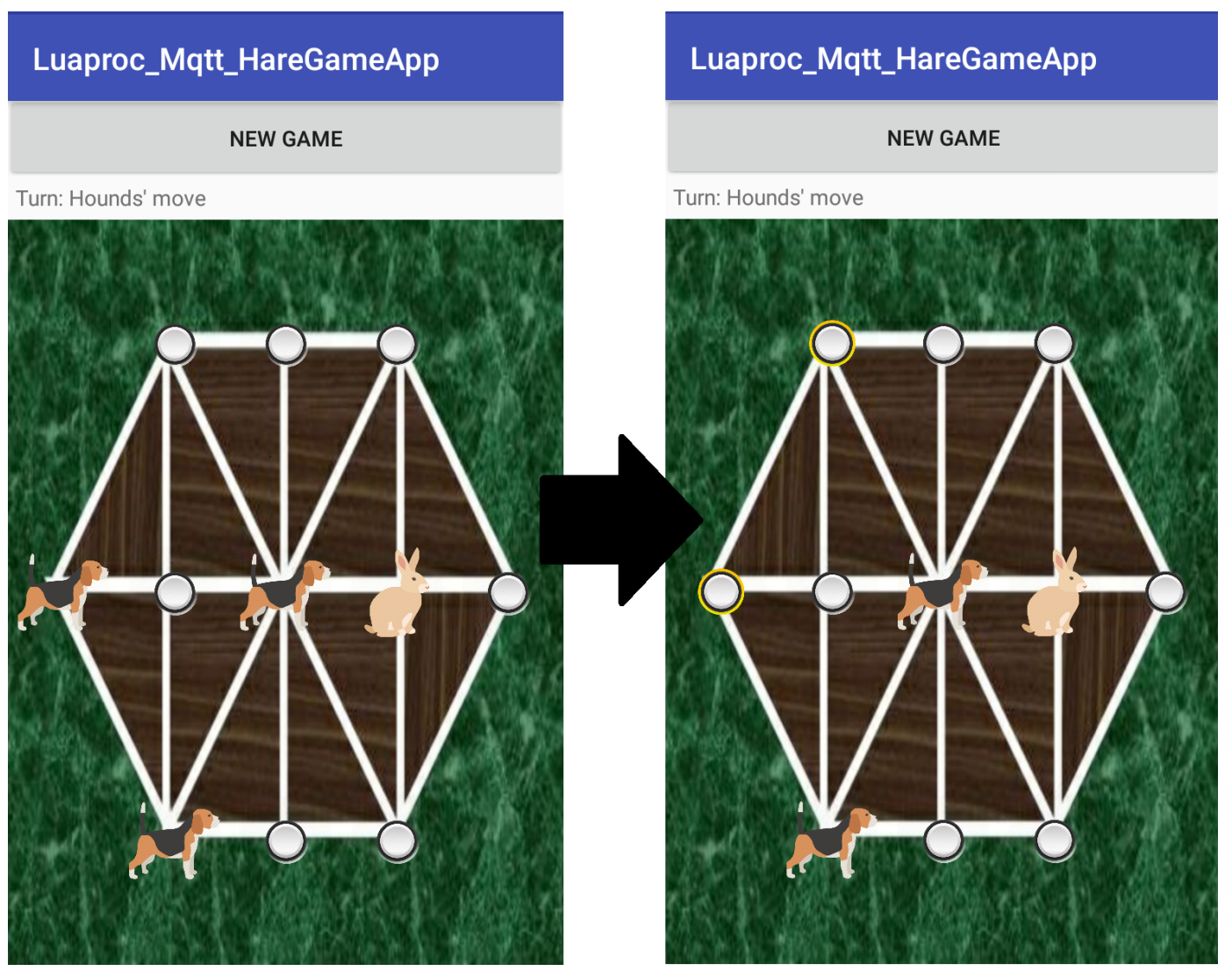

Figura 6.4: Antes e depois da sugestão de jogada.

${ }^{28}$ https://en.wikipedia.org/wiki/Hare_games\#Hare_and_Hounds 
O objetivo deste aplicativo foi exemplificar a exploração do paralelismo local com troca de informações entre aparelhos, já que a sugestão é calculada localmente de forma paralela depois de receber o tabuleiro atual do oponente.

A Figura 6.5 mostra o tempo de execução da sugestão de jogada desse aplicativo, comparando a sua execução serial com uma versão paralela. Assim, conseguimos ter uma ideia do ganho obtido ao tirar proveito do paralelismo Luaproc (após feita a comunicação entre os aparelhos). Variamos também a versão paralela utilizando 8 e 4 workers, como pode ser visto na Figura 6.5.

\begin{tabular}{|l|c|c|c|c|c|c|}
\cline { 2 - 7 } \multicolumn{1}{c|}{} & \multicolumn{6}{c|}{ Jogo Hare and Hounds } \\
\cline { 2 - 7 } \multicolumn{1}{c|}{} & \multicolumn{3}{c|}{ Início de jogo } & \multicolumn{3}{c|}{ Final de jogo } \\
\cline { 2 - 7 } \multicolumn{1}{c|}{} & 8 Workers & 4 Workers & Serial & 8 Workers & 4 Workers & Serial \\
\hline $\begin{array}{l}\text { Média } \\
\text { (segundos) }\end{array}$ & 13,92 & 15,18 & 48,07 & 0,84 & 0,86 & 1,64 \\
\hline aceleração & 3,45 & 3,17 & 1,00 & 1,94 & 1,91 & 1,00 \\
\hline
\end{tabular}

Figura 6.5: Tempo do cálculo da sugestão do jogo Hare and Hounds.

Medimos os tempos em duas situações: o início e final do jogo. Isto pois eles representam duas configurações, uma com muitas possibilidades de jogadas e outra com poucas. A quantidade de LP's criadas são de acordo com as jogadas immediatas possíveis (ou seja, apenas para a primeira jogada de cada possibilidade e não todas até o término), que no caso foram 8 e 7 LP's respectivamente para o início e final do jogo. Nota-se que houve um benefício no jogo Hare'n'Houds, porém não houve uma aceleração linear com aumento de workers. A utilização de 8 workers resultou em uma aceleração muito semelhante à obtida com 4 workers, apesar de estarmos utilizando um dispositivo com 8 cores. Isto se dá pelo balanceamento de tarefas de cada processo Lua, pois não necessariamente cada configuração do tabuleiro terá o mesmo custo para fazer o cálculo do algoritmo alpha-beta. Dessa forma, um LP está com uma carga grande de trabalho (responsável por maior parte do tempo) enquanto os outros terminam rapidamente. Nota-se também que ao final do jogo, quando há poucas possibilidades tanto de configurações de tabuleiros quanto de jogadas possíveis, a aplicação não usufrui tanto do paralelismo devido ao pouco trabalho (caindo também sua aceleração).

Uma dificuldade deste aplicativo em particular foi sincronizar os jogadores, por conta da comunicação em broadcast. Por se tratar de um jogo de tabuleiro entre dois jogadores, não é desejado nem necessário compartilhar ou receber jogadas com outro jogador além do oponente. A solução para isso foi dar a cada jogador um tópico único para que só fosse usado esse tópico (pelo oponente) durante o jogo. Assim, o jogador que estiver procurando um jogo 
realizará um broadcast de seu tópico a um tópico público. Os oponentes então receberão esse tópico e responderão através do mesmo com os seus respectivos tópicos. Para então completar o matchmaking, o jogador inicial irá acusar o recebimento para o primeiro tópico que receber e o jogo começará. Para os demais oponentes que podem estar aguardando uma resposta, foi definido um timeout para recomeçar caso eles não tenham sido escolhidos. A Seção C.2 do apêndice mostra o código do aplicativo.

O terceiro aplicativo trata do envio e recebimento de fotos. Um usuário pode escolher entre enviar ou receber fotos de um determinado tópico. Ao enviar, o usuário pode escolher manualmente um número determinado de fotos ou uma pasta contendo as fotos. Daí, as fotos escolhidas são serializadas e enviadas ao tópico adequado que então será recebido pelos usuários que escolheram receber fotos desse tópico.

O objetivo deste aplicativo foi exemplificar a exploração do paralelismo do envio de informações, já que cada foto é serializada e enviada de forma paralela e independente. Além disso, vários dispositivos poderem receber essas fotos, bastando apenas estarem inscritos no tópico correspondente.

Medimos o tempo de execução do envio das fotos desse aplicativo, comparando a sua execução serial e com uma versão paralela. Mais uma vez, variamos também a versão paralela utilizando 8 e 4 workers, como pode ser visto na Figura 6.6.

\begin{tabular}{|l|c|c|c|c|c|c|}
\cline { 2 - 7 } \multicolumn{1}{c|}{} & \multicolumn{6}{c|}{ Compartilhamento de fotos } \\
\cline { 2 - 7 } \multicolumn{1}{c|}{} & \multicolumn{3}{c|}{$\mathbf{1 0}$ fotos } & \multicolumn{3}{c|}{$\mathbf{6 0}$ fotos } \\
\cline { 2 - 7 } \multicolumn{1}{c|}{} & 8 Workers & 4 Workers & Serial & 8 Workers & 4 Workers & Serial \\
\hline $\begin{array}{l}\text { Média } \\
\text { (segundos) }\end{array}$ & 18,50 & 19,13 & 49,05 & 21,21 & 34,32 & 142,09 \\
\hline aceleração & 2,65 & 2,56 & 1,00 & 6,70 & 4,14 & 1,00 \\
\hline
\end{tabular}

Figura 6.6: Tempo do compartilhamento de fotos.

Foi criado um LP por foto para tratar da serialização, o que significa 10 LP's na primeira medida e 60 LP's na segunda. No caso do aplicativo de compartilhamento de fotos, quando são enviadas poucas fotos nota-se algo similar ao caso do app do jogo Hare'n'Hounds. O desempenho não melhora muito ao utilizar mais workers pois há uma foto "pesada" (em torno de alguns MB enquanto há outras na ordem de KB) que se tornou o gargalo da execução. Ao aumentar a quantidade de fotos estamos gerando mais trabalho de forma a compensar esse desbalanceamento, deixando mais evidente essa observação. Com mais fotos, notamos que a aceleração com 8 workers ficou melhor do que a execução com 4 workers (em contraste com o caso com menos fotos em que 
quase não houve diferença ao aumentar os workers de 4 para 8). A Seção C.3 do apêndice mostra o código do aplicativo.

O quarto aplicativo segue a ideia de "Encontrar pessoas perdidas"(9). O propósito da aplicação seria buscar pessoas (em geral crianças) perdidas de forma distribuída (em vários dispositivos). O usuário que estiver procurando, por exemplo, uma criança, utilizaria uma foto da mesma para enviar e buscar, através de reconhecimento facial ${ }^{29}$, dentre as fotos da Galeria dos outros usuários do aplicativo. O reconhecimento facial se divide em duas etapas, primeiro identificando as faces da foto e em seguida comparandoas e agrupando as faces cujo modelo classifica como sendo a mesma pessoa. Isto está ilustrado na Figura 6.7. Durante o desenvolvimento deste aplicativo apareceu a necessidade de utilizar a funcionalidade do recebimento assíncrono (mqrecieve), para encontrar os dispositivos disponíveis.

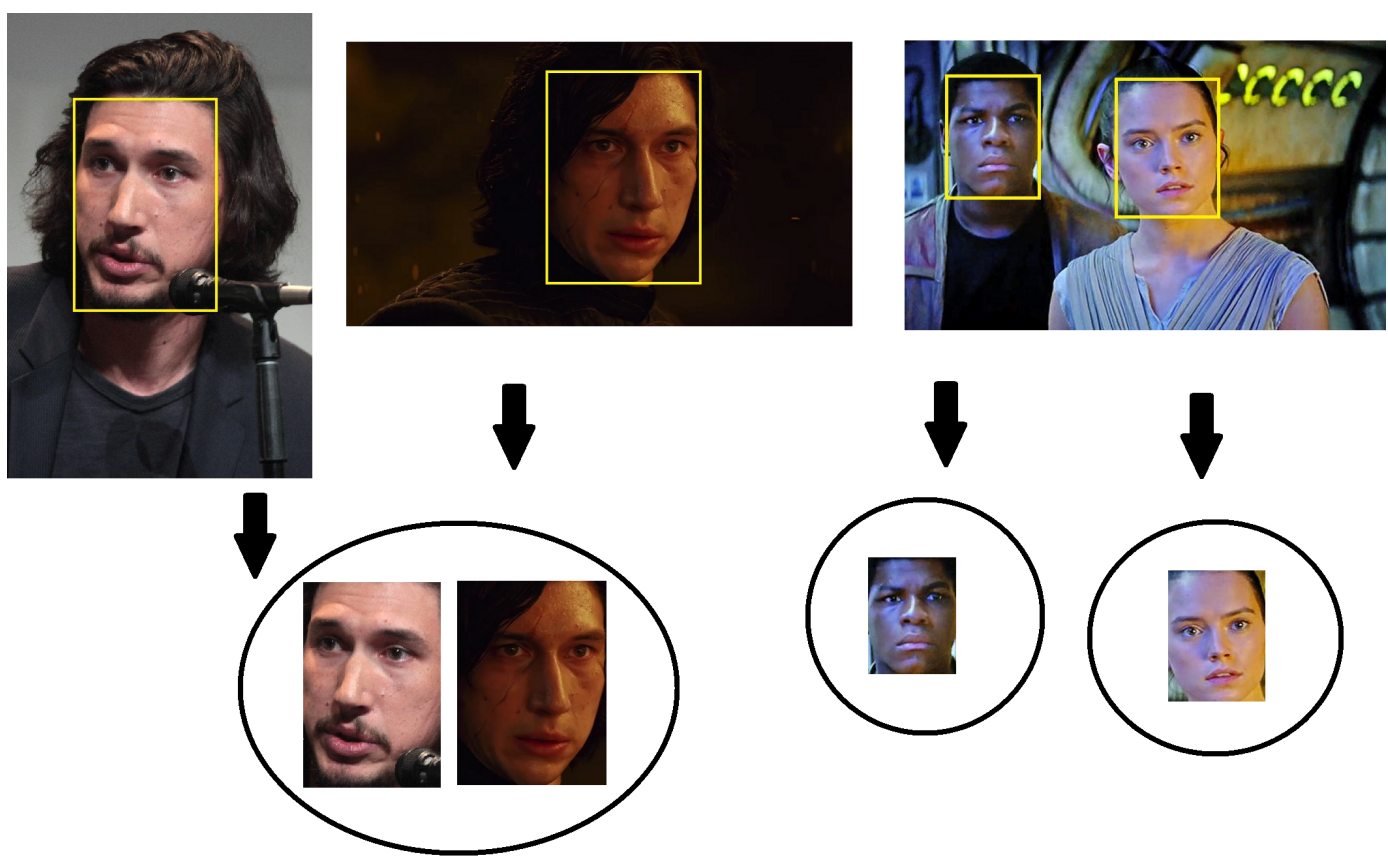

Figura 6.7: Clusterização por reconhecimento facial.

O objetivo deste aplicativo foi exemplificar a exploração da comunicação distribuída combinada com paralelismo no processamento local, já que vários aparelhos podem receber a foto de referência (para a busca) e procurar paralelamente dentre suas fotos locais. Assim, realizando uma forma de busca distribuída.

Medimos o tempo de execução da busca por reconhecimento facial desse aplicativo, comparando a sua execução serial com uma versão paralela.

\footnotetext{
${ }^{29}$ Para realizar o reconhecimento, utilizamos a biblioteca C++ "dlib" (https://github. com/davisking/dlib). Criamos um módulo Lua a partir de seu código fonte para então ser chamado em conjunto com Luaproc (para paralelizar a busca).
} 
Novamente variando também a versão paralela utilizando 8 e 4 workers, como pode ser visto na Figura 6.8.

\begin{tabular}{|l|c|c|c|c|c|c|}
\cline { 2 - 7 } \multicolumn{1}{c|}{} & \multicolumn{6}{c|}{ Busca por reconhecimento facial } \\
\cline { 2 - 7 } \multicolumn{1}{c|}{} & \multicolumn{3}{c|}{ Encontrando } & \multicolumn{3}{c|}{ Não encontrando } \\
\cline { 2 - 7 } \multicolumn{1}{c|}{} & 8 Workers & 4 Workers & Serial & 8 Workers & 4 Workers & Serial \\
\hline $\begin{array}{l}\text { Média } \\
\text { (segundos) }\end{array}$ & 105,25 & 123,17 & 230,40 & 30,04 & 48,55 & 152,91 \\
\hline aceleração & 2,19 & 1,87 & 1,00 & 5,09 & 3,15 & 1,00 \\
\hline
\end{tabular}

Figura 6.8: Tempo de busca no conjunto de fotos.

Testamos este aplicativo com uma base com 10 fotos e rodamos em duas configurações de teste: uma encontrando a pessoa e outra sem encontrar a pessoa. Isto foi feito pois ao encontrar a pessoa, o aplicativo retorna a foto desta pessoa ao solicitante e, como visto com o app de compartilhamento de fotos, este processo pode ser custoso. Assim, sem encontrar a pessoa, podemos avaliar simplesmente a busca desconsiderando o tempo de envio da foto. Foram criados 10 LP's, um para cada foto da base. De forma semelhante ao caso do app de compartilhamento de fotos, o uso de mais workers não gerou muito impacto devido a um gargalo gerado pelo LP que está enviando a foto da pessoa encontrada. Porém quando isto não ocorre nota-se uma aceleração significativa com relação ao aumento da quantidade de workers. A Seção C.4 do apêndice mostra o código do aplicativo.

\section{3}

\section{Teste do Caixeiro Viajante}

Realizamos um teste com o problema clássico do Caixeiro Viajante(10), com o objetivo de medir o ganho possível com processamento distribuído. Modelamos o problema com um dispositivo Produtor (que enviará o trabalho a ser feito) e outros aparelhos Consumidores (que executarão o trabalho, retornando o resultado). Medimos os tempos de duas estratégias para a execução distribuída. A primeira utilizou tópicos fixos e conhecidos para os Consumidores, assim o Produtor fica alternando entre elas para enviar o trabalho. A segunda utilizou um tópico de Consumidores livres (ou idle) de forma que o Produtor descobre os Consumidores disponíveis para então enviar trabalho a eles. Esta segunda implementação foi feita para garantir o balanceamento das tarefas. A Figura 6.9 mostra os tempos de execução que obtivemos para as diferentes estratégias e diferentes números de Consumidores. 


\begin{tabular}{|l|c|c|c|c|c|c|c|c|}
\cline { 2 - 9 } \multicolumn{1}{c|}{} & \multicolumn{9}{c|}{ Caixeiro Viajante } \\
\cline { 2 - 9 } \multicolumn{1}{c|}{} & \multicolumn{9}{c|}{ Tópicos Fixos } & \multicolumn{3}{c|}{ Tópico de Balanceamento } \\
\hline Consumidores & 1 & 2 & 3 & 4 & 1 & 2 & 3 & 4 \\
\hline $\begin{array}{l}\text { Média } \\
\text { (segundos) }\end{array}$ & 44,37 & 24,59 & 23,16 & 18,07 & 80,87 & 42,39 & 30,46 & 22,61 \\
\hline Aceleração & 0,95 & 1,71 & 1,81 & 2,32 & 0,52 & 0,99 & 1,38 & 1,86 \\
\hline $\begin{array}{l}\text { Aceleração } \\
\text { relativa }\end{array}$ & 1,00 & 1,80 & 1,92 & 2,46 & 1,00 & 1,91 & 2,65 & 3,58 \\
\hline
\end{tabular}

\begin{tabular}{|l|c|}
\cline { 2 - 2 } \multicolumn{1}{c|}{} & Caixeiro Viajante - Standalone \\
\hline $\begin{array}{l}\text { Média } \\
\text { (segundos) }\end{array}$ & 41,95 \\
\hline
\end{tabular}

Figura 6.9: Tempo da resolução do problema do Caixeiro Viajante.

Os testes foram executados com 14 cidades e uma quantidade fixa de 2 workers por Consumidor. A quantidade de LP's está relacionado à quantidade de cidades. Como se trata de um grafo completo e a cidade de origem não conta para o problema, a quantidade de LP's da versão standalone é então igual a 13. Para a versão distribuída esta quantidade depende do número de Consumidores e da estratégia utilizada. No caso da estratégia de tópicos fixos, a quantidade é simplesmente o resultado da distribuição, por exemplo para 4 Consumidores o primeiro criará 4 LP's e os demais 3 LP's. No caso da estratégia de balanceamento, não é possível dizer com certeza a quantidade criada por cada Consumidor pois dependerá da disponibilidade de cada um de receber as tarefas.

Além da aceleração com relação à versão standalone, também medimos a aceleração relativa, que diz respeito ao ganho da própria implementação com o aumento de Consumidores. Utilizando o tempo da execução standalone como base, podemos comparar com a execução distribuída com apenas 1 Consumidor para ter uma ideia da sobrecarga da comunicação pela rede. Notase que a segunda versão se mostrou bem mais lenta, devido à necessidade de sincronização para a comunicação, já que o Produtor deve esperar um Consumidor avisar que está livre para então enviar trabalho. Por outro lado, essa implementação obteve uma boa aceleração relativa em contraste com a primeira versão (dos tópicos fixos), que em particular se mostrou bem desbalanceada quando utilizamos 3 Consumidores (mostrando pouco ganho). Apesar da versão balanceada obter uma aceleração relativa próxima do ganho linear, ela ainda foi mais lenta que a versão dos tópicos fixos, o que demonstra a importância da sobrecarga de comunicação. 


\section{7}

\section{Conclusão e trabalhos futuros}

Neste trabalho estendemos a biblioteca Luaproc, oferecendo suporte à programação paralela e distribuída dentro do mesmo módulo, assim possibilitando o usuário tirar proveito tanto do paralelismo multicore quanto multidispositivo. Também combinamos as facilidades de um serviço de enfileiramento de mensagens de forma que o usuário desfrute do desacoplamento resultante, tornando o gerenciamento das mensagens uma preocupação a menos.

Apresentamos um modelo de comunicação multidispositivo para a biblioteca Luaproc. Para implementar este modelo, escolhemos o protocolo MQTT de comunicação e utilizamos a implementação da Eclipse Paho em nossa extensão Luaproc.

Implementamos também uma forma de execução de scripts Lua através de nosso Wrapper Lua, oferecendo uma maneira simples do usuário Android utilizar código Lua de dentro da plataforma.

Através de nossos testes na Subseção 2.2.2 e Subseção 6.1.1 constatamos que, apesar da camada extra de execução do interpretador Lua, a biblioteca se manteve competitiva com a própria versão $\mathrm{C}$ da Paho, além das concorrentes como a versão Android do RabbitMQ.

Para trabalho futuros, a biblioteca poderia ser estendida para incluir outros protocolos além do MQTT, como AMQP, de forma a oferecer uma maior flexibilidade ao usuário para escolher seu protocolo de preferência. Outra possibilidade seria a de realizar um estudo para avaliar outras formas de gerenciamento dos LP's bloqueados por MQ, de modo a tirar melhor proveito do tempo de CPU. Poderíamos reavaliar nossa tentativa (vista na Subseção 5.2.4) de utilizar as callbacks da Eclipse Paho para reinserir os LP's na fila de execução de forma a "aposentar" nosso MQ_Worker. 


\section{Referências bibliográficas}

[1] A. SKYRME; N. RODRIGUEZ; R. IERUSALIMSCHY. Exploring lua for concurrent programming. Journal of Universal Computer Science, 2.2, 2008.

[2] A. SKYRME; N. RODRIGUEZ. Um modelo alternativo para programação concorrente em lua. Dissertação de mestrado, Departamento de Informática, Pontifícia Universidade Católica do Rio de Janeiro, Rio de Janeiro, 2008.

[3] ANDY PIPER. Choosing your messaging protocol: Amqp, mqtt, or stomp. VMware Blogs, 2018. Acesso em: Julho de 2018.

[4] JORGE E. LUZURIAGA; MIGUEL PEREZ; PABLO BORONAT; JUAN CARLOS CANO; CARLOS CALAFATE; PIETRO MANZONI. A comparative evaluation of amqp and mqtt protocols over unstable and mobile networks. In: CONFERêNCIA IEEE, 2015.

[5] CALIN CASCAVAL; SETH FOWLER ;PABLO MONTESINOS ORTEGO; WAYNE PIEKARSKI; MEHRDAD RESHADI; BEHNAM ROBATMILI; MICHAEL WEBER; VRAJESH BHAVSAR. Zoomm: a parallel web browser engine for multicore mobile devices. In: 18TH ACM SIGPLAN SYMPOSIUM ON PRINCIPLES AND PRACTICE OF PARALLEL PROGRAMMING, 2013.

[6] CALIN CASCAVAL. Keynote talk: Parallel programming for mobile computing. In: 22ND INTERNATIONAL CONFERENCE ON PARALLEL ARCHITECTURES AND COMPILATION TECHNIQUES, 2013.

[7] F. LORDANEMAIL; ROSA M. BADIA. Compss-mobile: Parallel programming for mobile cloud computing. Journal of Grid Computing, 15, 2017.

[8] DONALD E. KNUTH; RONALD W. MOORE. An analysis of alpha-beta pruning. Artificial Intelligence, 6, 1975.

[9] CRISTIAN BORCEA; XIAONING DING; NARAIN GEHANI; REZA CURTMOLA; MOHAMMAD A KHAN; HILLOL DEBNATH. Avatar: Mobile distributed computing in the cloud. In: CONFERêNCIA IEEE, 2015. 
[10] GILBERT LAPORTE; SILVANO MARTELLO. The selective travelling salesman problem. Discrete Applied Mathematics - Southampton conference on combinatorial optimization, 26):193-207, 1990. 
A

\section{Interface Luaproc}

- mqconnect( table configuration )

Conecta ao servidor com as configurações da tabela "configuration". É esperado um campo obrigatório "host" (endereço do broker), e opcionalmente os campos "port" (porta em que se deve conectar cujo default é "1883") e "client_id" (nome/id do client mqtt cujo default é um id gerado aleatoriamente). Retorna 1 se bem sucedido, caso contrário retorna uma indicação de erro.

- mqdisconnect ()

Desconecta do servidor (broker) caso conectado. Se não conectado, apenas retorna. Retorna 1 se bem sucedido, caso contrário retorna uma indicação de erro.

- mqregister( string topic )

Registra o cliente ao tópico fornecido. As mensagens publicadas para esse tópico serão recebidas e armazenadas. Retorna 1 se bem sucedido, caso contrário retorna uma indicação de erro.

- mqunregister( string topic )

Cancela o registro do cliente ao tópico recebido, além de eliminar as mensagens armazenadas deste tópico. Retorna 1 se bem sucedido, caso contrário retorna uma indicação de erro.

- mqsend( string message, string topic)

Envia a mensagem ao tópico escolhido, caso conectado. Retorna 1 se bem sucedido, caso contrário retorna uma indicação de erro.

- mqreceive( string topic, [ boolean asynchronous ] )

Bloqueia o processo até a chegada de uma mensagem, retornando-a. Caso o booleano "asynchronous" seja verdadeiro e não haja uma mensagem disponível no momento da chamada, retorna uma indicação de erro. 
B

\section{Processo para a utilização da extensão Luaproc para Android}

\section{B.1}

\section{Gerando o pacote AAR}

1. Deve-se primeiro selecionar a arquitetura desejada através do filtro de compilação

No arquivo "build.gradle", Há a possibilidade de escolher o filtro adequado para a arquitetura desejada. Como por exemplo, "x86" ou "armeabi-v7a".

2. Assim o próximo passo é iniciar a geração do pacote AAR da biblioteca no modo "release"

Terminada essa etapa, o pacote se encontrará no diretório "build/outputs/aar" do Android Studio.

\section{B.2}

\section{Importando o pacote AAR Luaproc em seu aplicativo}

1. Importando o pacote AAR

O pacote Luaproc deve ser importado como um novo módulo em seu aplicativo. Assim, deve-se selecionar a opção de criar um novo módulo em seu aplicativo, em seguida selecionando a opção de importar um pacote JAR/AAR.

2. Configurando seu App para utilizar o pacote AAR

Com o pacote importado, deve-se adicioná-lo como uma dependência de seu aplicativo. Para isso, deve-se entrar nas configurações de seu app (clicando com o botão direito para selecionar Module Settings). Em seguida, adicionando o pacote Luaproc na aba de dependências (Dependencies). 


\section{B.3}

\section{Alternativa para utilizar Luaproc Android em seu aplicativo}

Caso desejado, pode-se importar o projeto Luaproc diretamente em seu aplicativo ao invés do pacote AAR. Para isso deve-se usar a opção de importação Import Module.

Em seguida, deve-se fornecer o caminho do projeto Luaproc para finalizar a importação. Os próximos passos são os mesmos da importação de um pacote AAR, ou seja deve-se adicioná-lo como uma dependência de seu aplicativo. Para isso, deve-se entrar nas configurações de seu app (clicando com o botão direito para selecionar Module Settings). Em seguida, adicionando o pacote Luaproc na aba de dependências (Dependencies).

\section{B.4}

\section{Utilizando o pacote AAR Luaproc em seu aplicativo}

Para executar os scripts Lua, serão necessários alguns passos que serão descritos a seguir:

1. Criar a pasta Assets do Android Studio

Esta pasta pode ser criada automaticamente pelo Android Studio, clicando com o botão direito em seu aplicativo e selecionando essa opção. Dentro desta pasta deve-se criar outra pasta "files", que deve conter os scripts Lua que se deseja executar (além dos módulos Lua, utilizados pelo "require" de Lua). Todos os arquivos fora desta pasta serão ignorados, porém não há problema em utilizar sub-pastas dentre dela. Deve-se ter em mente que "files" age como a pasta raiz e isto deve ser refletido nos "requires" dos scripts Lua.

2. Utilizando o LuaScriptWrapper

Os scripts Lua serão rodados através deste Wrapper, que irá executar o script enxergando a pasta "files" (do Assets) como seu diretório de execução. Basta passar o caminho do script (dentro de "assets/files/"), opcionalmente com argumentos de entrada (que serão armazenadas na variável global "arg"). 
C

\section{Código dos aplicativos}

\section{C.1}

\section{Aplicativo de chat}

- connect.lua

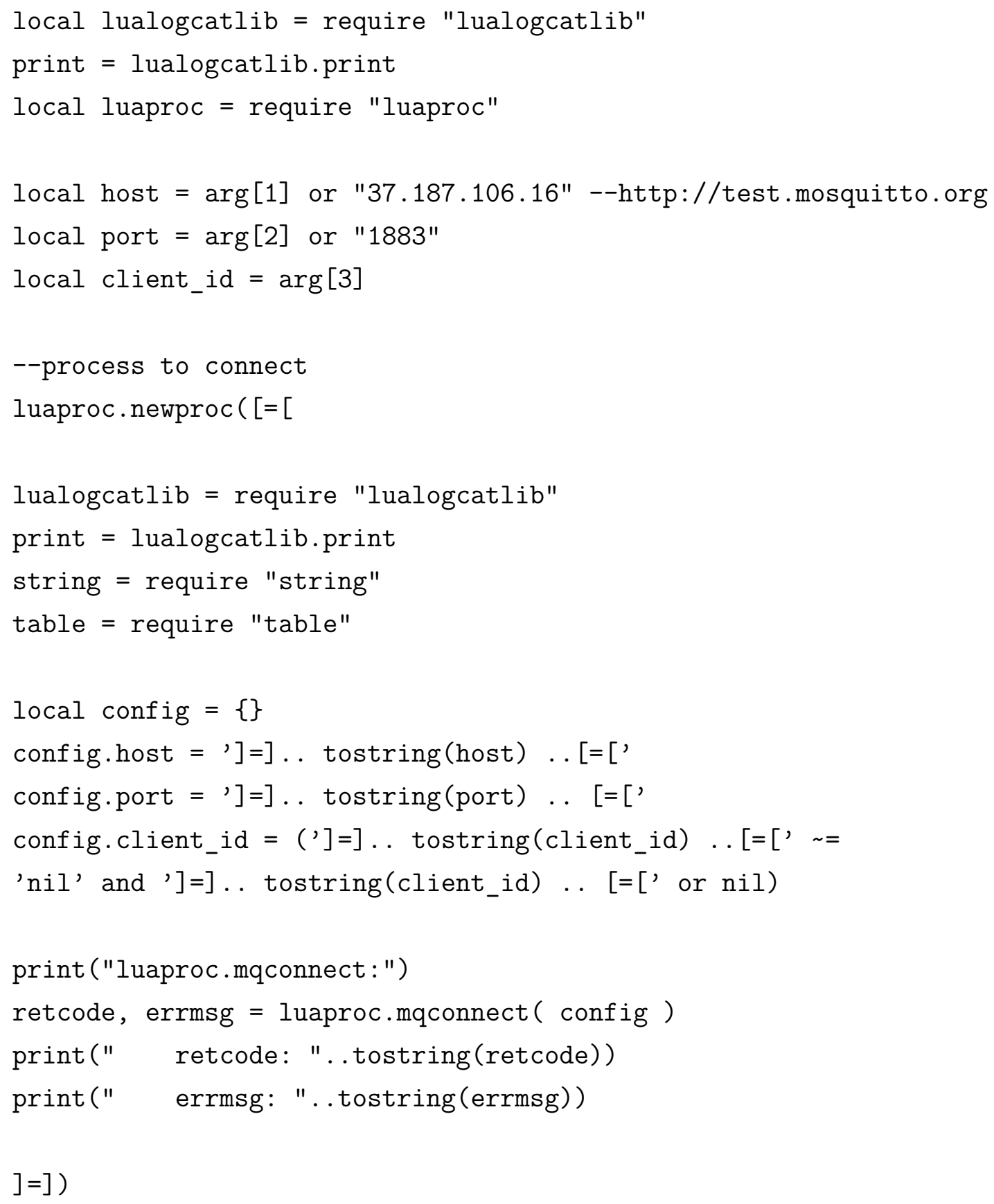




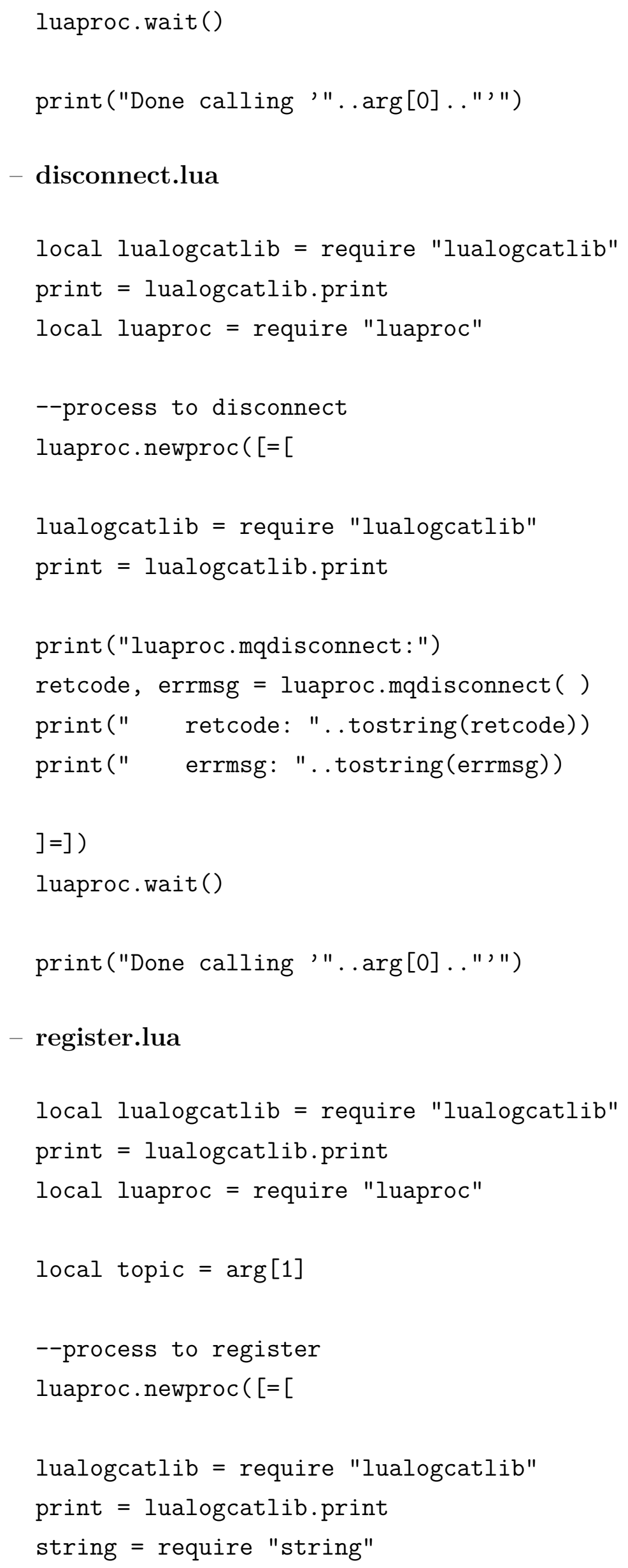




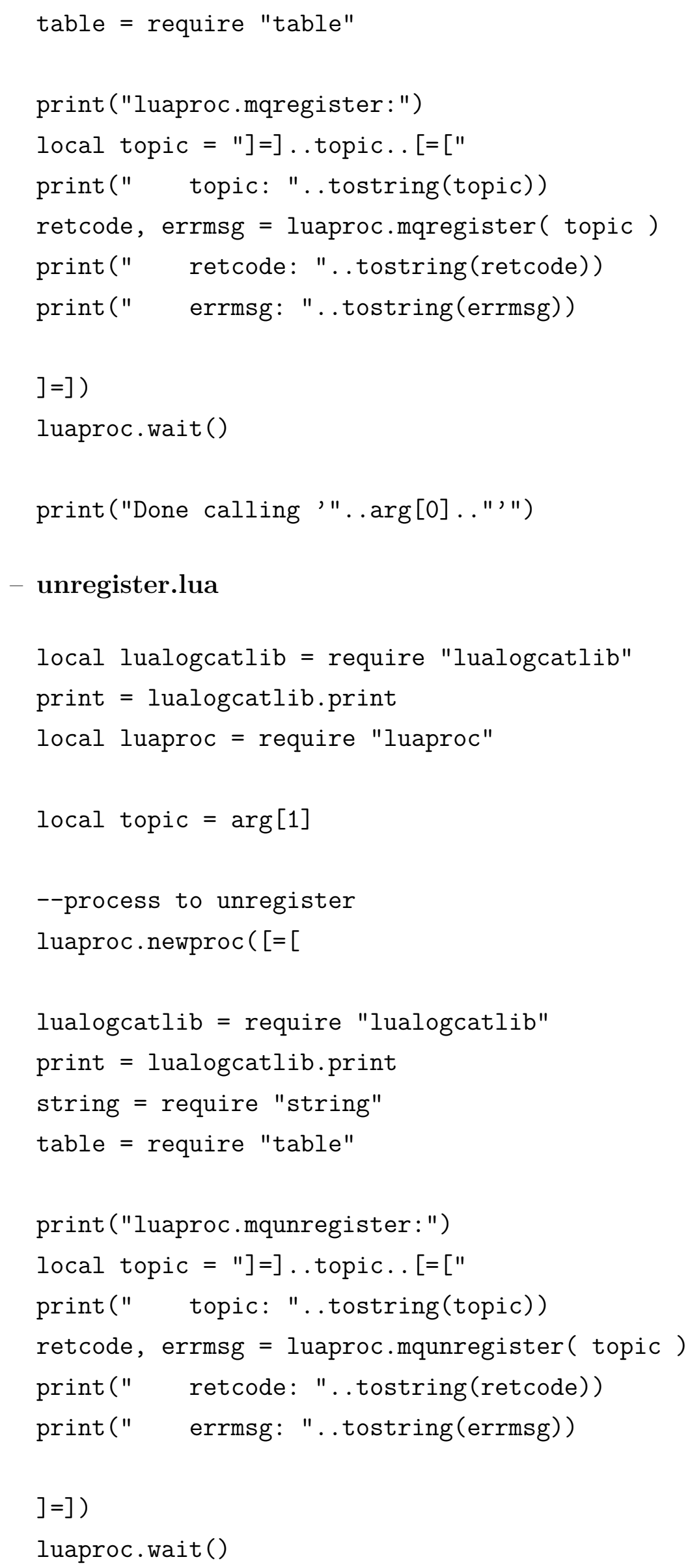




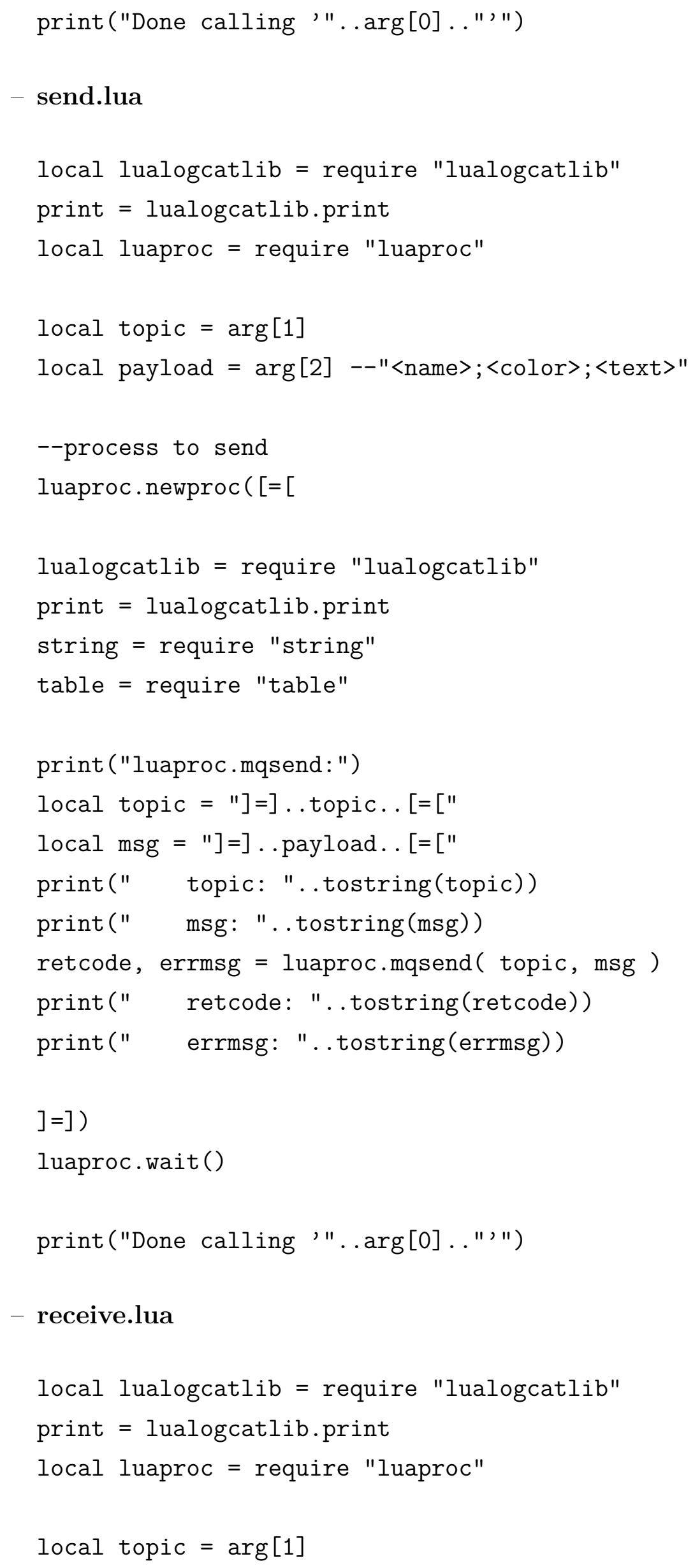




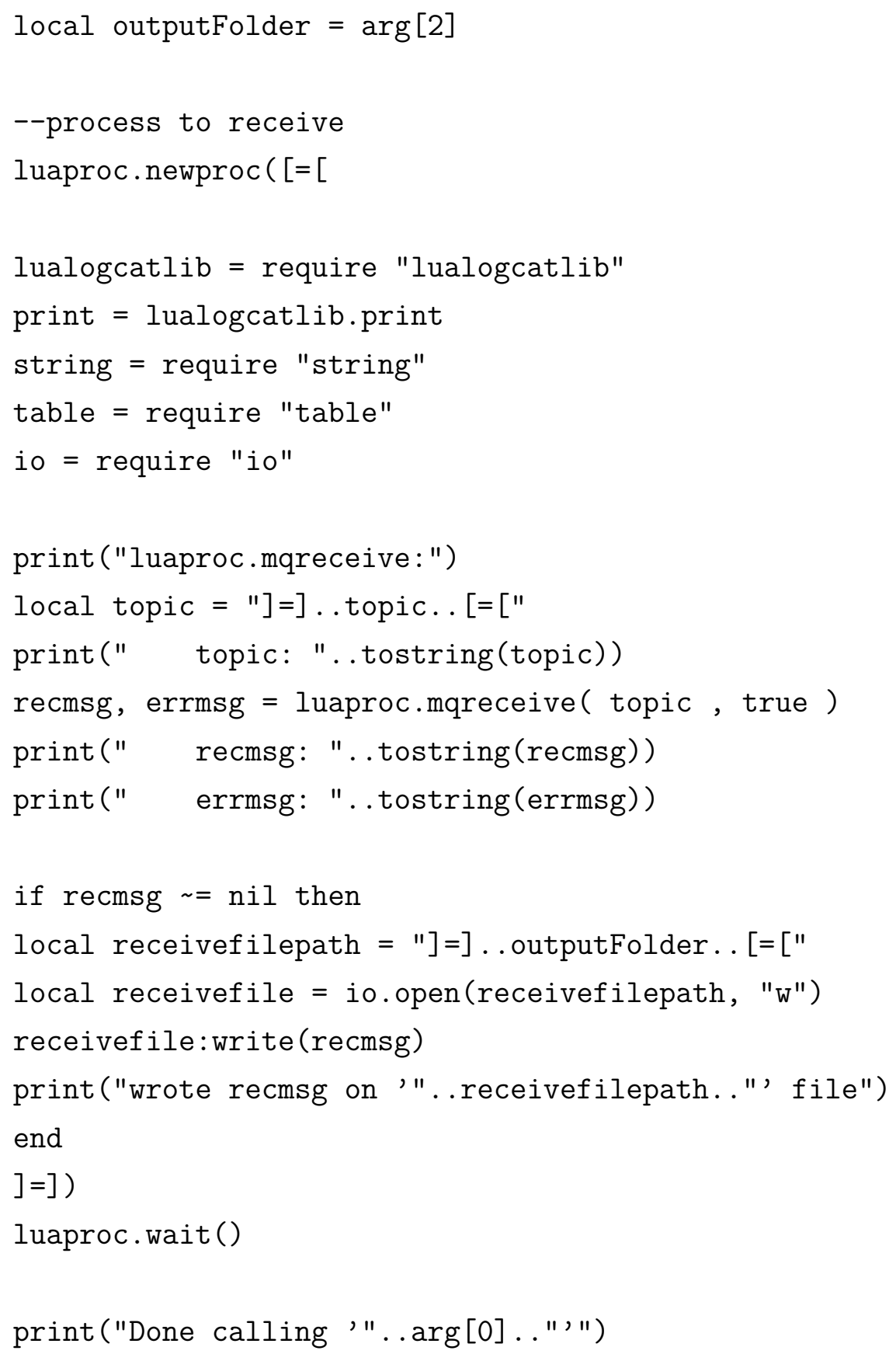

\section{2}

\section{Aplicativo do jogo "Hare and hounds"}

\section{- findplayer.lua}

local lualogcatlib = require "lualogcatlib"

print = lualogcatlib.print

local luaproc = require "luaproc"

local otherPlayerResultFilePath $=\arg [1]$

local mytype $=\arg [2]$ 


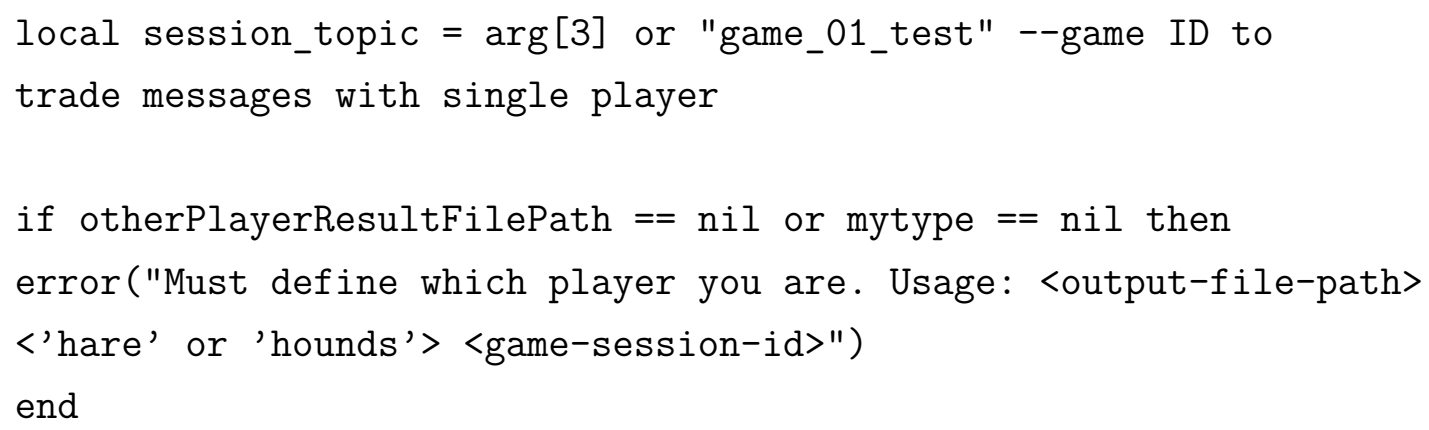




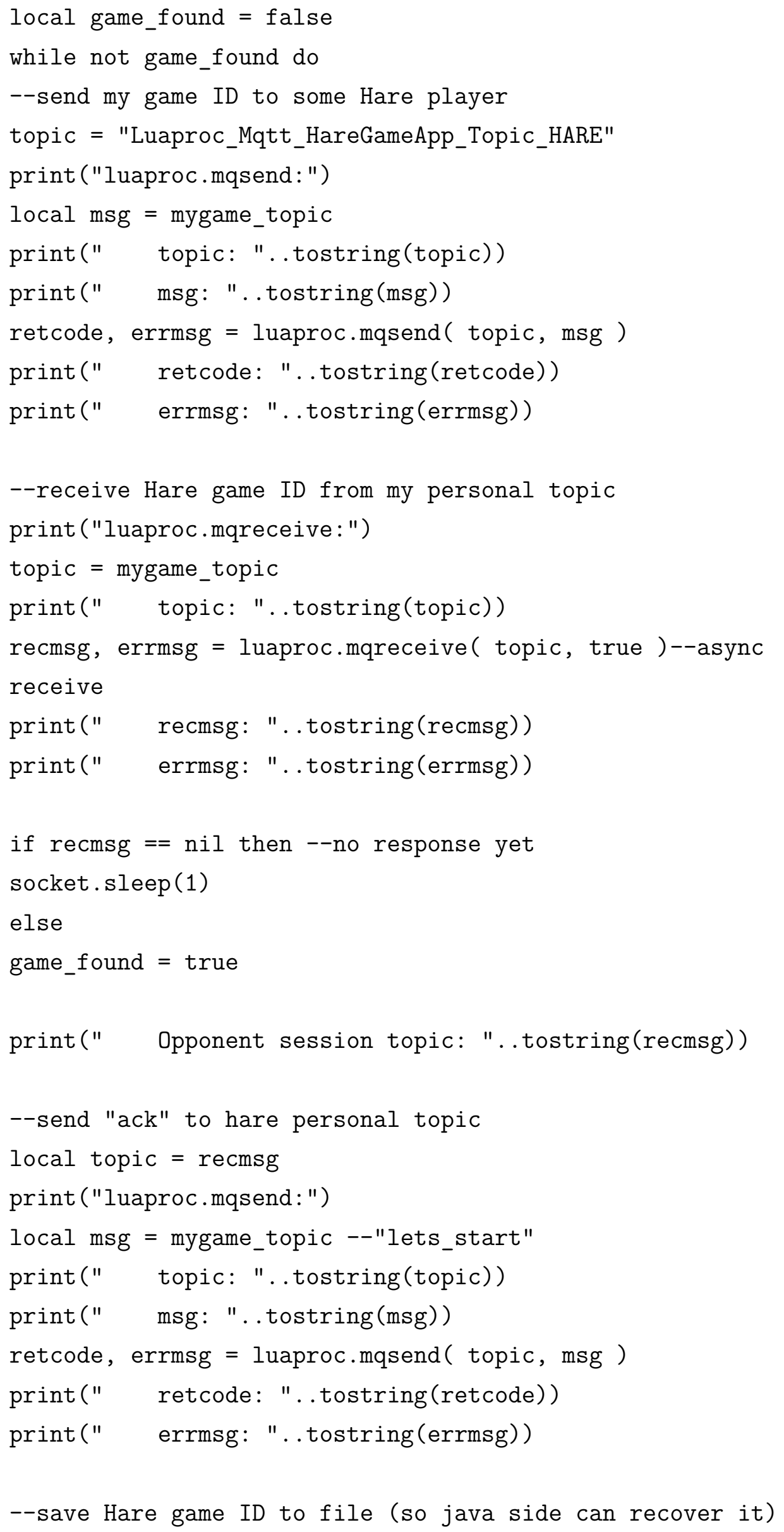




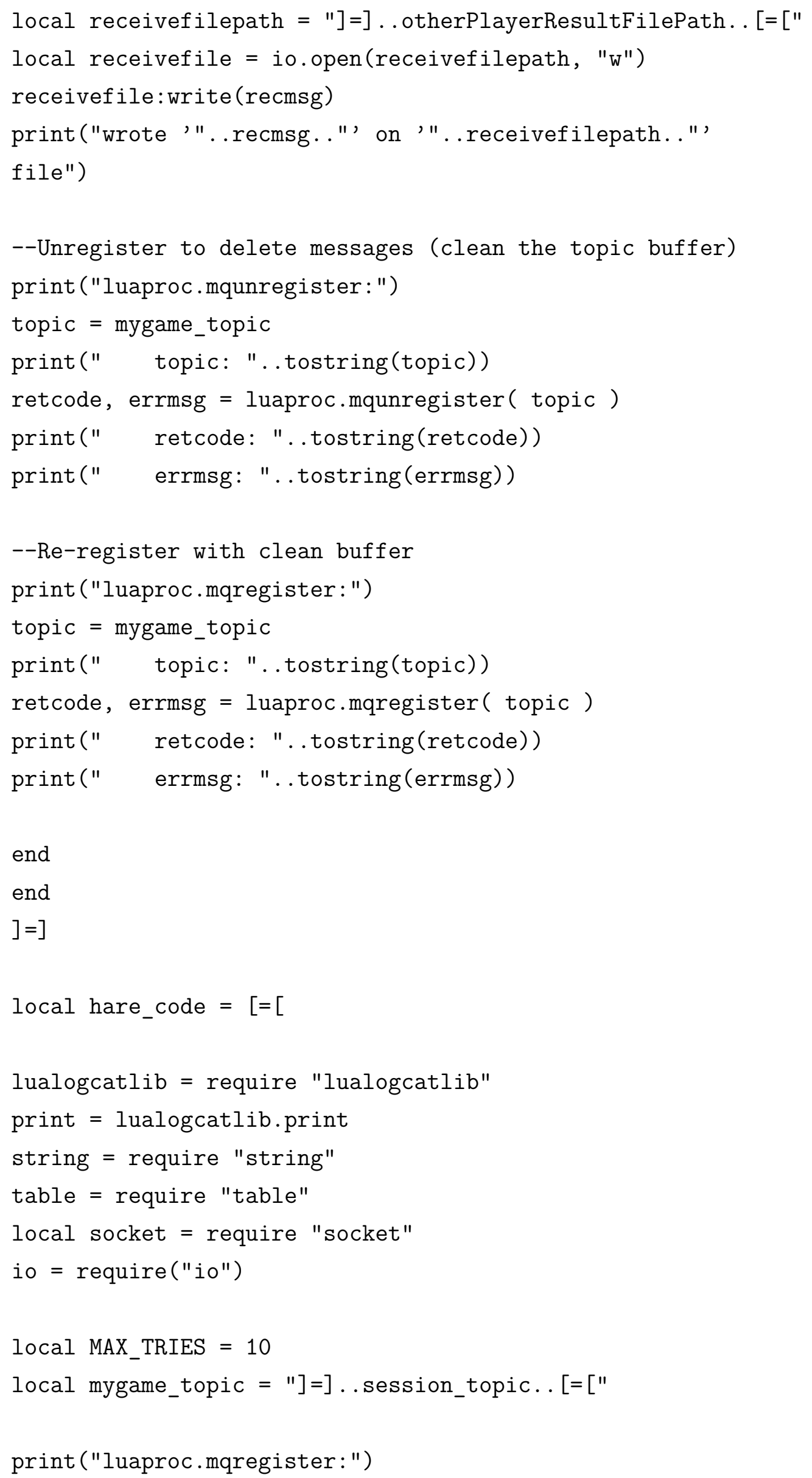




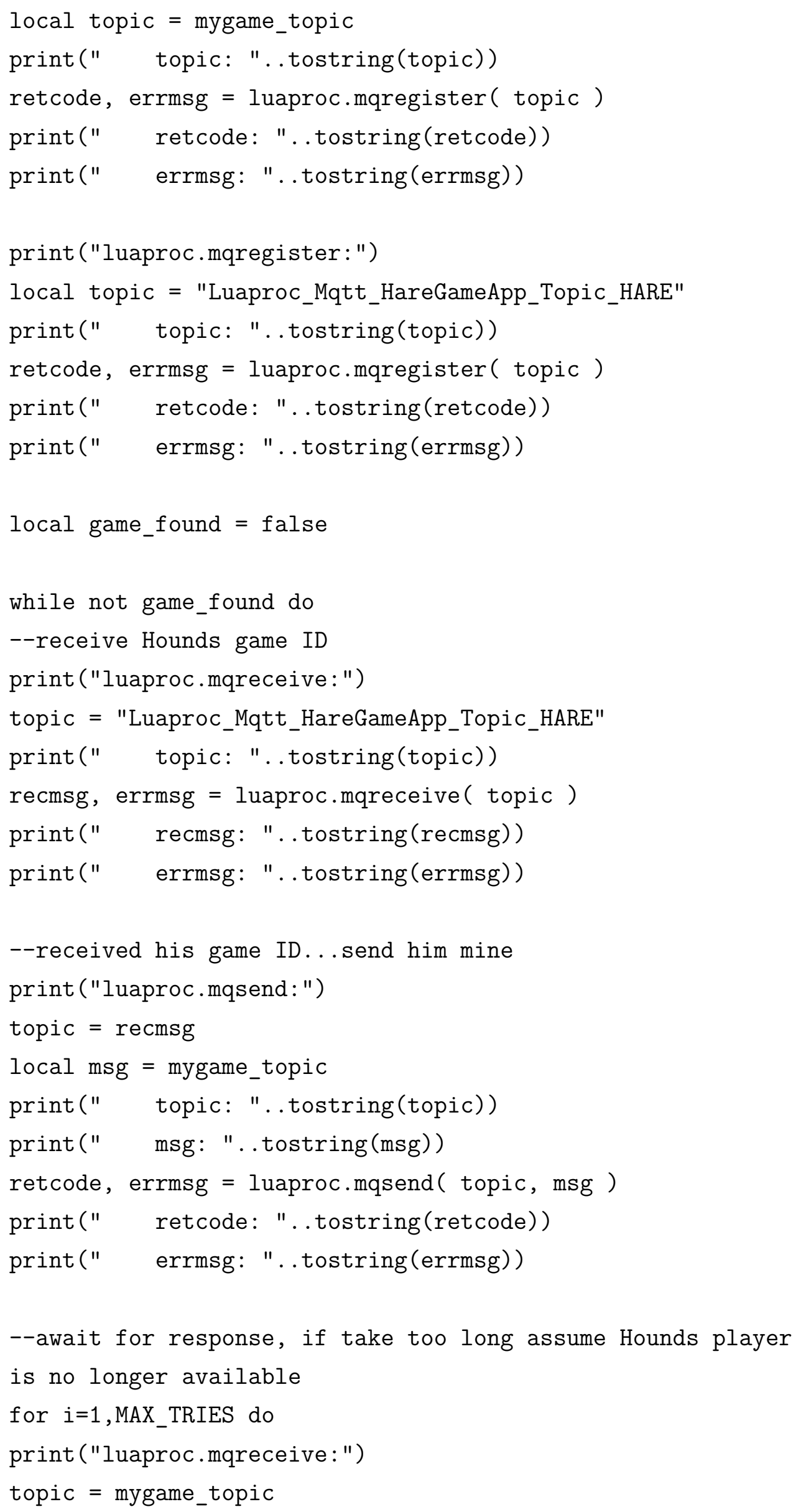




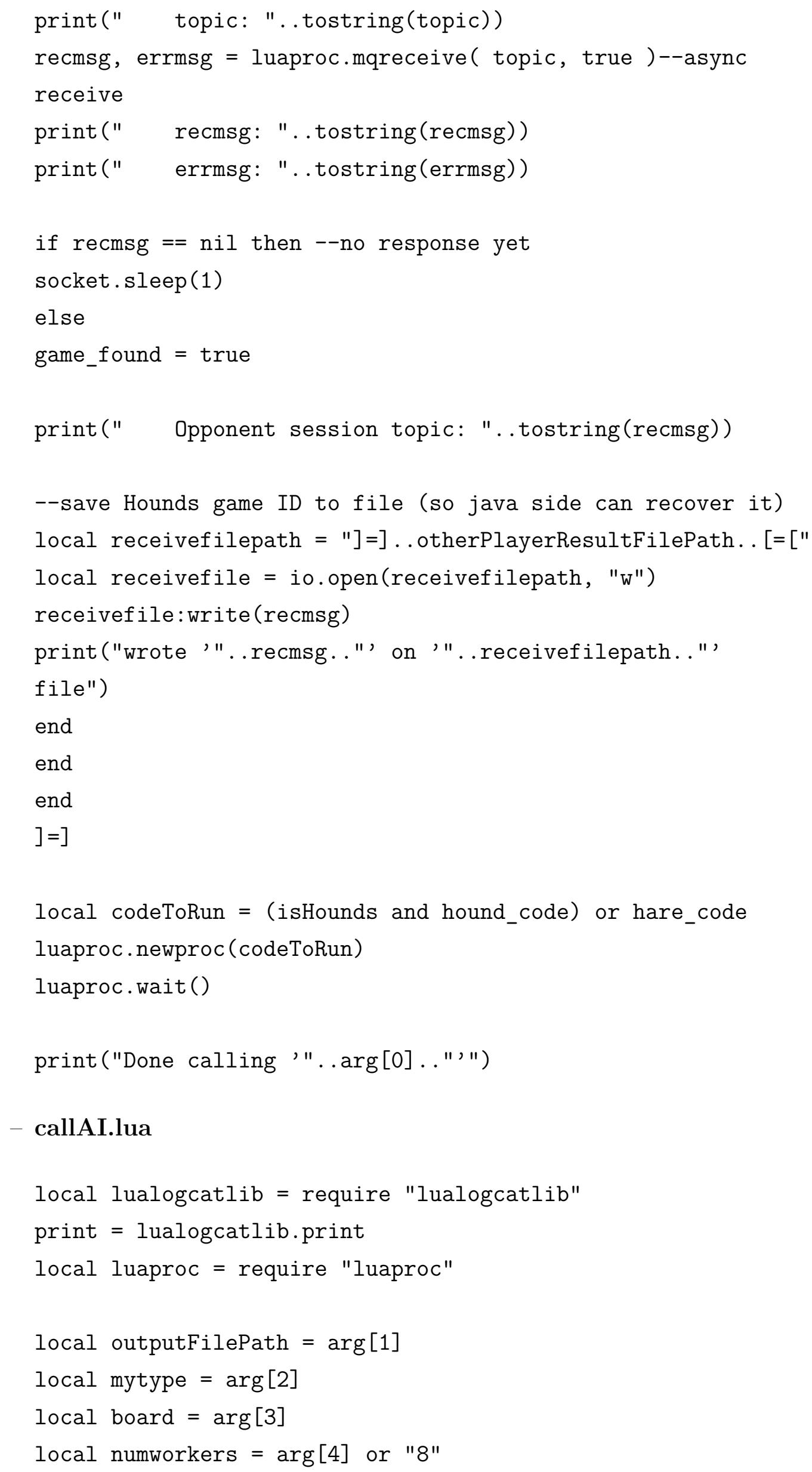




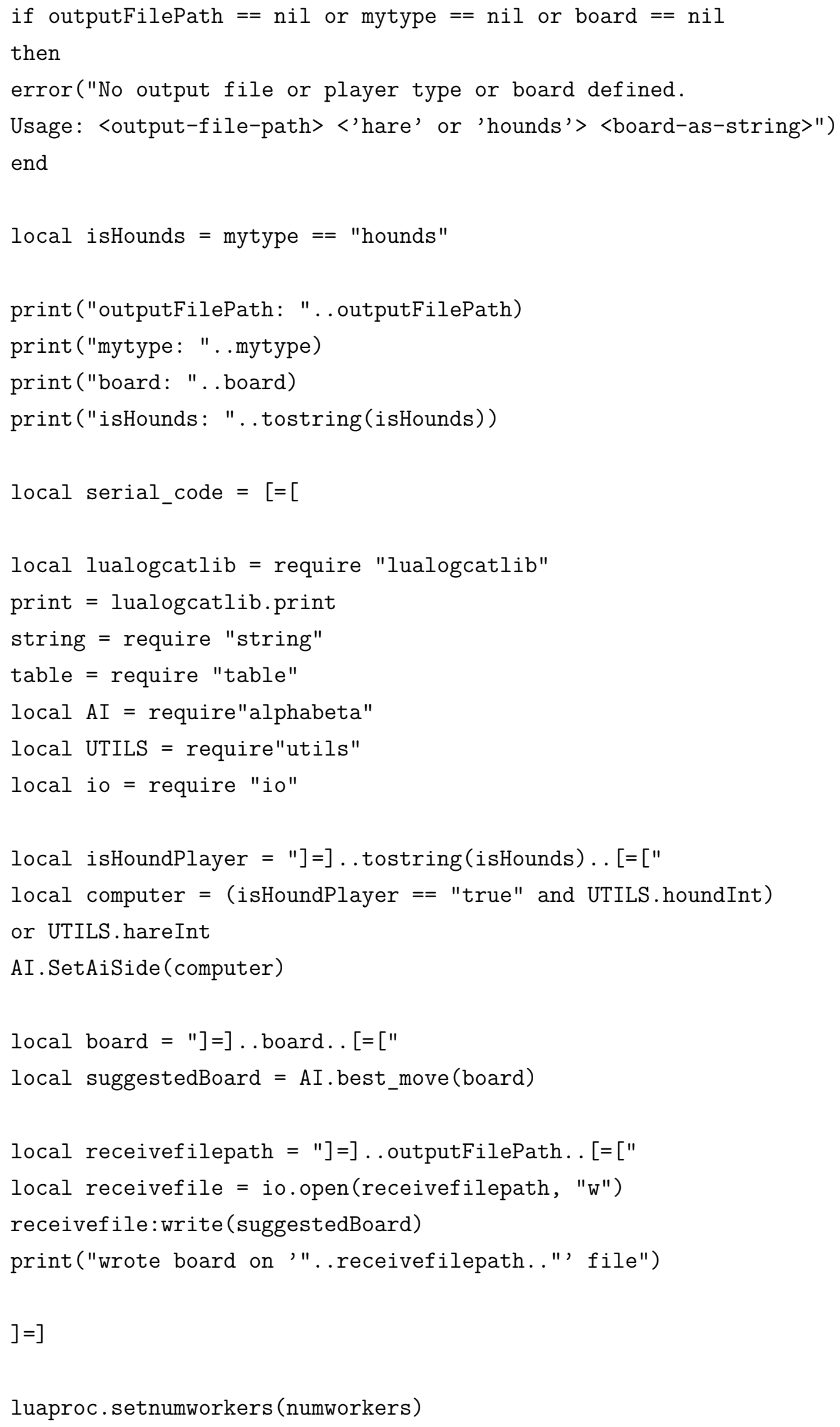




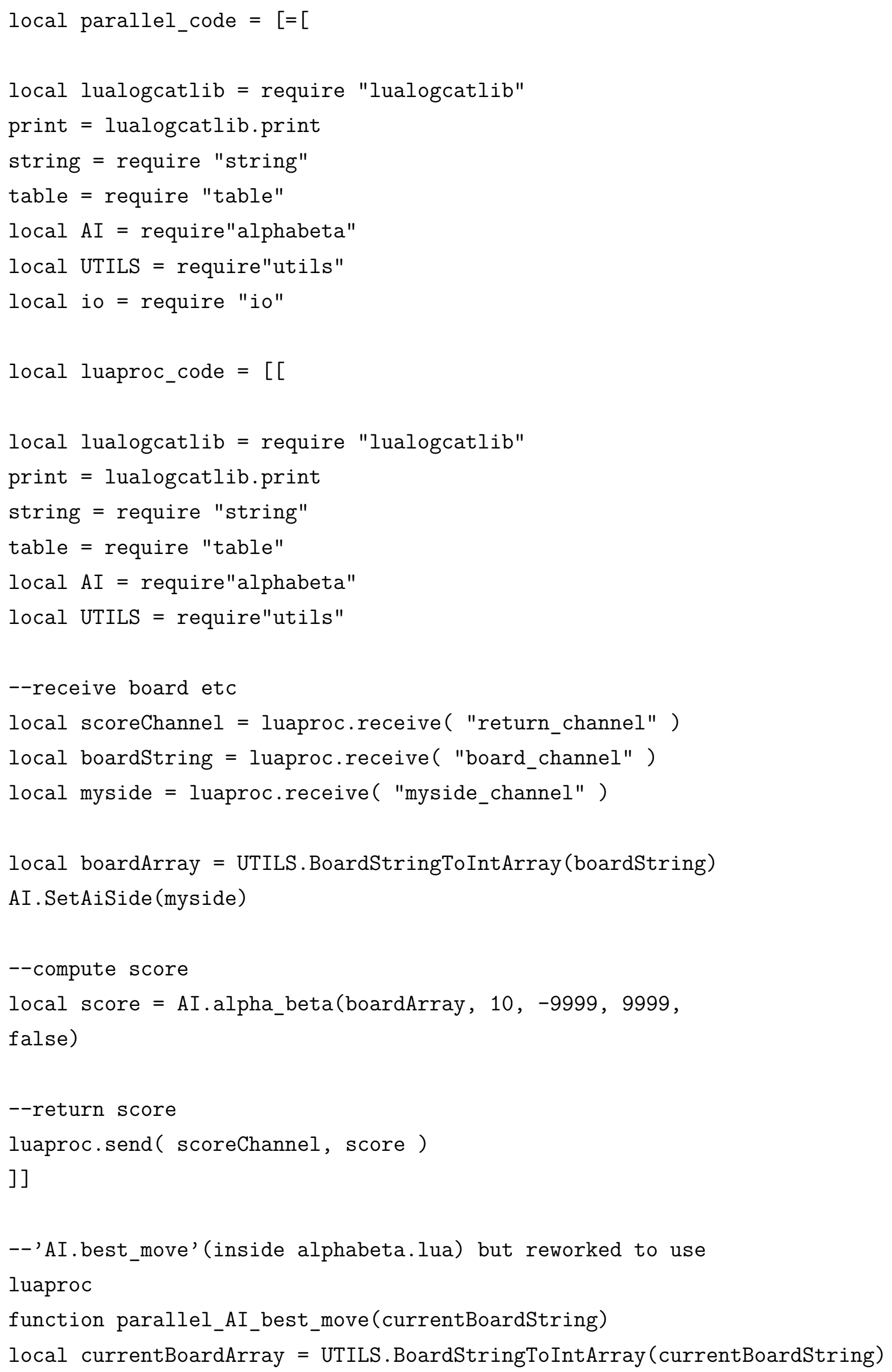




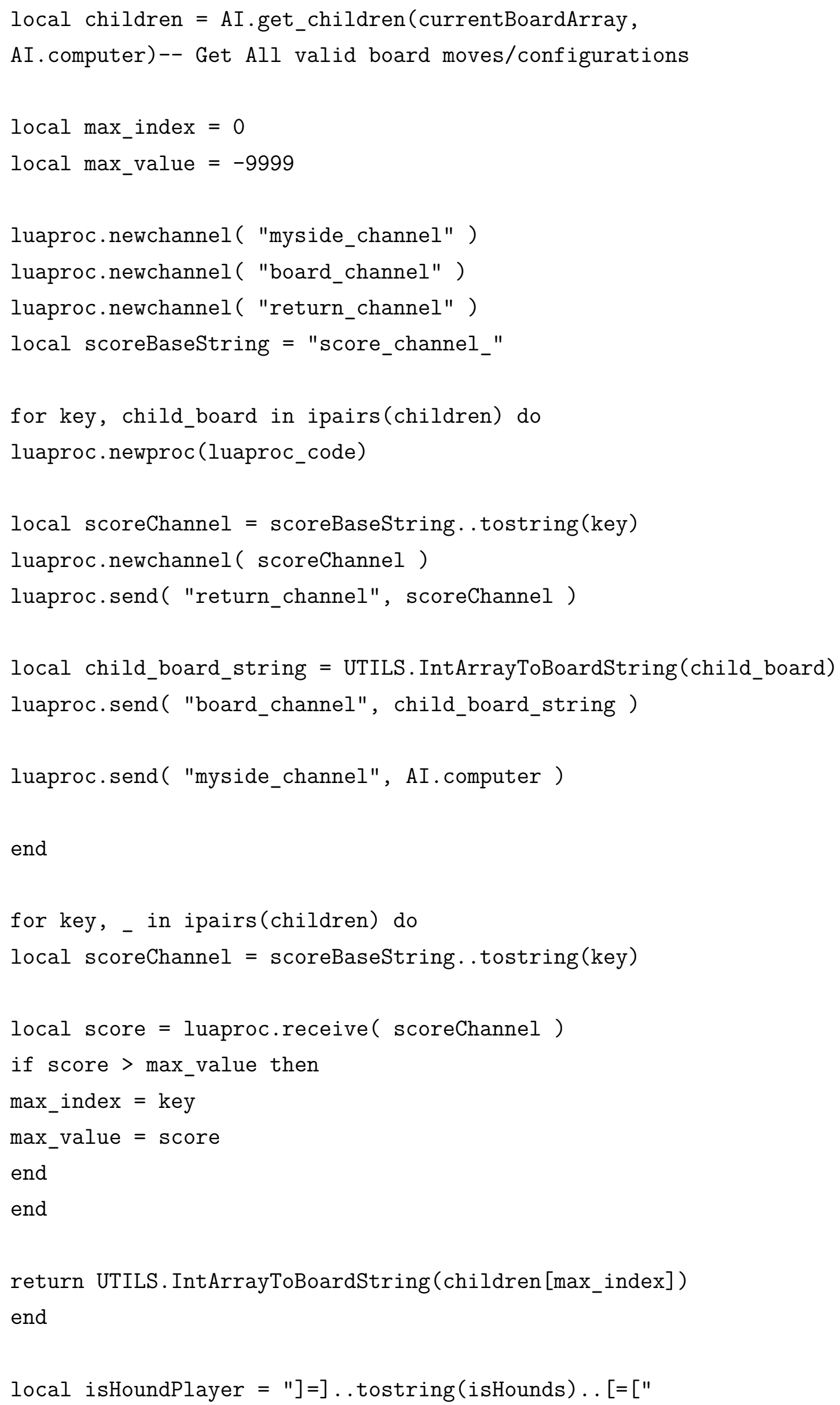




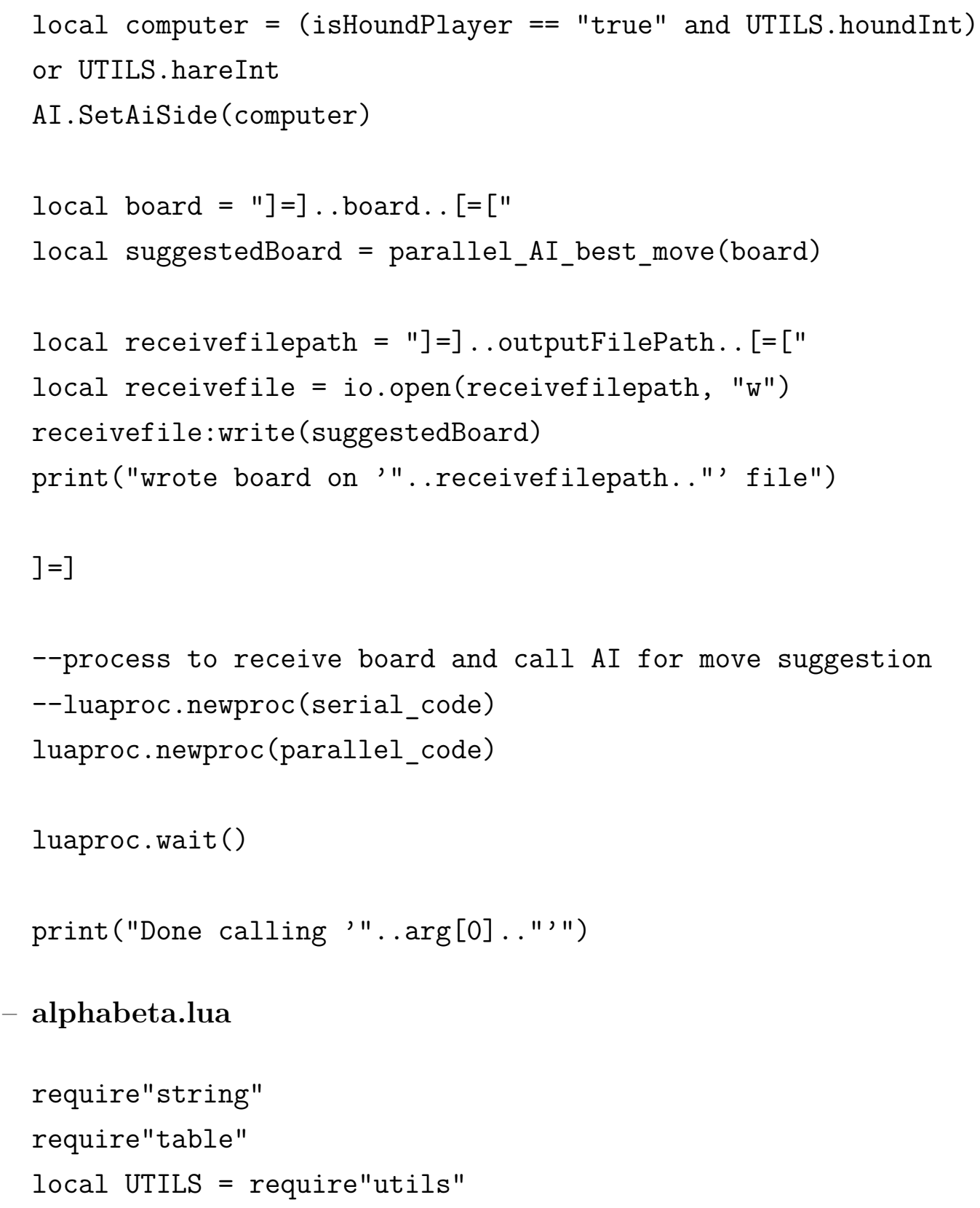




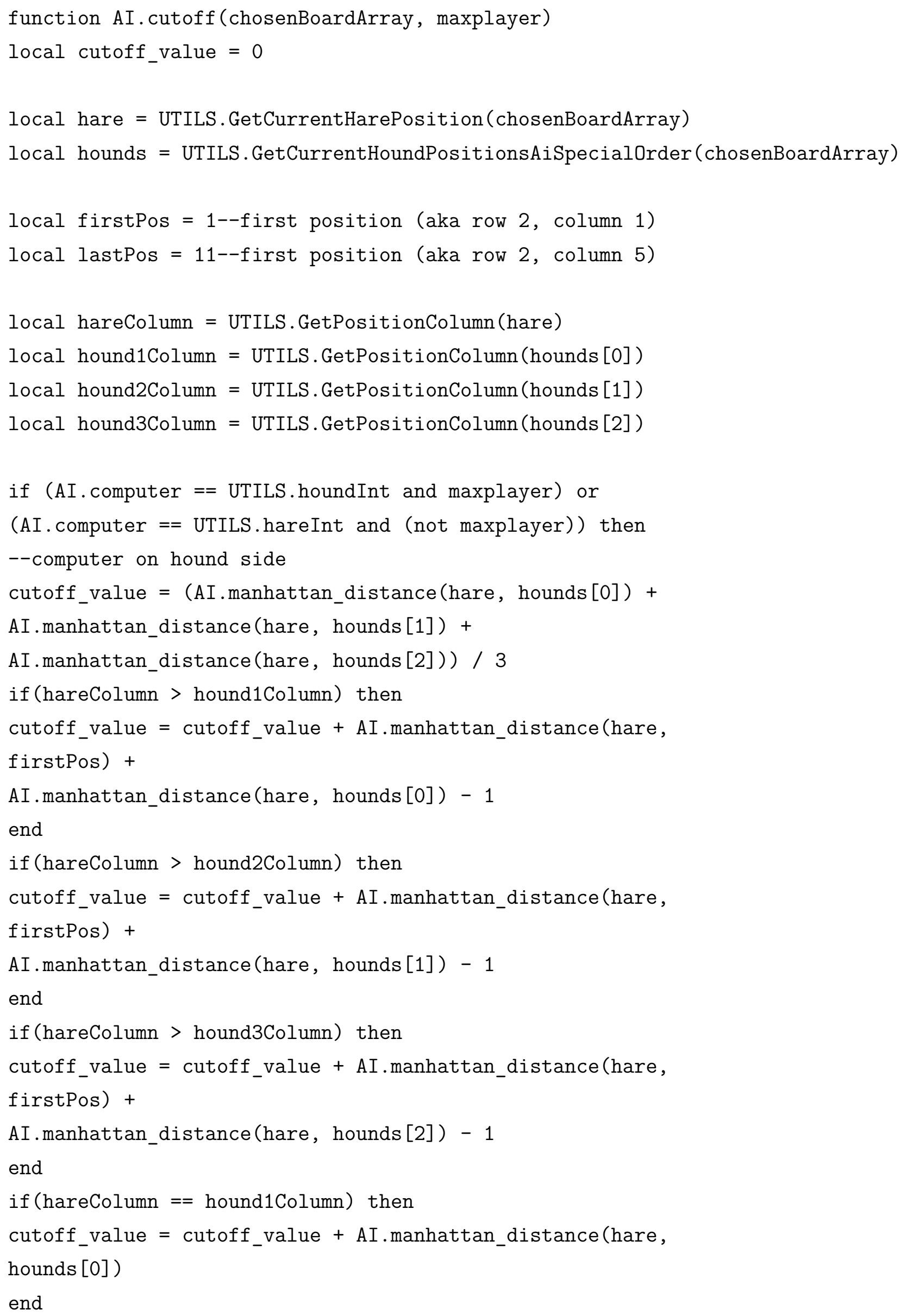




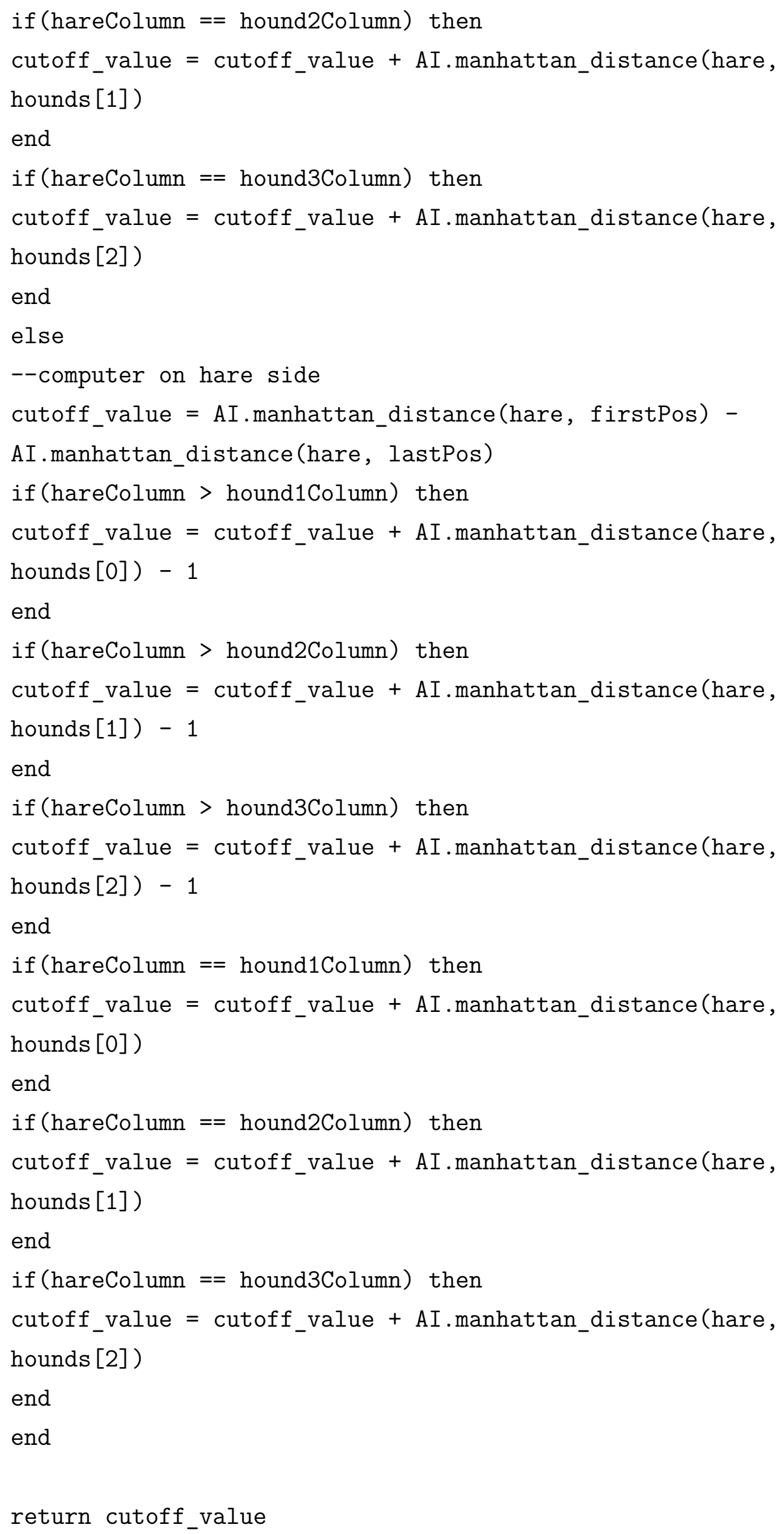




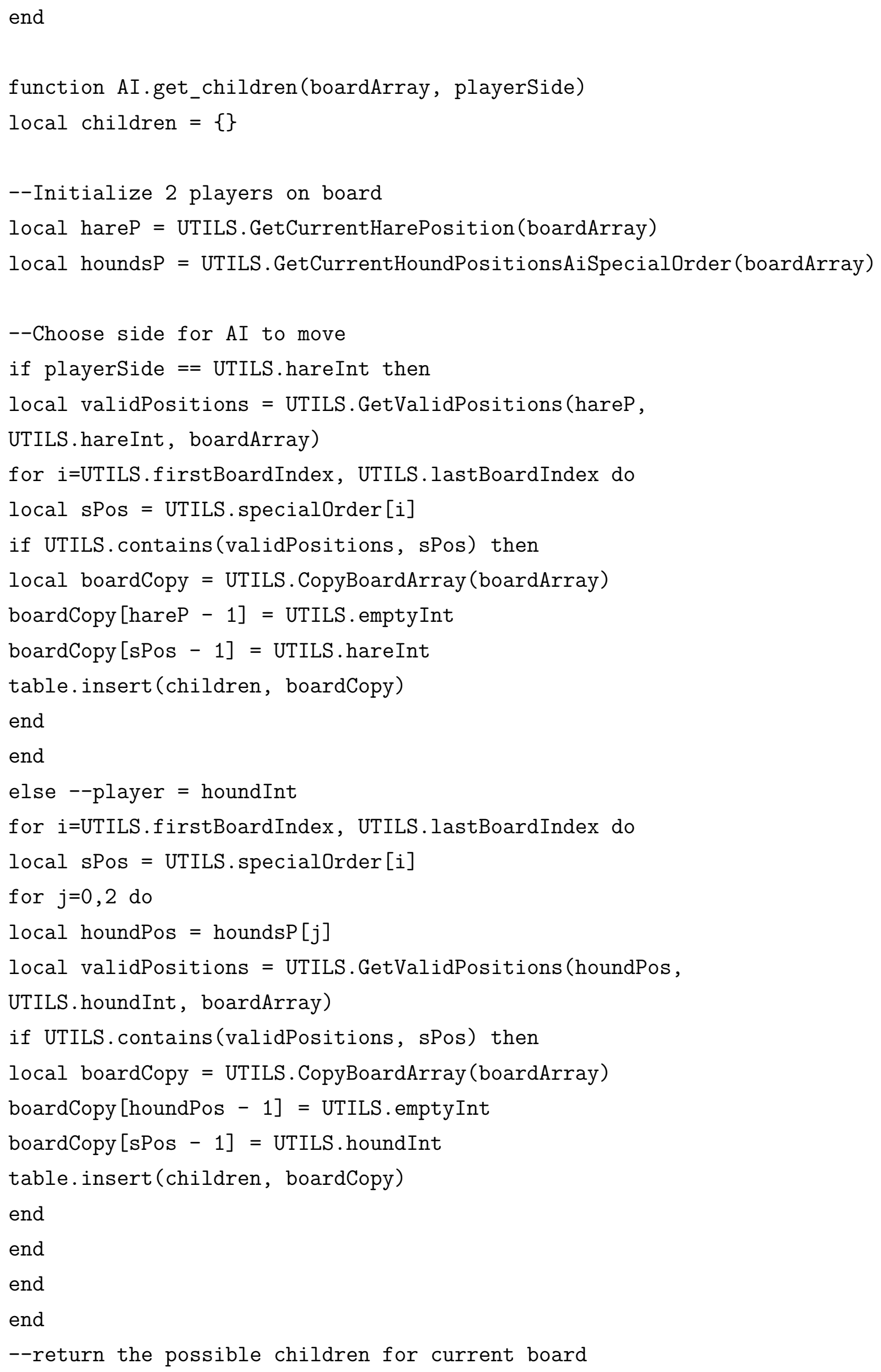




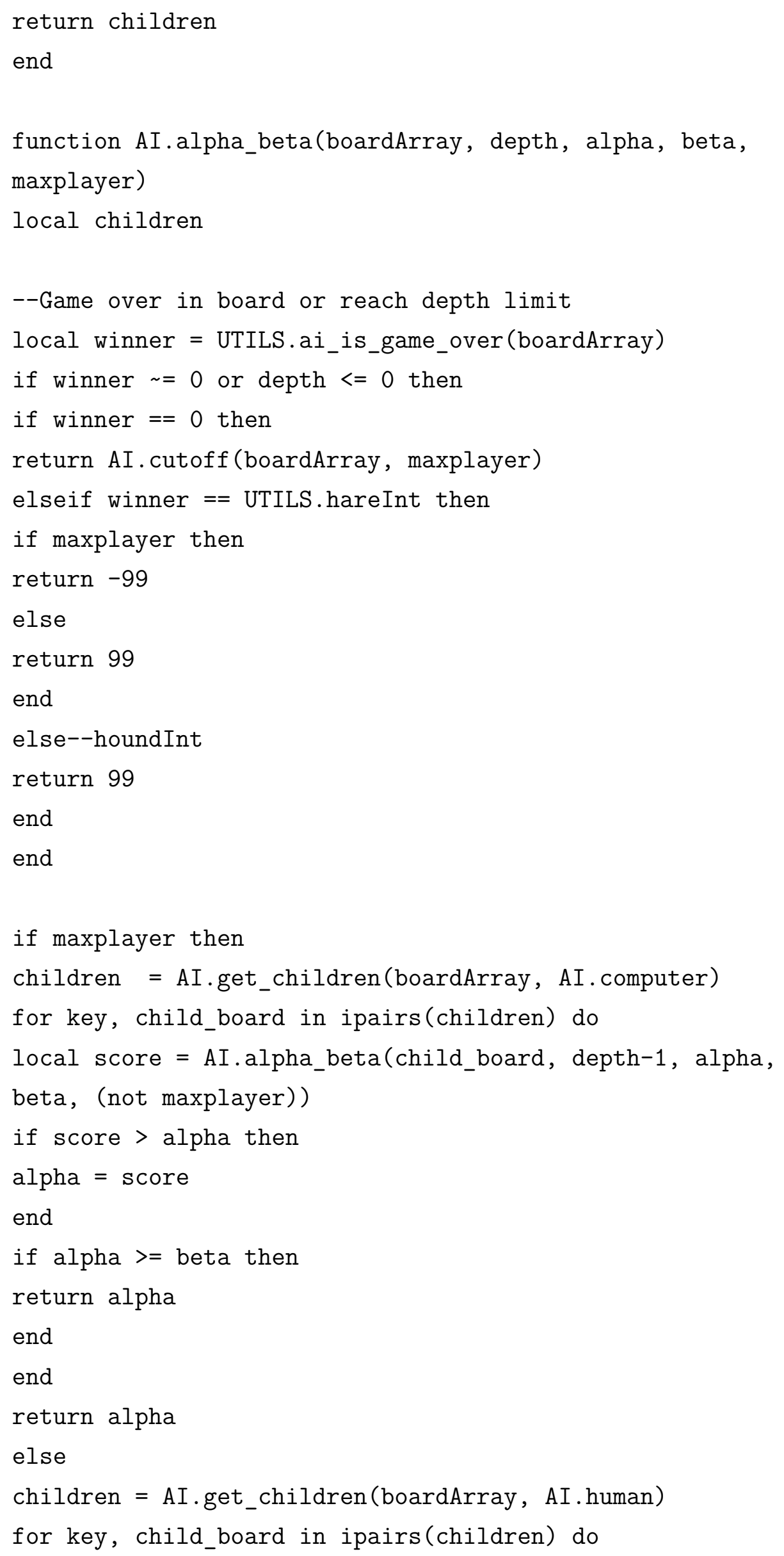




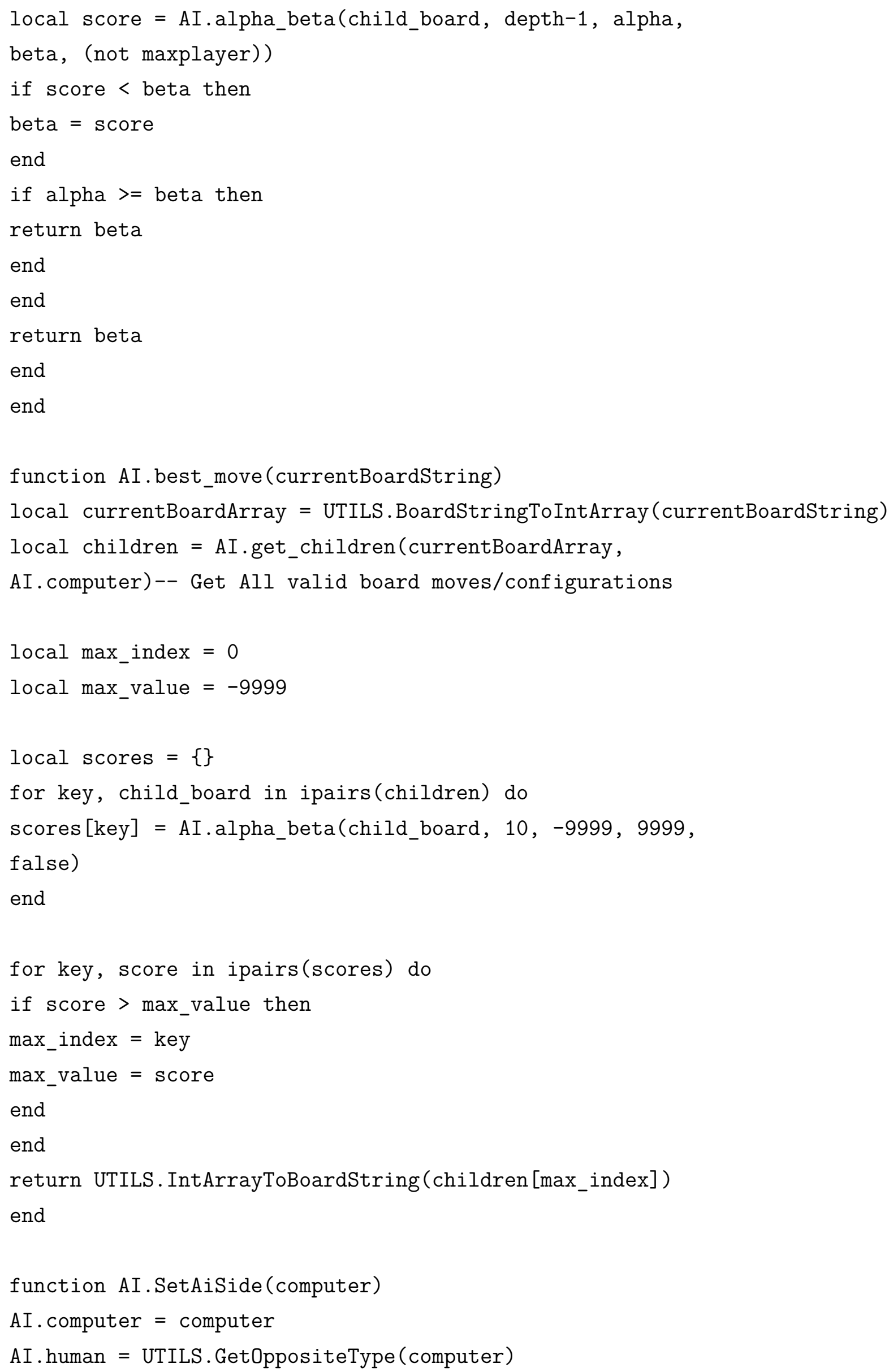




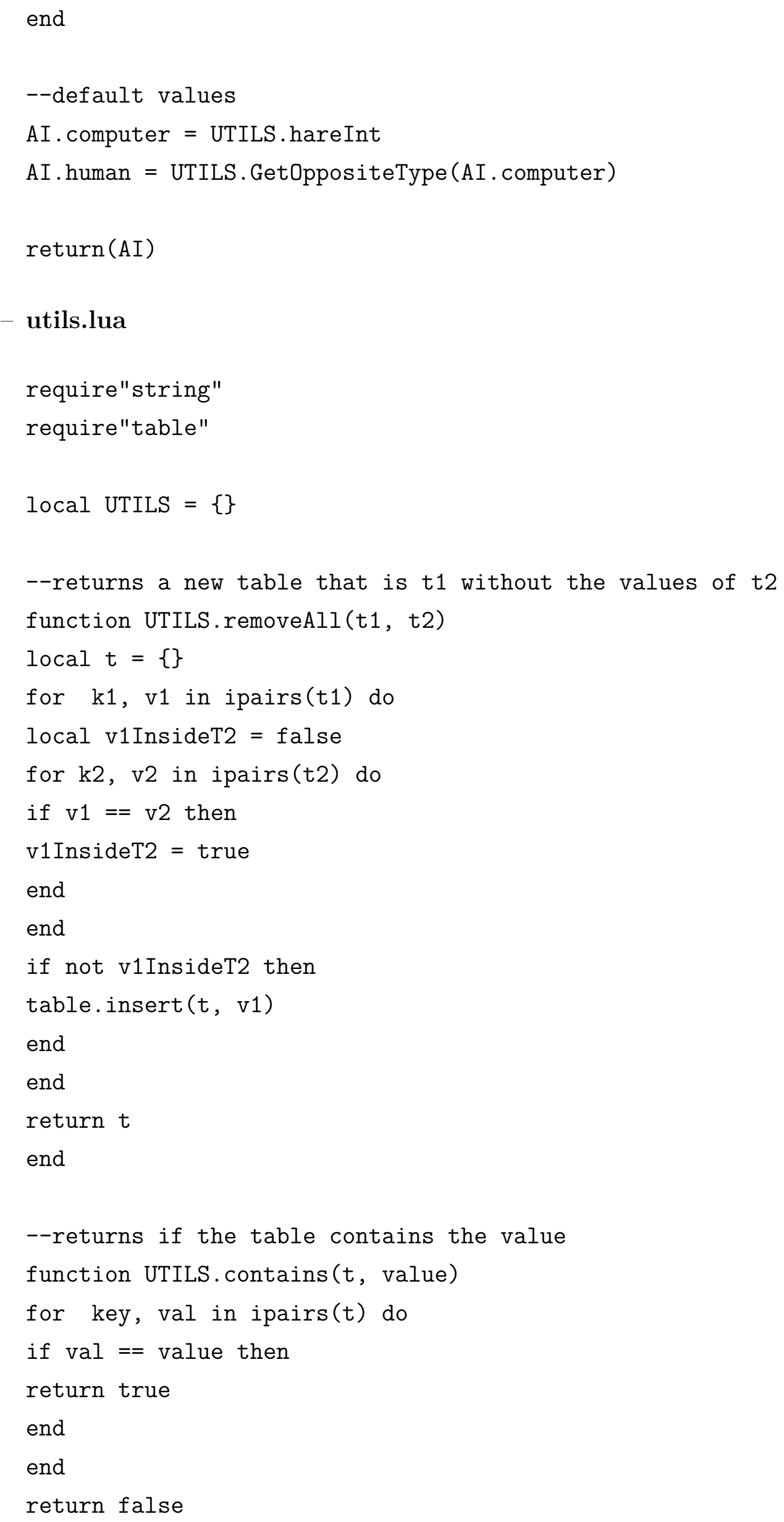




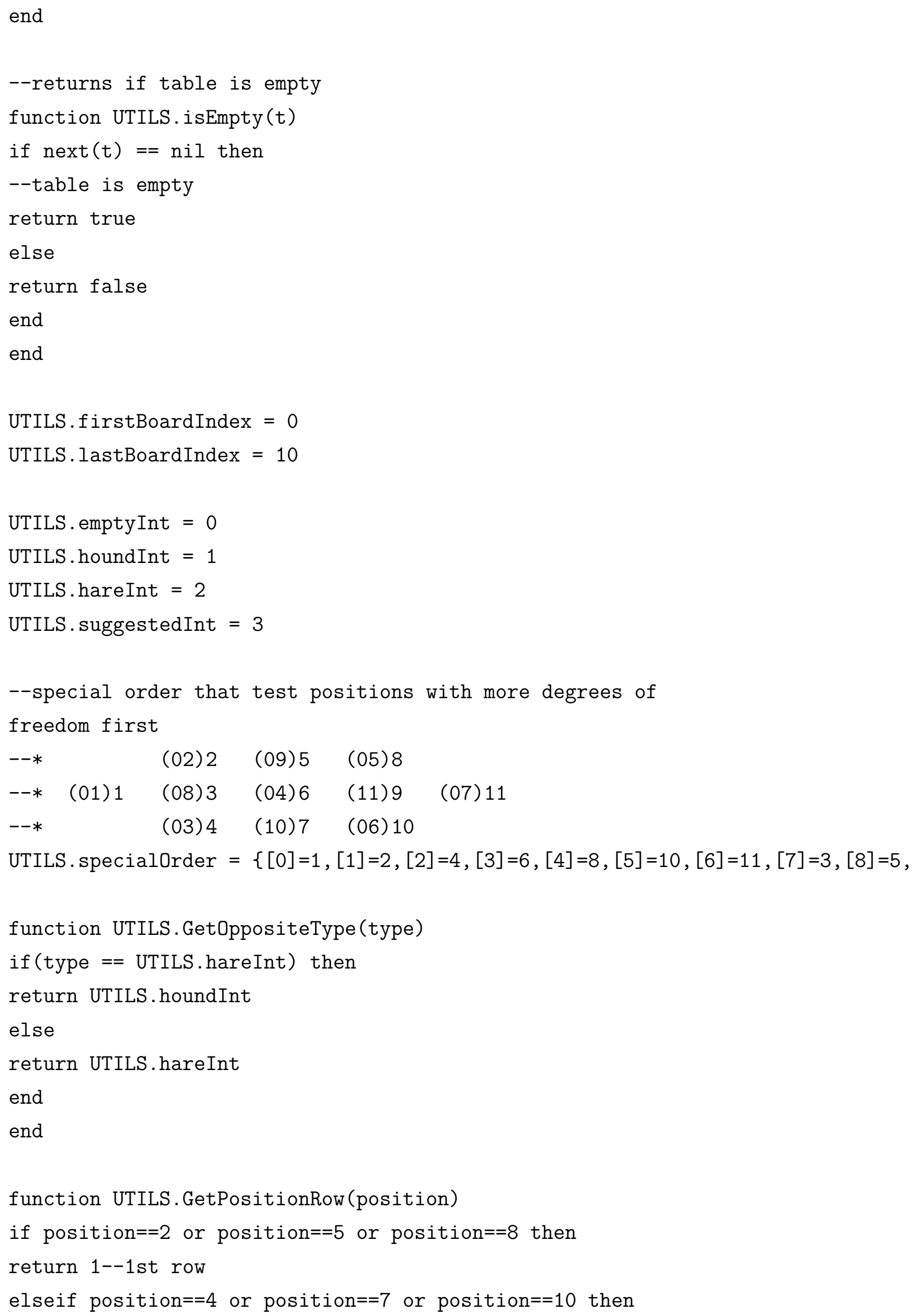




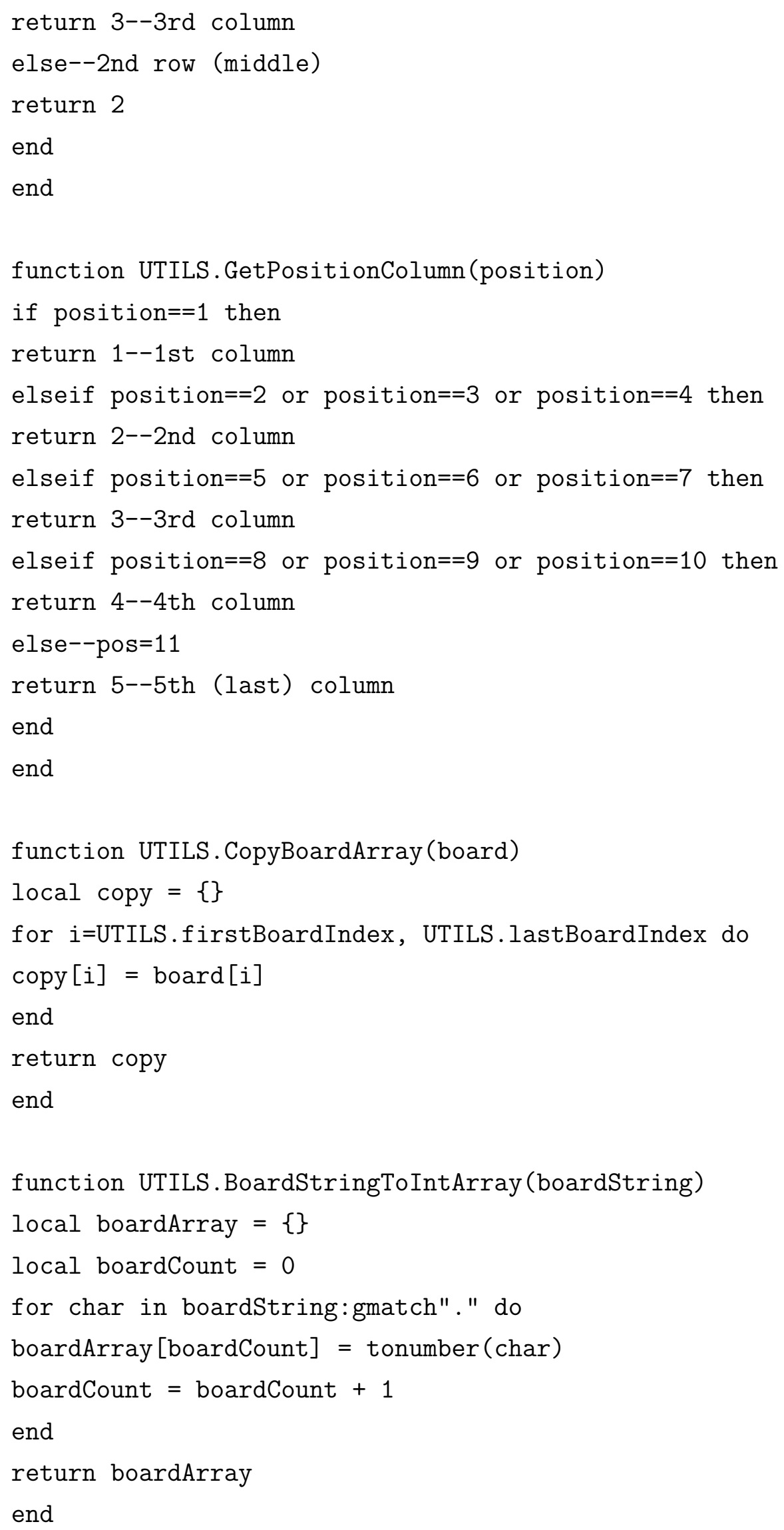




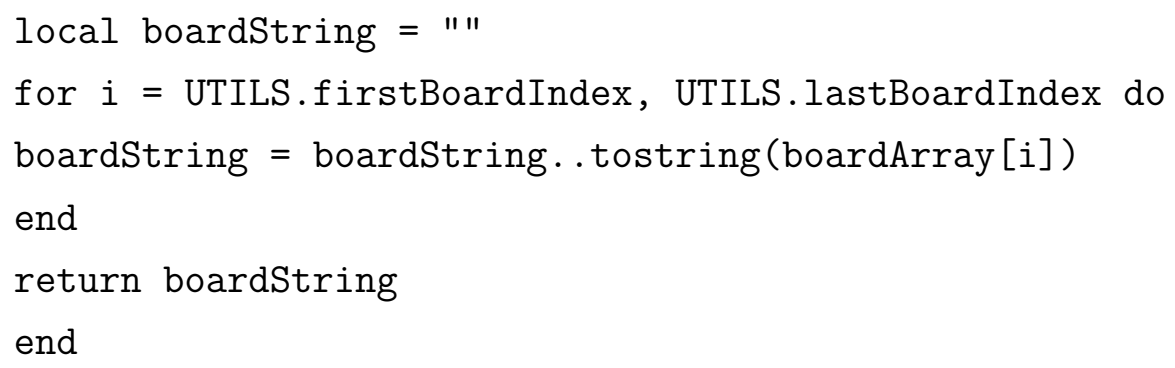




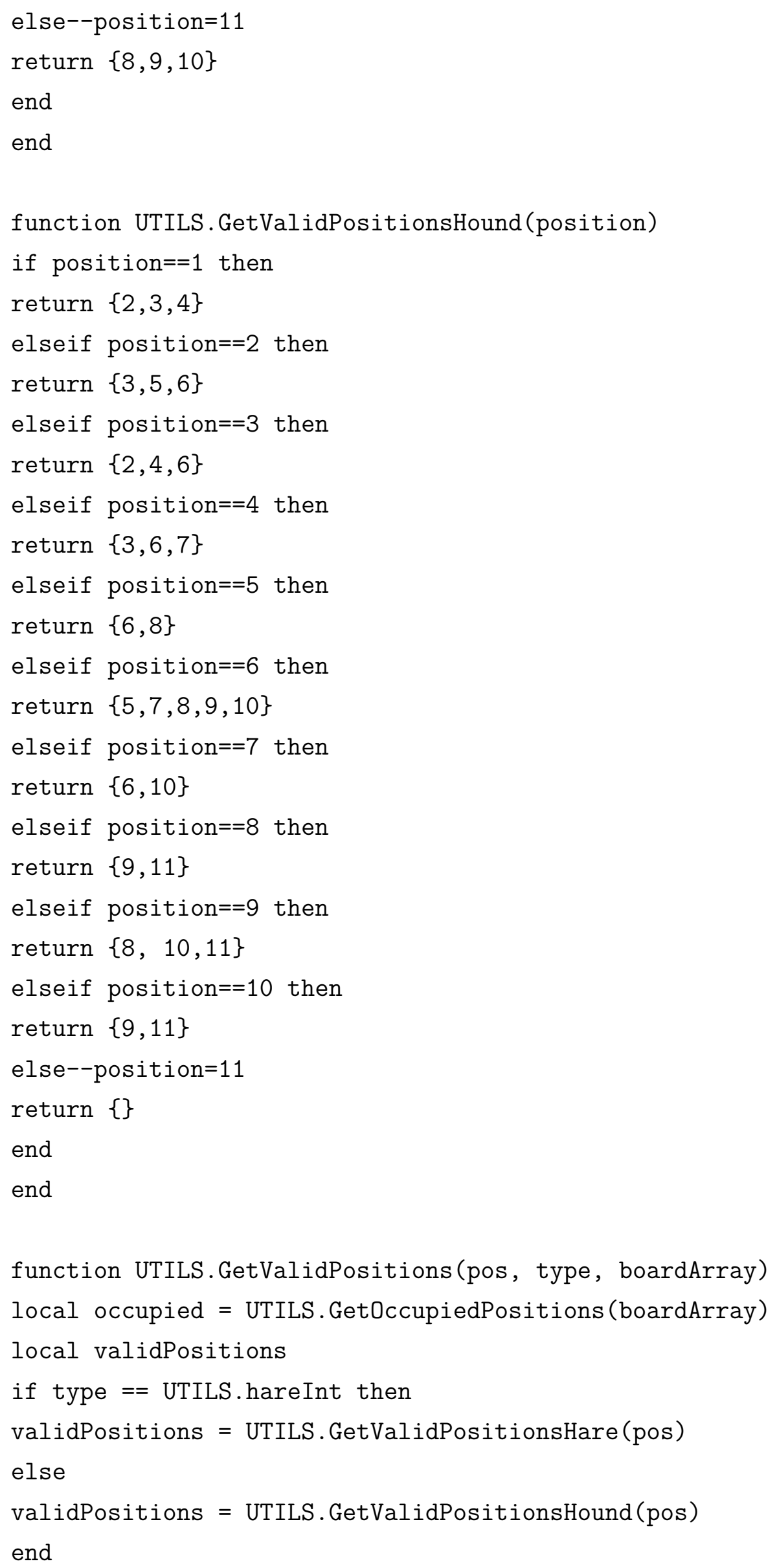




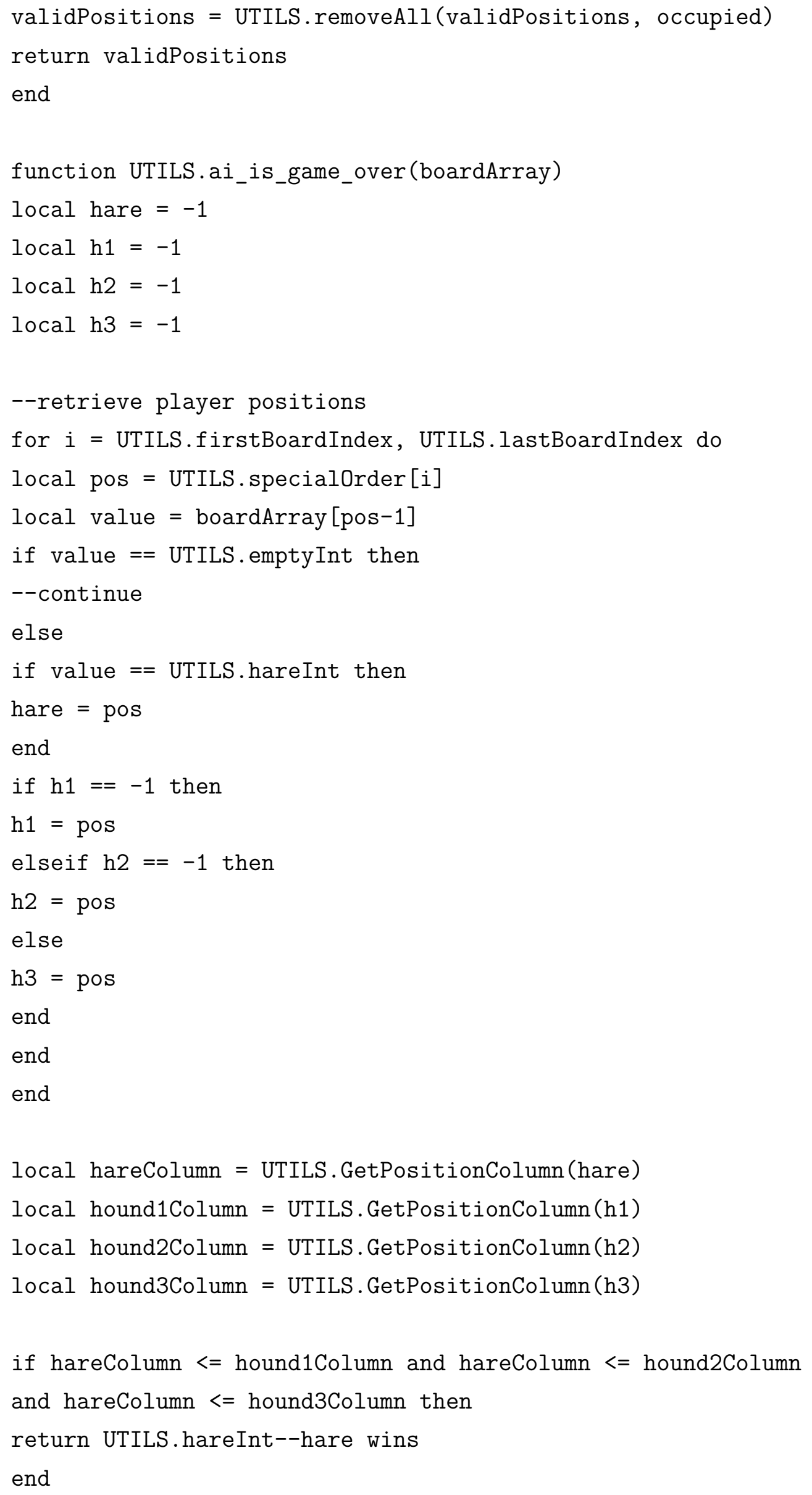




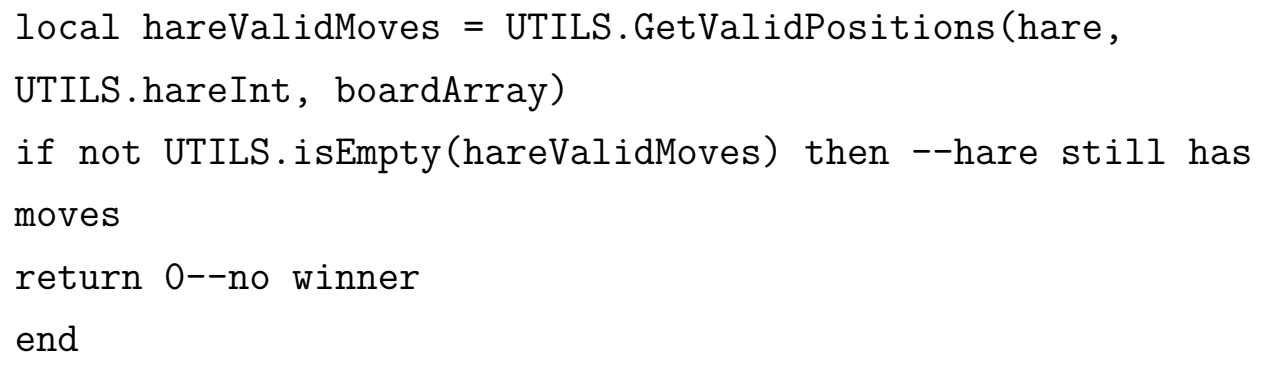




\section{C.3}

\section{Aplicativo de compartilhamento de fotos}

\section{- serialize\&send.lua}

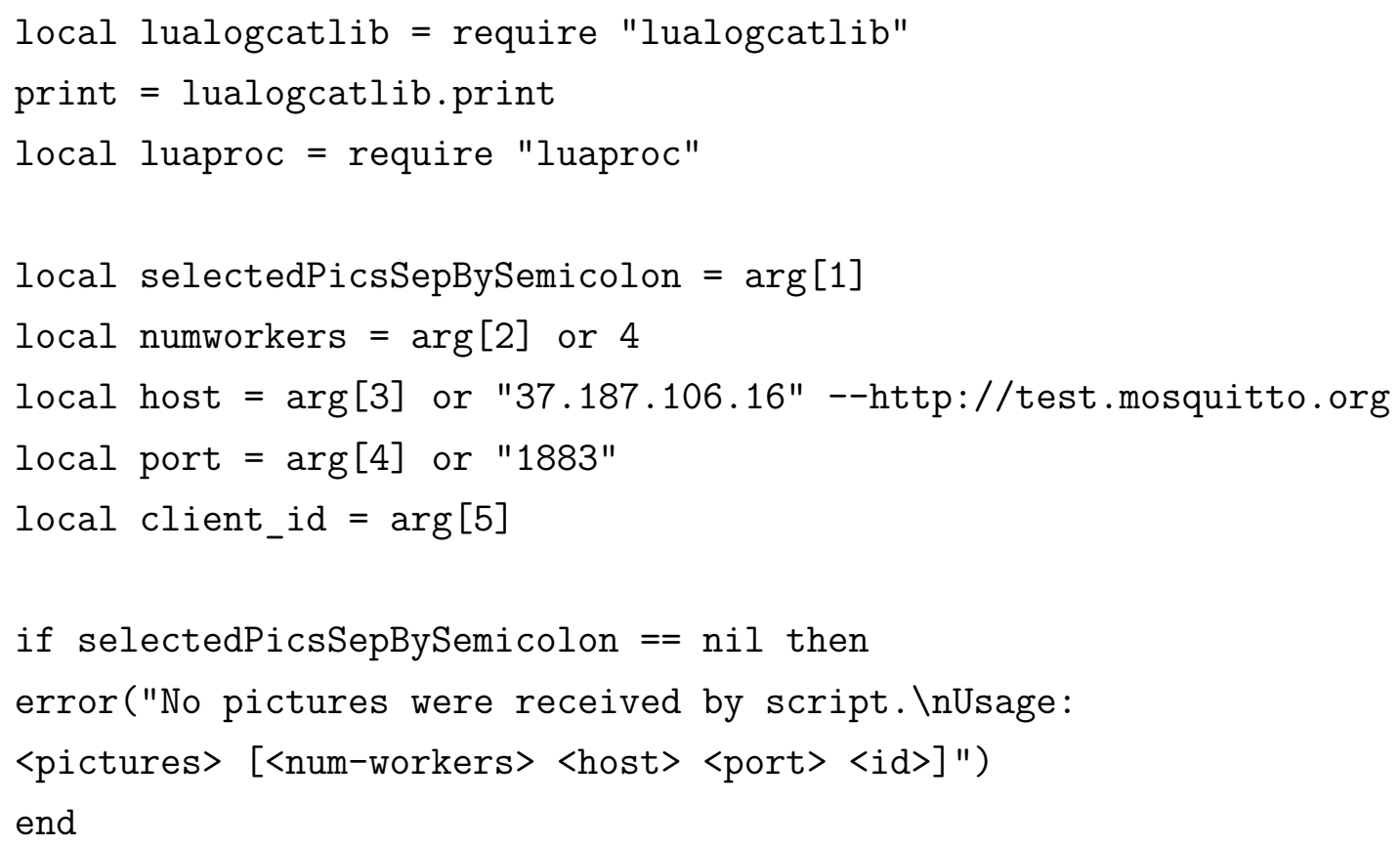




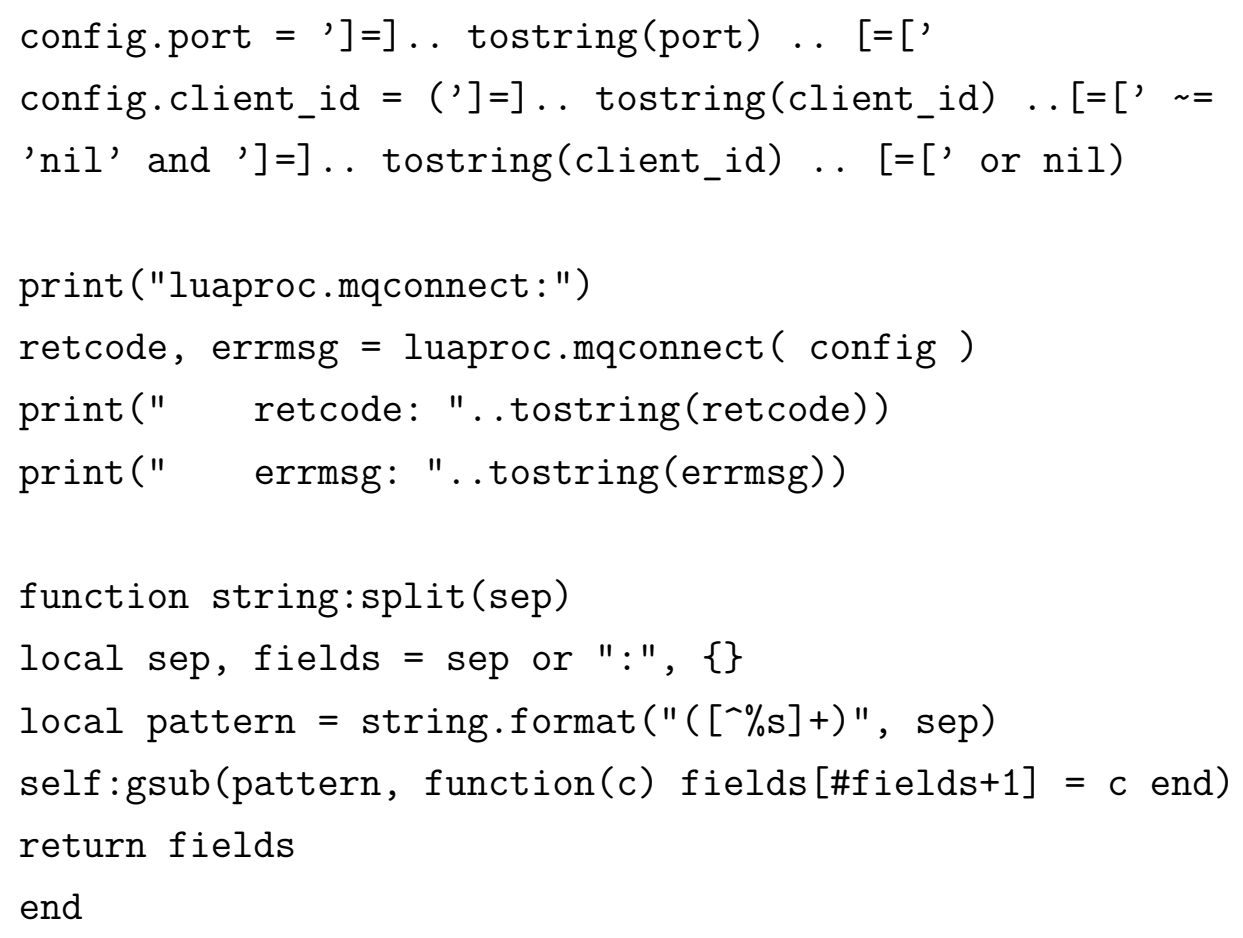




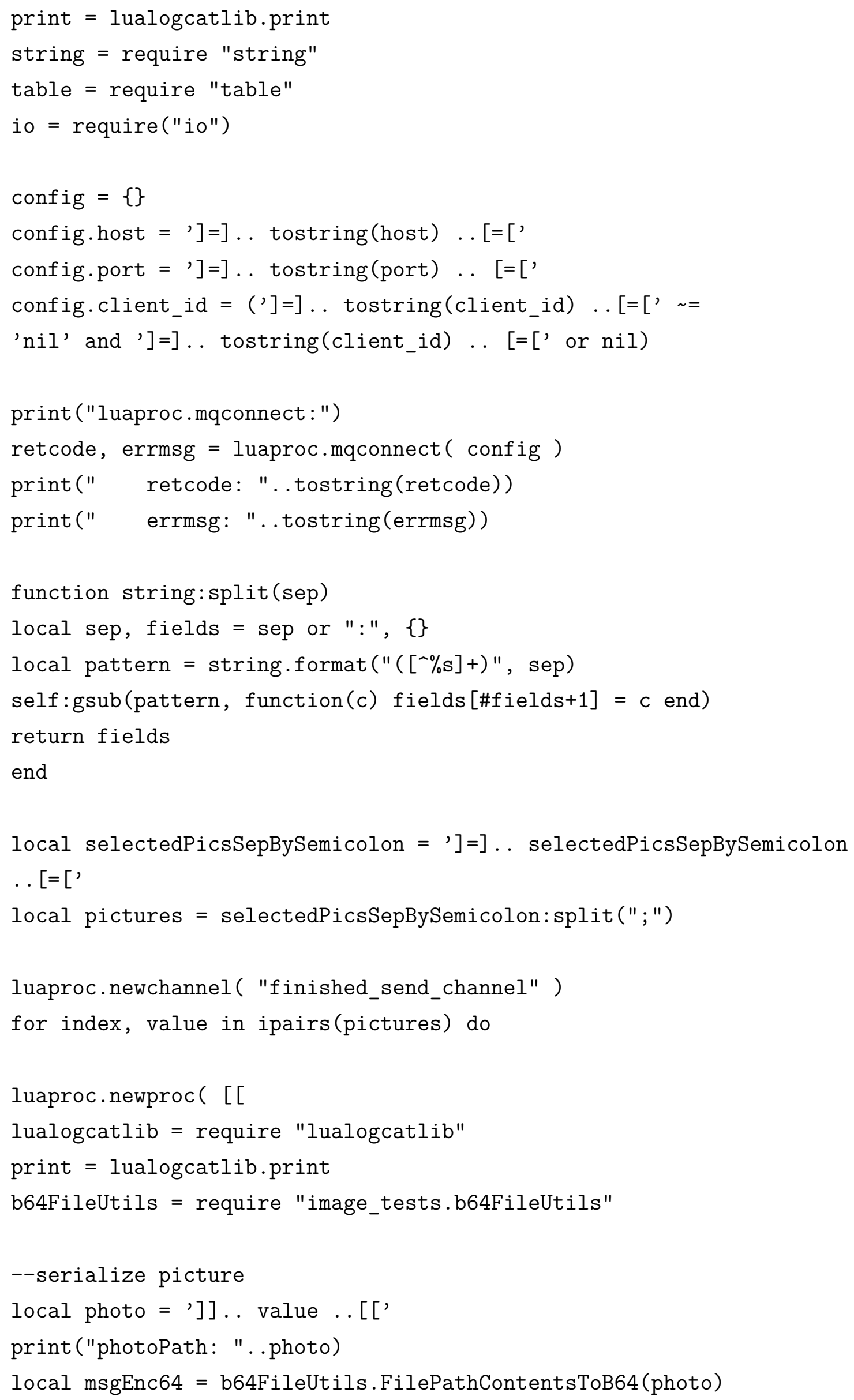




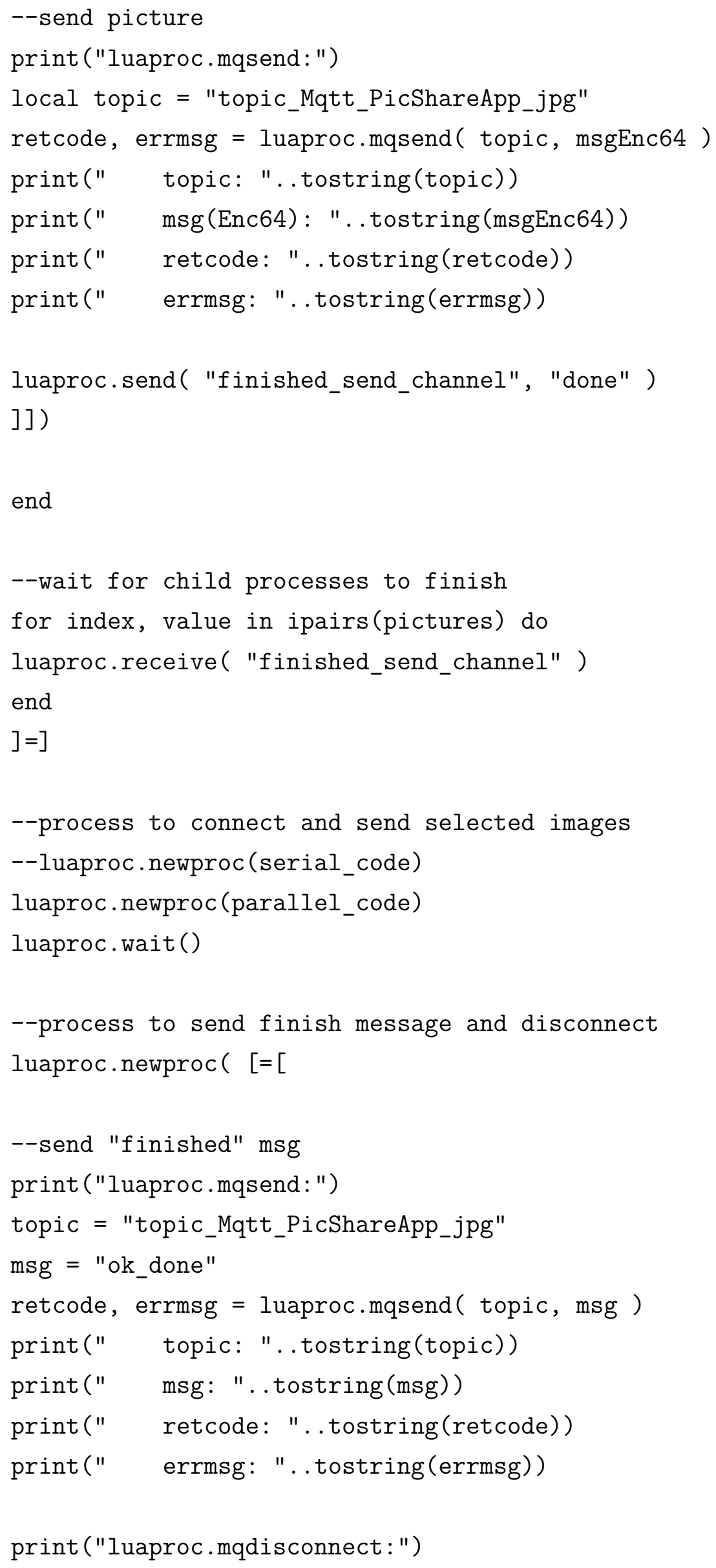




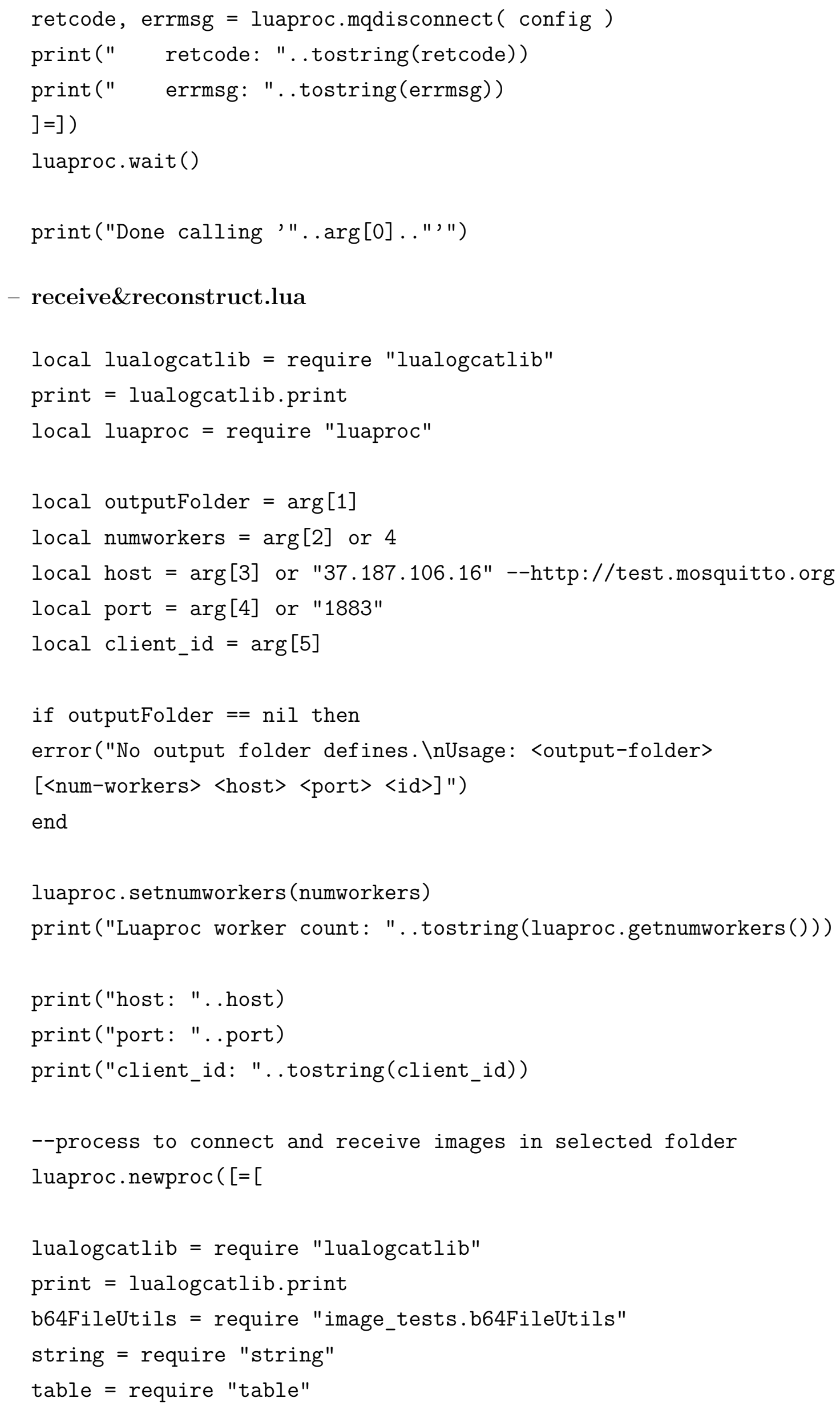




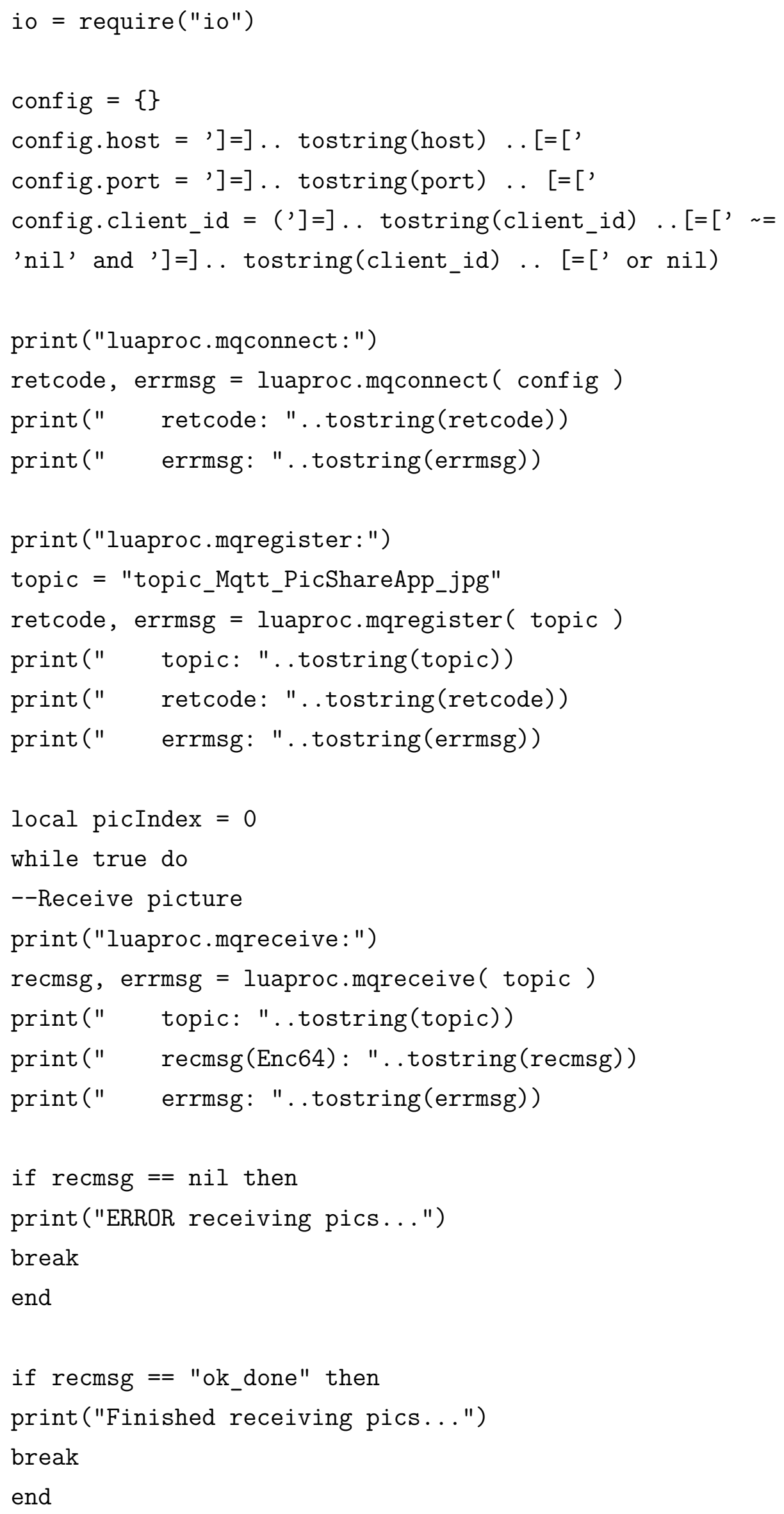




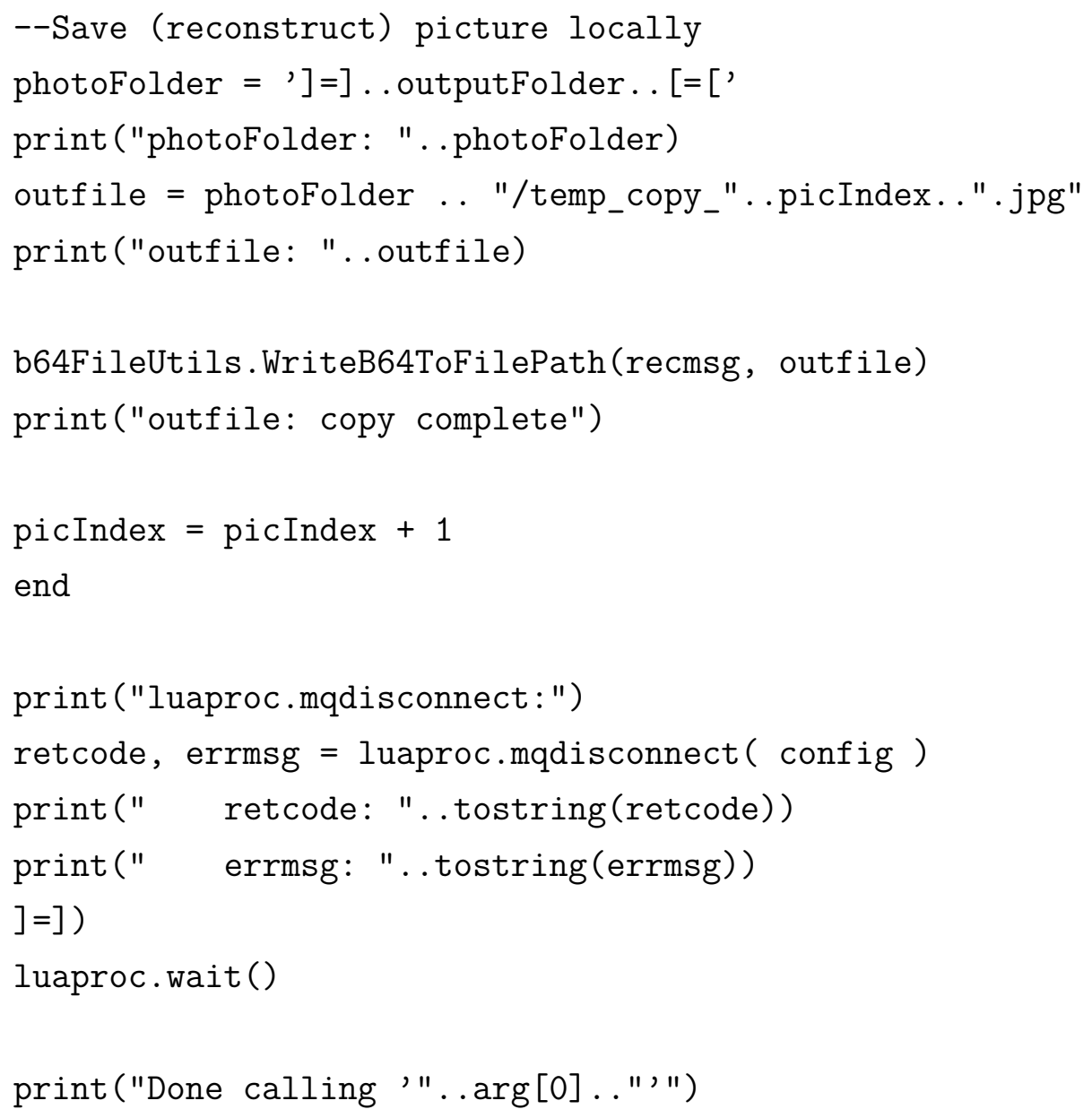

\section{4}

\section{Aplicativo de busca e reconhecimento facial}

\section{- sendpicforsearch.lua}

local lualogcatlib = require "lualogcatlib"

print = lualogcatlib.print

local luaproc $=$ require "luaproc"

require"string"

require"table"

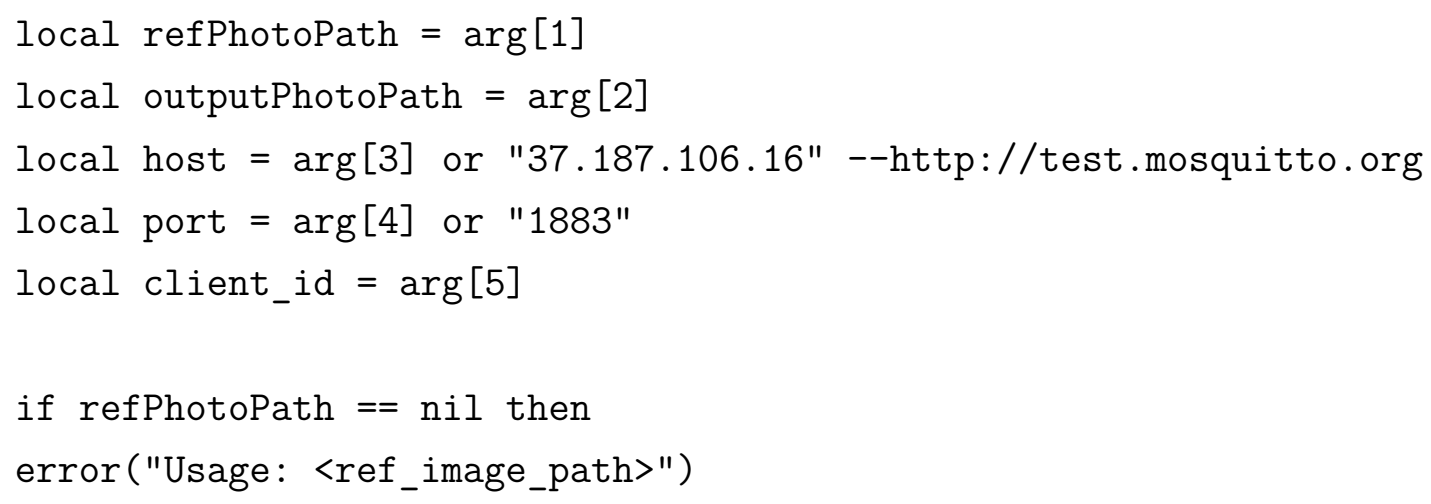




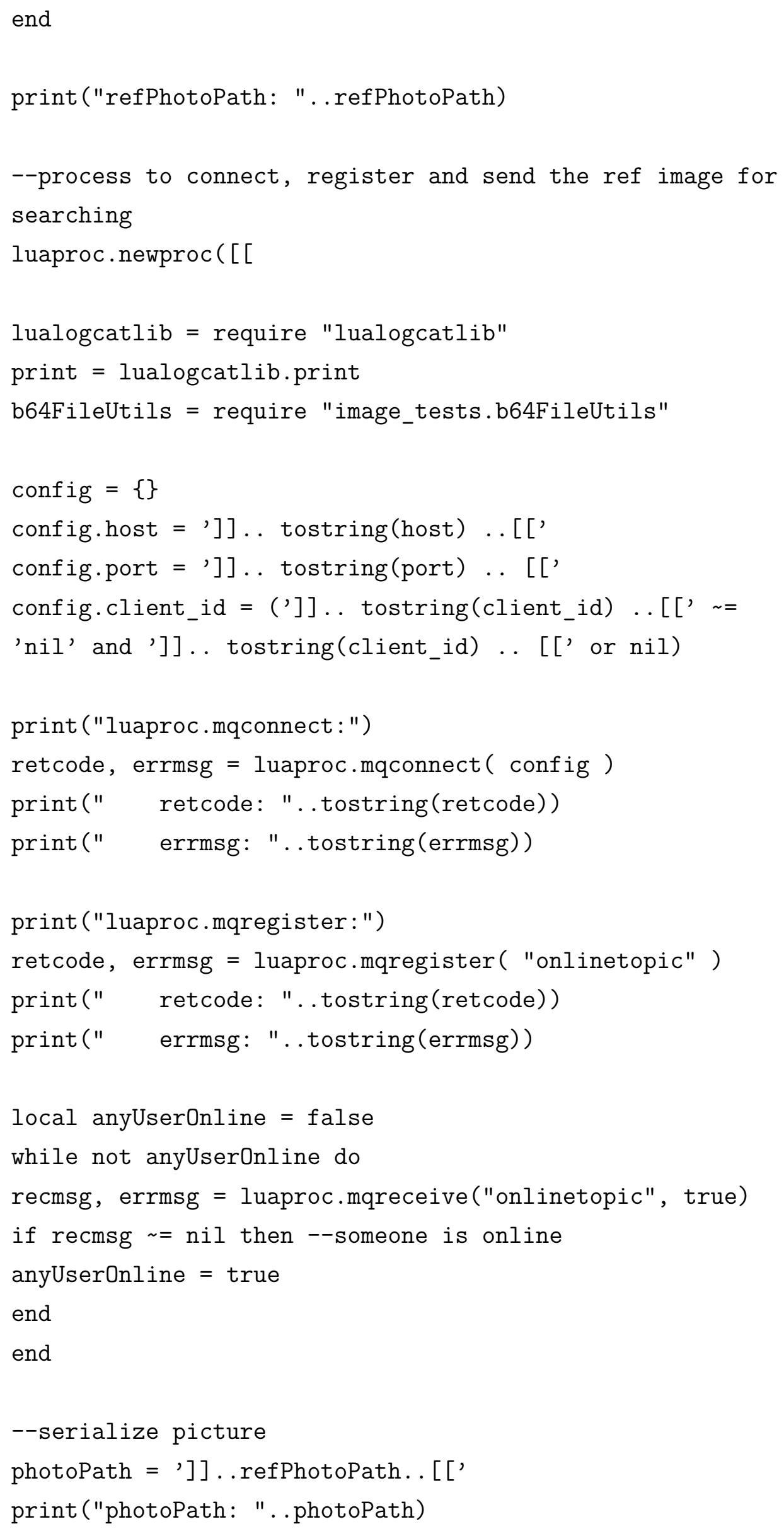




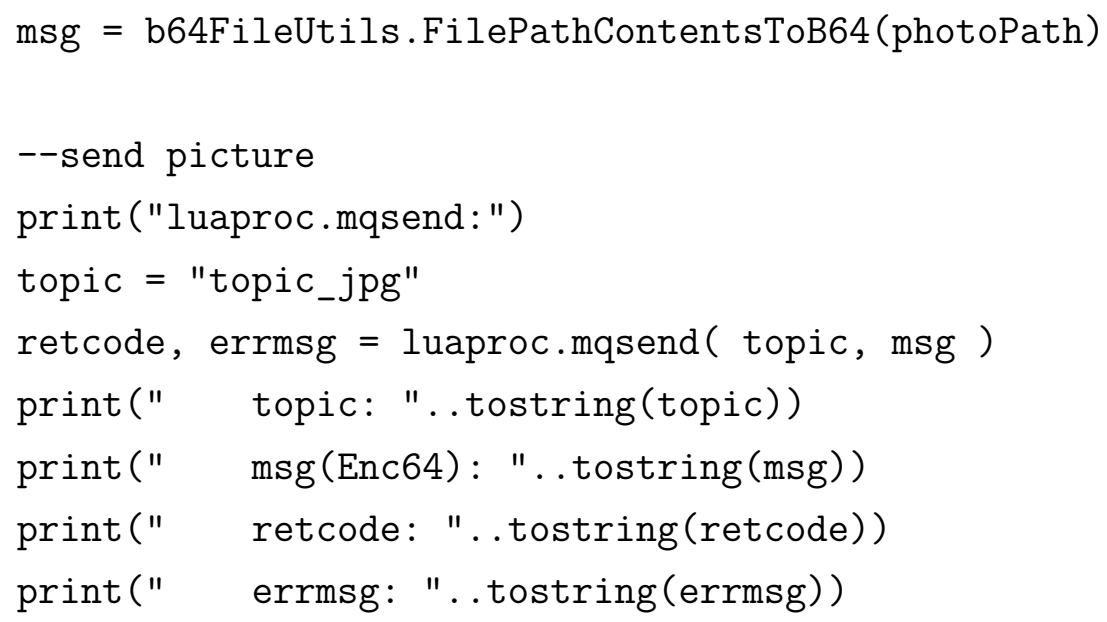




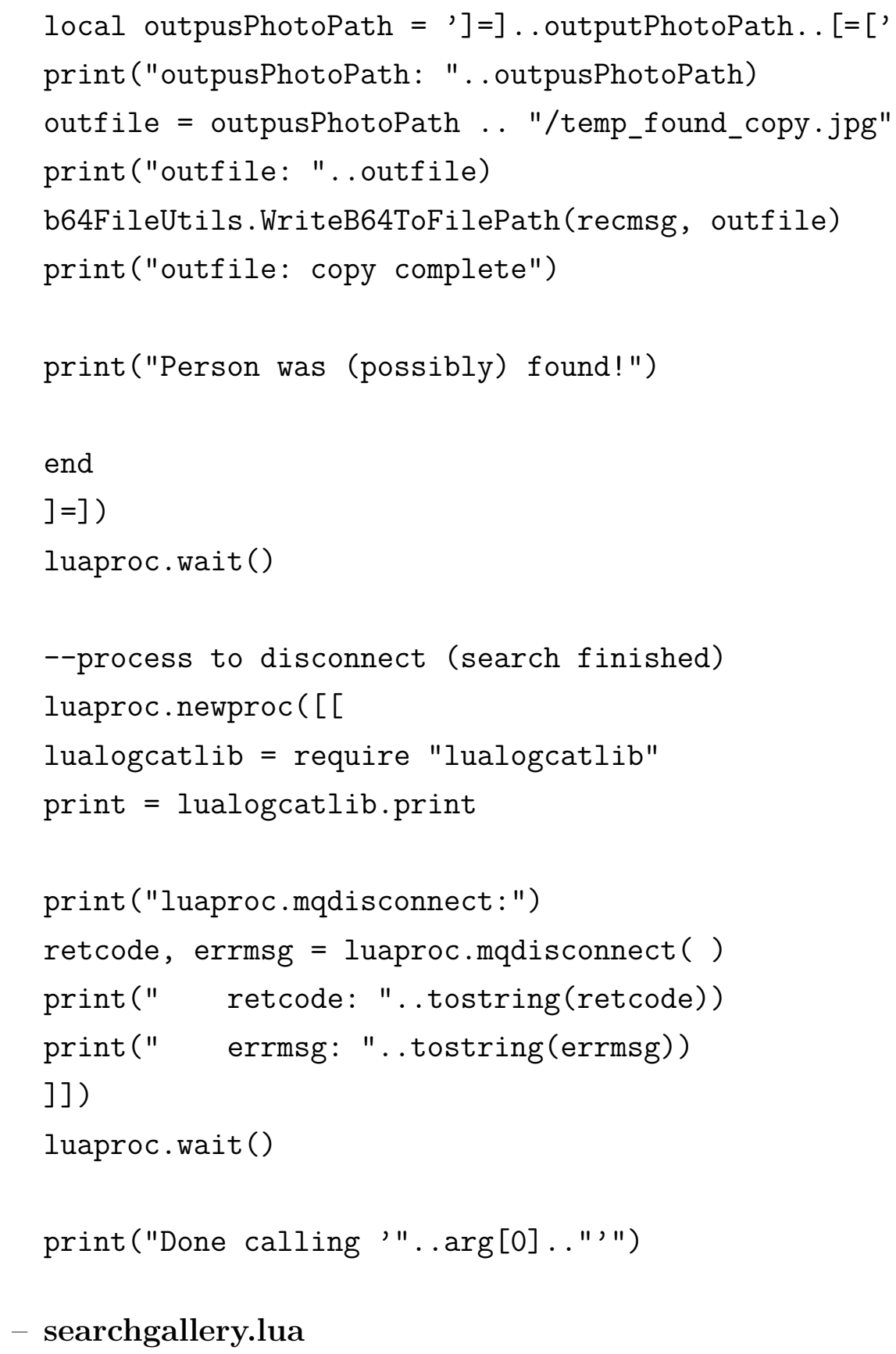


if wholeGallerySepBySemicolon == nil or modelsFolderPath == nil then

error("Usage: <whole_gallery_image_paths> <models_folder_path>")

end

print ("wholeGallerySepBySemicolon: " . wholeGallerySepBySemicolon)

print ("modelsFolderPath: " . modelsFolderPath)

luaproc.setnumworkers (numworkers)

print("Luaproc worker count: ". tostring(luaproc.getnumworkers()))

--process to connect, register and recieve ref image to

search in gallery

luaproc.newproc $([=[$

lualogcatlib = require "lualogcatlib"

print $=$ lualogcatlib.print

b64FileUtils = require "image_tests.b64FileUtils"

string = require "string"

table = require "table"

io = require ("io")

config $=\{\}$

config.host $=$ ' $]=]$. tostring(host) $\ldots[=[$ '

config.port $=$ ' $]=] \ldots$ tostring (port) $\ldots[=[$ '

config.client_id $\left.=\left(^{\prime}\right]=\right] \ldots$ tostring(client_id) $\ldots\left[{ }^{\prime}\left[{ }^{\prime} \sim=\right.\right.$

'nil' and ']=].. tostring(client_id) . . [=[' or nil)

print ("luaproc.mqconnect:")

retcode, errmsg = luaproc.mqconnect ( config)

print(" retcode: "..tostring(retcode))

print(" errmsg: "..tostring(errmsg))

print ("luaproc.mqregister:")

topic = "topic_jpg"

retcode, errmsg = luaproc.mqregister ( topic )

print(" topic: "..tostring(topic))

print(" retcode: "..tostring(retcode))

print(" errmsg: "..tostring(errmsg)) 


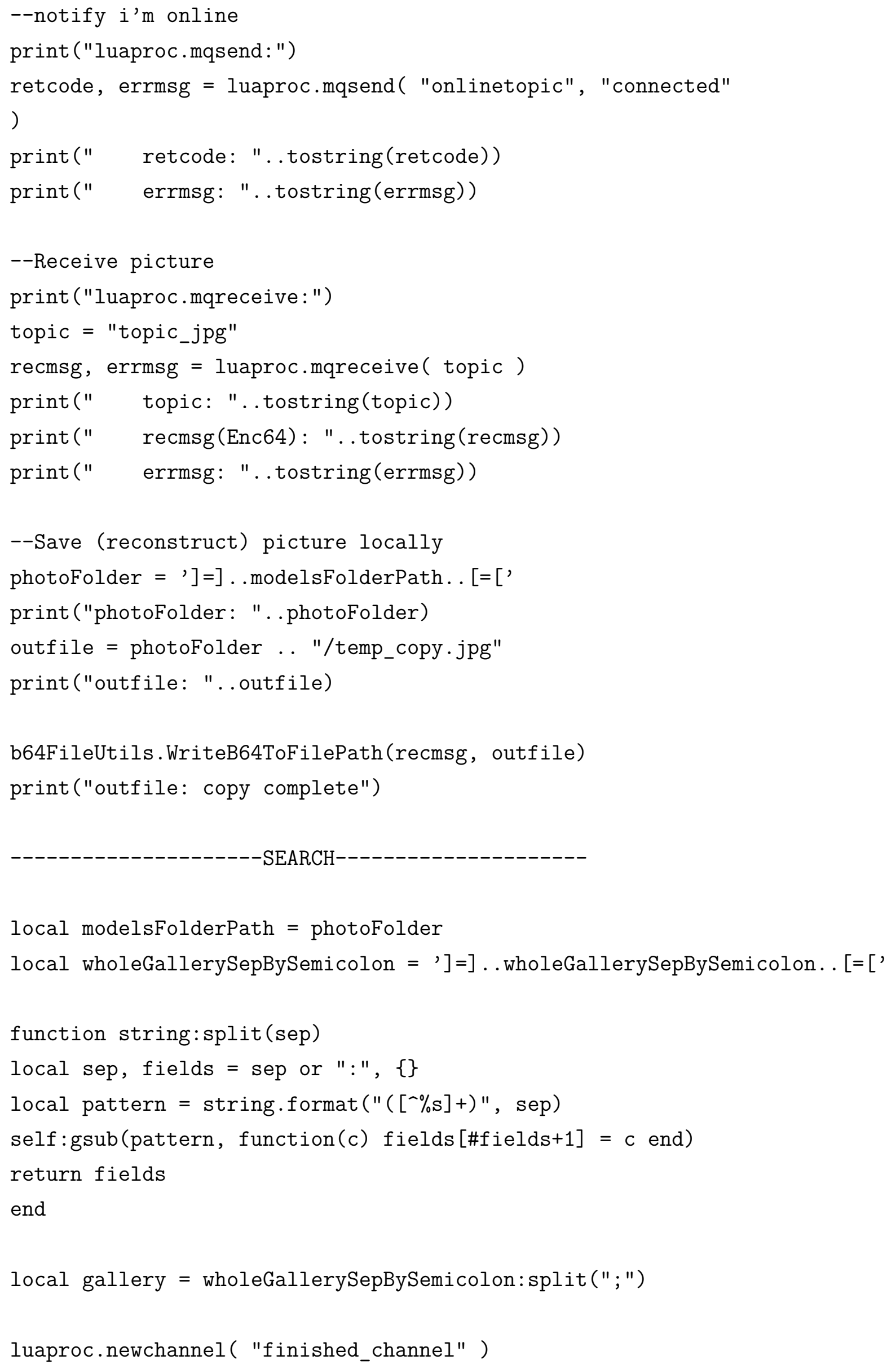




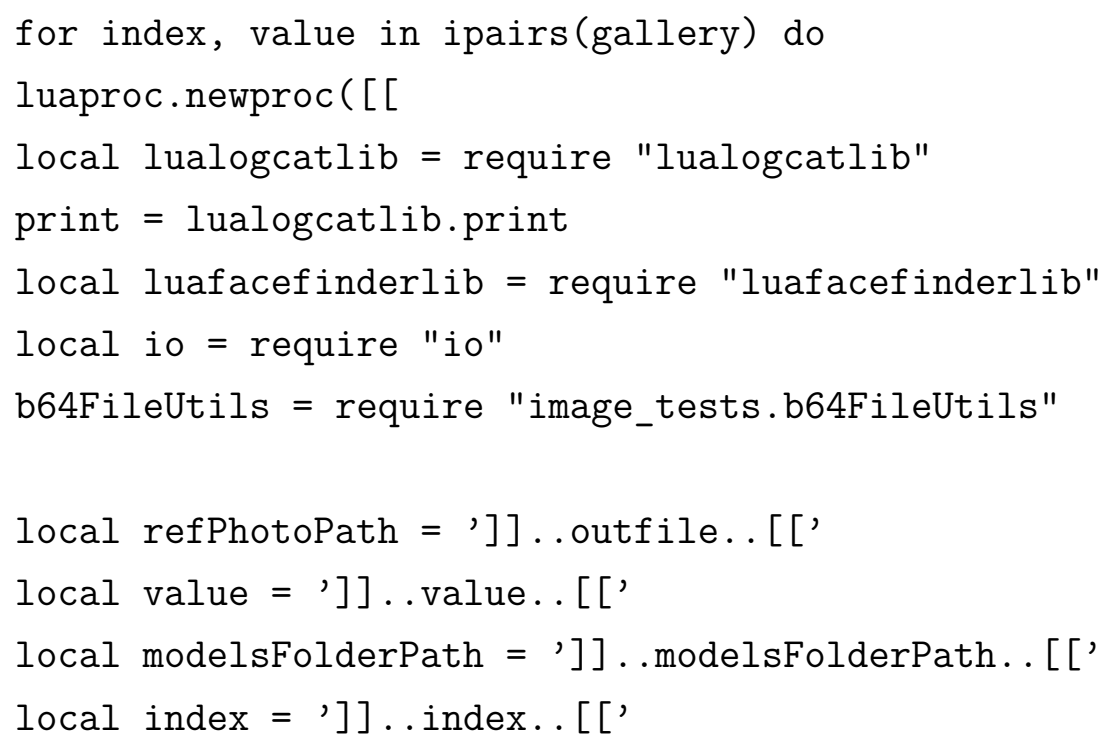




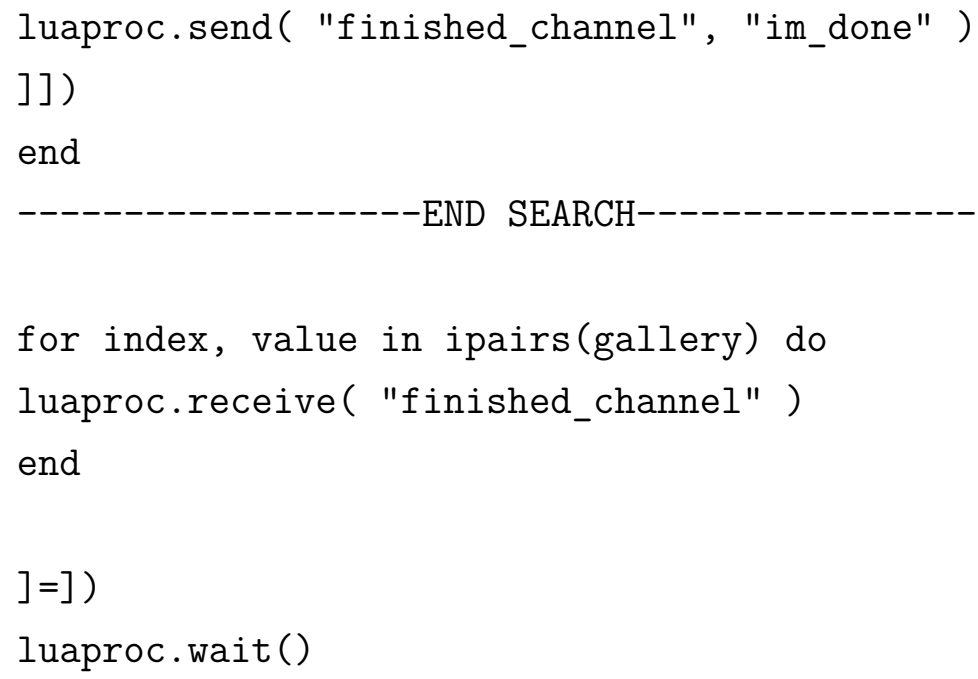




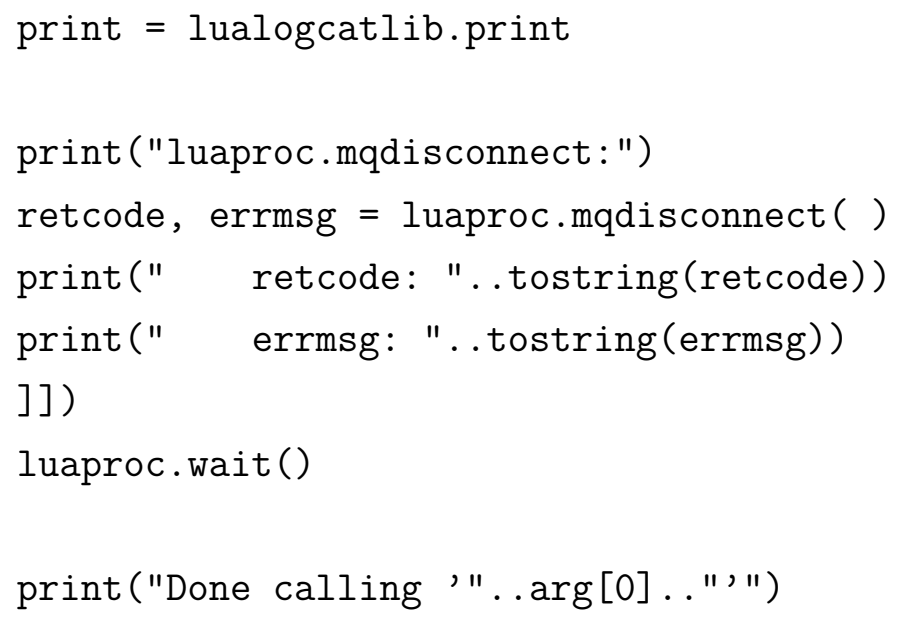

